David Josua Schönheit

\title{
Short- and mid-term uncertainties affecting the trade and transmission of electricity with a focus on flow-based market coupling
}




\section{IMPRESSUM}

Herausgeber:

Technische Universität Dresden

Fakultät der Wirtschaftswissenschaften

Lehrstuhl für Energiewirtschaft

01062 Dresden

Tel.: $\quad$ +49351463-33297

Fax: $\quad+49351463-39763$

E-Mail: ee2@mailbox.tu-dresden.de

Internet: http://www.ee2.biz

Stand: $\quad 07 / 2021$

Alle Rechte vorbehalten. 


\section{Short- and mid-term uncertainties affecting the trade and transmission of electricity with a focus on flow-based market coupling}

\section{Dissertation}

zur Erlangung des akademischen Grades Dr. rer. pol.

vorgelegt an der

Fakultät Wirtschaftswissenschaften

der Technischen Universität Dresden

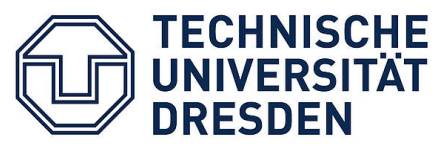

von

David Josua Schönheit

geb. 31. Juli 1990 in Berlin

Eingereicht: 27.01.2021

Verteidigt: 14.06.2021

Betreuender Hochschullehrer

Prof. Dr. Dominik Möst

Professur für BWL, insb. Energiewirtschaft

Erstgutachter

Prof. Dr. Dominik Möst

Professur für BWL, insb. Energiewirtschaft
Zweitgutachter

Prof. Dr. Stefan Eichler

Professur für VWL,

insb. Internat. Monetäre Ökonomik 



\section{Foreword}

The European Union and the federal government in Germany have set themselves ambitious targets to reduce greenhouse gases and expand renewable energies. Various challenges accompany the expansion of renewable energies: On the one hand, the feed-in is weather-dependent which challenges energy systems, electricity trading, and electricity grids. Thereby, the organisation of electricity trading and electricity transport plays a crucial role. Over the past 25 years, the market organisation and market design have changed continuously with the liberalisation of the electricity markets. With the beginning of liberalisation, trading capacities for cross-border electricity trading were auctioned separately from (national) electricity trading. Implicit auctions have replaced the auctioning of transmission capacity as a more efficient form of trading. Still, the challenge persisted that physical and commercial flows diverged. To better reflect physical bottlenecks in the power grid in power trading, flow-based market coupling had been introduced in Central Western Europe in 2015. With it, physical load flows and commercial flows of electricity shall be better synchronised. The electricity flow-based market coupling is a crucial component to achieve a European network-compatible internal electricity market. With this new market organisation and the further increasing share of weather-dependent renewable energies, challenges and questions are associated with the specific market design and the detailed design of the market coupling and effects on welfare effects and network operation.

David Schönheit takes up this comprehensive set of topics in his dissertation entitled "Shortand mid-term uncertainties affecting the trade and transmission of electricity with a focus on flow-based market coupling". He divides his cumulative thesis into two parts. In the first part, he deals with the effects of the expansion of renewable energies on the German electricity system concerning electricity price developments, the export balance and the reduction of $\mathrm{CO}_{2}$ emissions. The second part is devoted to the newly introduced flow-based market coupling in Europe.

David Schönheit methodically uses empirical and statistical analyses and fundamental electricity market models to examine the interaction between electricity trading and electricity flow. The dissertation's contribution lies on the one hand in quantifying the effects of renewable energies on electricity trading and, on the other hand, in the detailed description and analysis of flow-based market coupling and the parameters used for this. He is a pioneer in analysing flow-based market coupling in this level of detail, including relevant factors such as critical network elements, prediction of power plant output, minimum trading capacities and generation shift keys. Additional, he provides an open-access model and elementary guide to flow-based market coupling as a starting basis for students, researchers and operative users. The strength of the work is the systematic, quantitative, and sophisticated analysis of the subject of flowbased market coupling and the interactions between renewable energy and electricity markets. Anyone who has read David Schönheit's dissertation understands better how flow-based market coupling is organised and which factors impact electricity trading. That makes this cumulative thesis and its articles helpful for students, researchers, practitioners, and policymakers. Despite the complexity, I hope you enjoy reading this informative dissertation!

Prof. Dr. Dominik Möst 


\section{Summary}

Electricity markets and grids in Europe and Germany have undergone substantial changes over the past 25 years, largely characterized by the liberalization of energy markets as well as the goal of creating sustainable, decarbonized energy systems. The European Union also envisions a single, interconnected market for electricity, the so-called European internal electricity market, with the goal of securely providing clean and affordable energy. The ongoing pursuit of this major goal has altered the trading of electricity considerably. Initially, trading capacities for cross-border exchanges were auctioned separately from the trading of electricity, but implicit auctions are now established for most borders in Europe. Importantly, in 2015 flow-based market coupling was introduced in Central Western Europe and will be geographically expanded to Central Eastern Europe in the coming years, soon encompassing 13 countries. Flow-based market coupling not only manages the trading of electricity but also provides trading capacities to the power markets. It does so by i) predicting the utilization of the electricity grid, ii) anticipating how the utilization changes due to trade as well as iii) considering important physical constraints of the grid as limits to trade. Thereby, flow-based market coupling counteracts the divergence of power markets and physical power flows, namely the differences between commercial exchanges and actual physical flows. Flow-based market coupling is a key component to achieve the European internal electricity market in a grid-compatible manner. The rather recently introduced methodology of flow-based market coupling sparks many research questions, not only pertaining to the design of its predictive parameters but also to its effects on market welfare and grid operation. Some of the most important research questions are answered in this dissertation.

To appreciate the current challenges of energy economics and politics in Europe and Germany, it is important to heed the current transformation of many European energy systems. The path to decarbonization is realized by the expansion of power generating renewable energy sources. The major technologies, wind turbines and photovoltaic modules, are weather-dependent. Thus, a greater proliferation of renewable energy sources in an electricity market subjects the supply side to greater uncertainties as it transitions from an almost completely controllable to a fluctuating, weather-dependent state. This fluctuating state can take on two extremes: A very low or very high amount of renewable energy-based supply of electricity. These situations raise questions of security of supply, when conventional capacities or storages need to compensate for the lack of sunshine and/or wind, as well as questions of system flexibility, namely integrating large amounts of renewable energy. The European internal electricity market is a major pillar in rendering possible the realization of decarbonized energy systems. It does so by i) facilitating the integration of renewable energy sources when their supply is geographically distanced from a matching demand and ii) enabling a greater reliance on generation capacities in other European countries during times of low renewable energy supply. These aspects are pivotal as they align with the goals of avoiding curtailed renewable energy and maintaining high levels of security of supply. The latter has received growing attention in Germany in light of political decisions to phase-out nuclear and coal-fired power plants. Although the European internal electricity market plays a part in enabling the path to decarbonization, it is important to consider that the transforming energy system, increasingly reliant on renewable energy sources, makes the 
trading and transmission of electricity extensively more complex. Both, market participants, such as operators of power plants and traders, as well as grid operators have to make decisions with less certain information. The increased uncertainties that come with the hard-to-predict weather-dependent supply of the power system lead to a greater need for flexible markets and result in a larger requirement for grid operators to anticipate and manage grid congestions.

Against the described background this dissertation answers several research questions in eight articles within two main parts. Article 1-3 constitute the first part "Short- and mid-term interactions between renewable energy and electricity markets" and Article 4-8 amount to the second part "Modeling of and predictions within flow-based market coupling." The first part deals with the effect of power generation from renewable energy sources on Germany's power exports and prices, carbon emissions and uncertainties in power prices. It answers the questions i) how wind and solar energy affect the electricity prices and trade surplus of Germany, ii) to what extent carbon emissions and the electricity generation of conventional power plants in Germany are affected by the availability of renewable energy, and iii) how short-term corrections in the availability of wind energy affect electricity prices in different market situations. The second part is concerned with the design of key predictive parameters within flow-based market coupling as well as modeling the process of flow-based market coupling and quantifying the effects of changing decision parameters. It answers the questions iv) if different generation shift keys substantially alter trading domains and the effect of trade on individual critical network elements, v) what statistical or statistical learning methods are suited to predict the power output of generating units, vi) how a data-driven, dynamic and feasible statistical approach can be designed to obtain generation shift keys, vii) if larger minimum trading capacities lead to welfare losses, and finally viii) how the role and coherence of fundamental parameters within flow-based market coupling can be communicated in an easy-to-understand manner.

Article 1 finds that in Germany increasing renewable electricity generation leads to price decreases and consequently greater exports and that these effects are amplified by the introduction of flow-based market coupling. Solar and wind energy exhibit different shares of exported power that also largely depend on the given renewable feed-in. Article 2 describes that Germany's carbon emissions are driven by long-term transitions of the power sector, prominently the expansion of renewable energy generation capacities and carbon prices, as well as short-term market factors, especially gas prices. To achieve carbon emissions reductions, policy makers should focus on the steerable transition aspects. Article 3 ascertains that the weather-dependency of wind energy can introduce large forecast errors into the power sector that need to be balanced in the intraday market. The negative effect of wind energy on electricity prices largely depends on the composition of the merit order and can take on substantially different magnitudes, depending on the position, i.e. market situation, within the merit order. Article 4 works out that the efficacy of flow-based market coupling, i.e. its ability to correctly anticipate grid congestions and provide correct trading capacities to the market, is based on predictive parameters, importantly congestion forecasts, selection of critical network elements, consideration of outages and generation shift keys. The latter parameter needs to be carefully constructed, as it has a substantial effect on the cross-border capacities as well as individual network elements. Article 5 discovers 
that statistical learning approaches can help to accurately forecast the unit-specific power output as an important element of two-days ahead congestion forecasts within flow-based market coupling. It can be helpful to split up the forecasting task into classification and regression due to the on/off-status of power plants. Article 6 develops an approach to compute generation shift keys that is flexible, data-driven and can take into account historical dispatch decisions as well as day-to-day operative information from the congestion forecasts. The approach not only indicates the participation of units within the generation shift keys but also provides criteria to select units, the second important task of generation shift keys computations. Article 7 identifies that imposing minimum trading capacities on flow-based market coupling leads to overall welfare losses. The stipulation fosters price convergence and boosts market coupling welfare, but also impedes the system's ability to anticipate and account for grid congestions, which leads to higher costs for congestion management measures. Dynamic generation shift keys that take into account base case information are cost minimizing and should be preferred. Article 8 provides an easy-to-understand guide to the methodology of flow-based market coupling. The developed open-access model helps to understand how flow-based market coupling can find a model-based representation for academic and operative activities.

This dissertation makes important contributions to the field of quantifying the effects of renewable energy on power markets as well as the field of flow-based market coupling. This dissertation i) isolates the effects of electricity generated from renewable energy sources on energy exports, carbon emissions reductions as well as price levels and price uncertainties (Article 1-3), ii) develops and uses optimization model-based representations of flow-based market coupling to estimate the effects of the most important parameters within its procedure (Article 4, 7 and 8), iii) provides first analyses regarding the anticipated effect of trade on the grid and on the detailed level of individual critical network elements within flow-based market coupling (Article 4), iv) tests various statistical and statistical learning approaches for the prediction of power plant output (Article 5), v) develops a feasible, data-driven and dynamic approach for generation shift keys (Article 6), vi) measures the effects of minimum trading capacities on overall welfare and congestion management amounts and costs (Article 7), and vii) provides an open-access model and easy-to-understand guide to flow-based market coupling as a starting point for students, researchers and operative users (Article 8). 


\section{Acknowledgments}

First and foremost, I would like to express my sincere gratitude toward my doctoral advisor Prof. Dr. Dominik Möst for supervising this dissertation. Throughout many conversations and seminars he patiently accompanied this process, always providing insightful remarks on approaches and results and giving guidance for the next steps. I appreciate the academic freedom he gave me within this dissertation to explore and analyze relevant topics. Also, I would like to thank Prof. Dr. Stefan Eichler very much for agreeing to review and grade my dissertation. Many thanks to Prof. Dr. Alexander Kemnitz and Prof. Dr. Udo Buscher.

I would like to express my utmost thankfulness to my wife, Amy, for her endless support and cheers as well as her patience and selflessness along the way of this dissertation. I am most grateful to my parents, sister and friends for their love, support and encouraging conversations before and during the process of this dissertation. Special thanks to my parents and grandparents, without whose sacrifices many things would have been impossible in my life.

I thank my colleagues at the Chair of Energy Economics of TU Dresden, Carl-Philipp Anke, Constantin Dierstein, Julia Gutierrez-Lopez, Philipp Hauser, Dirk Hladik, Hannes Hobbie, Samarth Kumar, Steffi Misconel, Hendrik Scharf, Matthew Schmidt, Michael Zipf and Christoph Zöphel, for many helpful and eye-opening conversations over the course of several doctoral seminars, numerous meetings, countless (but really $n<1000$ ) lunch breaks and the occasional get-together after work hours. Also, I thank my co-authors (beyond my supervisor and colleagues), Prof. Dr. Sjur Westgaard, Prof. Dr. Erik Delarue, Dr. Kenneth Bruninx, Richard Weinhold, Michiel Kenis, Lisa Lorenz and Lasse Homann, for the constructive collaborations. I also thank my academic and industry project partners for everything I learned through our common projects. Last, but by no means least, I thank the Research Group Energy Systems Integration \& Modeling of KU Leuven for welcoming and hosting me during a short research stay and providing helpful comments on my work.

Dresden, June 2021 


\section{Contents}

Foreword .......................... $\mathrm{i}$

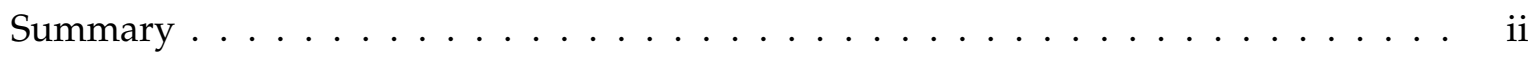

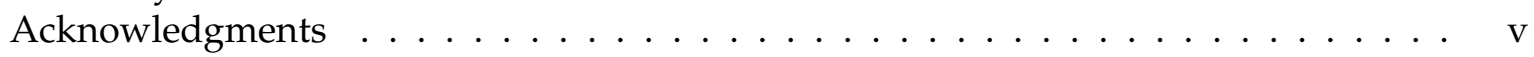

List of Figures $\ldots \ldots \ldots \ldots \ldots \ldots \ldots$. . . . . . . . . . . . . . . . . . . . . . . . . . . . . .

Nomenclature and short definitions $\ldots \ldots \ldots \ldots$. . . . . . . . . . . . . . . .

\begin{tabular}{|lll}
\hline A Introductory background, research questions and conjunction of research articles & $\mathbf{1}$
\end{tabular}

A.1 Energy political goals and challenges of the European Union . . . . . . . . . . . 1

A.2 Fundamentals of electricity price formation, market coupling and congestion

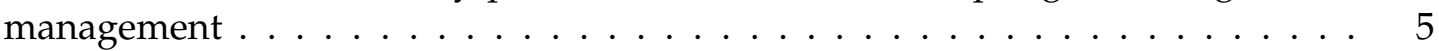

A.2.1 The merit order: Formation of electricity prices in a country . . . . . . . 5

A.2.2 Market coupling: Enabling cross-border trade of electricity . . . . . . . . . 7

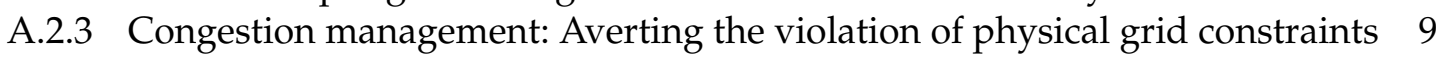

A.2.4 Trading capacities: Limiting cross-border exchange of electricity as a form of preventative congestion management . . . . . . . . . . . 11

A.2.5 Flow-based market coupling: Combining trading capacities, market coupling and congestion management . . . . . . . . . . . . . . 12

A.3 Addressing the research questions $\ldots \ldots \ldots \ldots \ldots \ldots$

A.3.1 Overview of articles as part of this cumulative dissertation . . . . . . . . . 17

A.3.2 Brief overview of used methods to address the research questions . . . . . 19

A.3.3 Relation and coherence of articles . . . . . . . . . . . . . . . . 20

A.3.4 Main findings of articles . . . . . . . . . . . . . . . . . . . . . . 21

A.3.5 Concluding remarks and further research . . . . . . . . . . . . . . . . 36

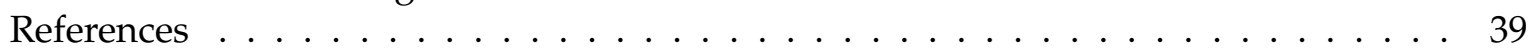

B Published and submitted articles 43

B.1 Parsing the Effects of Wind and Solar Generation on the German Electricity Trade

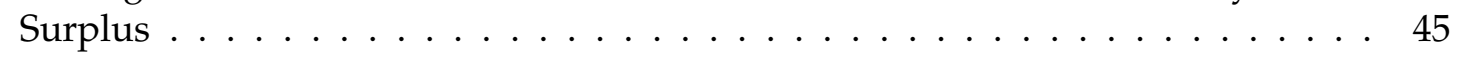

B.2 What caused 2019's drop in German carbon emissions: Sustainable transition or short-term market developments? $\ldots \ldots \ldots \ldots$. . . . . . . . . . 47

B.3 The effect of corrective short-term updates for wind energy forecasts on intraday

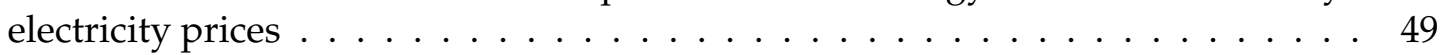

B.4 The impact of different strategies for generation shift keys (GSKs) on the flowbased market coupling domain: A model-based analysis of Central Western Europe 75

B.5 Zone-wide prediction of generating unit-specific power outputs for electric grid

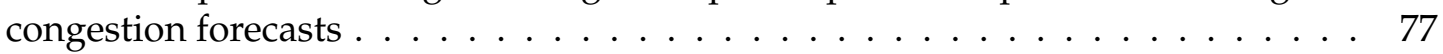

B.6 An Improved Statistical Approach to Generation Shift Keys: Lessons Learned from an Analysis of the Austrian Control Zone . . . . . . . . . . . . . . . . 79

B.7 Do minimum trading capacities for the cross-zonal exchange of electricity lead to

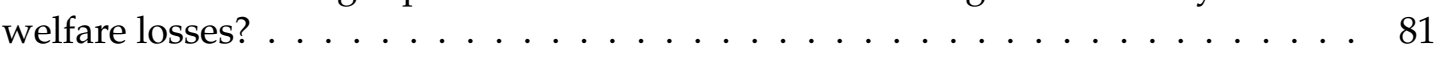

B.8 Toward a fundamental understanding flow-based market coupling for crossborder electricity trading $\ldots \ldots \ldots \ldots \ldots \ldots$ 


\section{List of Figures}

A.1 Merit order with and without available renewable energy. $\ldots \ldots \ldots \ldots \ldots$

A.2 Unlimited and limited trading of electricity between two zones. . . . . . . . . . 8

A.3 Historical gross electricity generation from renewable energy sources (2013 to 2020 ) as well as congestion management amounts and costs in Germany (2013 to

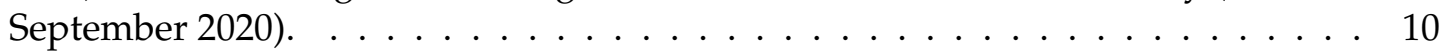

A.4 Two-dimensional static (ATC, available transfer capacity) and dynamic (FB, flowbased) trading domain between three zones. $\ldots \ldots \ldots \ldots 11$

A.5 Overview and structure of articles as part of this cumulative dissertation. . . . . 17

A.6 Key result of Article 1 - Effect of power generation from renewable energy sources on electricity prices. Figure from Kumar et al. (2019). . . . . . . . . . . 22

A.7 Key result of Article $2-$ Recent drivers of $\mathrm{CO}_{2}$ emissions reductions. Figure from Anke and Schönheit (2020). . . . . . . . . . . . . . . 24

A.8 Key result of Article 3 - Relation between available wind energy and intraday

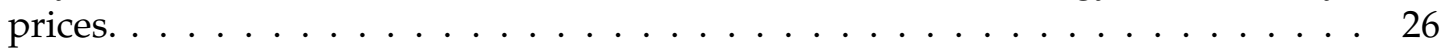

A.9 Key result of Article $4-$ Effect of bilateral trade on an individual network element.

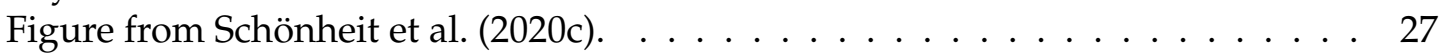

A.10 Key result of Article 5 - Average forecast errors for each generating unit. Figure from Schönheit et al.|(2021a). . . . . . . . . . . . . . . . . . 29

A.11 Key result of Article 6 - Computed generation shift keys with the statistical approach. Figure from Schönheit(2019). . . . . . . . . . . . . . . . . 31

A.12 Key result of Article 7 - Market and grid effects of growing minimum trading capacities. Figure from Schönheit et al.(2020a). . . . . . . . . . . . . . . 33

A.13 Key result of Article 8 - Relation between considered critical network elements and domain size in flow-based market coupling. Figure from Schönheit et al.

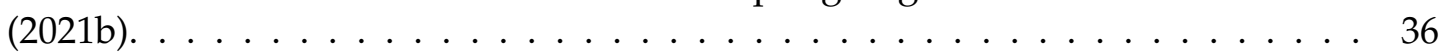




\section{Nomenclature and short definitions}

ATC available transmission capacity

bilateral capacities for cross-border power trade, currently used for most EU borders

CEE Central Eastern Europe

Austria, Croatia, Czech Republic, Germany, Hungary, Luxembourg, Poland, Romania, Slovakia and Slovenia

CNE critical network element elements of the electricity grid, monitored before and during market coupling in FBMC

CWE Central Western Europe Belgium, France, Germany, Luxembourg and the Netherlands

FBMC flow-based market coupling load flow-based provision of cross-border capacities, established in CWE since 2015

GSK generation shift key key predictive parameter in FBMC to anticipate power plant behavior during trade

MW megawatt unit for measuring power; often used for power plants and grid line capacities

PTDF power transfer distribution factor (nodal or zonal) indicating the sensitivity of lines flows to nodal injections or zonal trade positions

RAM remaining available margin amount of line capacity made available for trade; serves a constraint for market coupling

TSO transmission system operator responsible for transporting electricity; Germany has four, CWE/CEE: one per country

TWh terawatt-hour(s)

unit for measuring electrical energy; often used for energy economic figures 


\section{Chapter A}

\section{Introductory background, research questions and conjunction of research articles}

This chapter gives a concise introduction to the energy economic background pertaining to this dissertation, explains its structure, discusses the relation of its articles and provides a brief summary for each article (listed in Chapter B). Section A.1 gives a brief overview of the current overarching political goals, relating to a secure, affordable and sustainable provision of electricity. Section A.2 provides a short theoretical background of the dissertation's main topics: Electricity price formation, coupling of different electricity markets and electricity grid operation, especially congestion management. Particularly, it addresses the distinctiveness of flow-based market coupling. Based on this theoretical foundation the individual articles can be better contextualized and understood. The main research questions are derived, one representative for each article. Section A.3 provides an overview of the articles, detailing their titles, authors and date and place of submission or publication. The section also briefly explains the main methods of this dissertation and how the articles are tied together. Lastly, it gives a short summary of each contribution, including the motivation, approach and main results.

\section{A.1 Energy political goals and challenges of the European Union}

Complying with the commitments of the European Union (EU) to the Paris Agreement requires the reduction of greenhouse gas emissions by decoupling economies from fossil fuels and substituting them with electricity generation capacities based on renewable energy sources (The European Green Deal, European Commission, 2019b). The European path to decarbonization has to be considered in the wider context of the changes and challenges of the European energy market liberalization over the last 25 years, including the goal of a more efficient and competitive provision of electricity. The liberalization entails replacing vertically integrated companies, responsible for the generation, transmission and distribution of power, with market structures. Most EU member states have formally completed liberalization in the 2000s (Pepermans, 2019). However, the EU also has the superordinate goal of a well-functioning, interconnected electricity market, the European internal electricity market, which has been progressively implemented since 1999 but has yet to be completed. This electricity market aims to increase cross-border trade, 
achieve efficiency gains and contribute to sustainability (cf. Regulation (EU) 2019/943, Council of the EU and European Parliament, 2019). Regulation (EU) 2019/943 relates to the "Clean energy for all Europeans" package, laying out actions to put into effect a sustainable energy system, adhering to high levels of security of supply and achieving competitive energy price (European Commission, 2019a).

To appreciate the current challenges of these actions, it is important to understand the steps leading to the goal of a European internal electricity market. Capacities for cross-border trading used to be auctioned explicitly, i.e. separately from the trade of electricity. In Germany this was the case until 2010, when the country joined the trilateral market coupling and implicit auctioning system of France, Belgium and the Netherlands, in line with the liberalization of electricity markets. By now, it is a 19-country multi regional coupling, covering $85 \%$ of Europe's electricity consumption (Van den Bergh et al., 2016; Amprion, 2020). The implicit capacity auctioning was based, and still is for many borders, on so-called available transmission capacities (ATCs), defining the amount of electricity that can be traded across a given border, only under the consideration of bilateral transactions (Kristiansen, 2020). Generally, cross-border capacities try to account for the fact that when electricity is traded within a market zone $\varrho^{1}$ and across market zones, the physical transmission of electricity can become the constraining element due to limited grid infrastructure. In the long-run, this can be relieved by grid expansion, which is, however, a much-debated topic that can also spark resistance among the affected parts of the population (cf. Neukirch, 2016). Therefore, it is desirable to utilize the existing grid to its full capacity and avoid unnecessary and costly expansion measures (cf. Grimm et al., 2016). The resulting goal is to allow the greatest amount of trade, while considering and anticipating grid constraints and maximizing the utilization of the existing grid. The challenge of providing accurate trading capacities is complicated due to the difference between commercial electricity exchanges and physical flows (Van den Bergh et al., 2016).

In an ongoing process since 2015, the EU attempts to cope with this posed challenge and counteract the divergence of power markets and physical power flows by introducing the so-called flow-based market coupling, currently only in Central Western Europe (CWE) but with a planned geographical expansion to Central Eastern Europe (CEE) (Amprion, 2019). Flow-based market coupling manages the trading of electricity between zones and allocates cross-border capacities, considering how the electricity grid is affected by trade (Van den Bergh et al., 2016). In other words, flow-based market coupling bases its cross-border capacities on the computation of 1) electricity grid utilization, 2) changes in grid utilization due to the trade of electricity as well as 3) the limits of grid utilization. This feature is of utmost significance as it enables a more realistic representation of physical grid constraints during trade, which leads to welfare increases with sufficient levels of reliability, stability and robustness (Van den Bergh et al., 2016). The effective, feasible, transparent and harmonized implementation of flow-based market coupling

\footnotetext{
${ }^{1}$ In a market zone, a uniform price is formed during trade. Geographically a zone typically corresponds to one country or part of a country, with the exception of Germany and Luxembourg, forming one common market/bidding zone. Before October 2018, Austria was part of this market zone, namely DE/AT/LU (Austrian Power Grid. 2020).

${ }^{2}$ Together CWE (Belgium, France, Germany, Luxembourg and the Netherlands) and CEE (Austria, Croatia, Czech Republic, Germany, Hungary, Luxembourg, Poland, Romania, Slovakia and Slovenia) form the Core Region (ENTSO-E, 2016; :ENTSO-E, 2019).
} 
is a highly relevant, current energy economic and political challenge that brings forth many research questions regarding the design of flow-based market coupling itself as well as its effects on electricity market welfare and grid operation. This dissertation addresses some of the most important questions of flow-based market coupling, discussed in greater detail below.

Cross-border trade of electricity in general and specifically the design and implementation of flow-based market coupling are not happening in an isolated environment. On the contrary, these aspects are subject to the current transition of the European power system to sustainability (dubbed Energiewende in Germany). This transition is not only changing the power systems of European countries but the transition itself is changing: While in the 2000s electricity generation from renewable energy sources had to be subsidized at high rates-driven by the goal of decarbonization-, their competitiveness has drastically increased since. Renewable energy sources are now often competitive without subsidies and can be or become the most inexpensive way of providing electricity, especially with growing $\mathrm{CO}_{2}$ prices (Kost et al. 2018). However, a rising reliance on renewable sources, such as solar and wind power, subjects the generation side of an energy system to a greater degree of weather dependency and uncertainties. Consequently, the supply side is progressively transitioning from an almost completely dispatchable (i.e. controllable) state to a more fluctuating, exogenous state. This raises questions regarding the adequate security of supply during times of no or low amounts of sunshine combined with absent or slow wind speeds, an event whose extreme form has been referred to as a Dunkelflaute in German - a dark (or overcast), windless (or low-wind) period (Jessen-Thiesen et al., 2019). These events are receiving growing attention in light of political decisions, such as the nuclear and coal phase-out (cf. Kommission "Wachstum, Strukturwandel und Beschäftigung", 2019). On the other end of the spectrum of renewable energy supply, challenges emerge regarding the integration and storage of electricity during sunny and windy times to avoid curtailing, i.e. discarding available renewable energy. This increases the power system's need for flexibility in form of highly flexible power plants, energy storages and demand-side response (Huber et al., 2014: Schill, 2014), or, alternatively, exchanges with neighboring countries. The longer the weather-dependent share of the supply side remains in one of the two extremes, very low or very high amounts of feed-in, the greater the implications for the energy system.

Beside the economic goal of affordable energy prices, also the challenge of integrating the growing shares of renewable energy into power markets and grids increases the necessity of implementing the European internal electricity market (European Commission, 2019a and results by Huber et al. 2014). Power from renewable energy sources is not always available where needed or, on the contrary, needed where available. While renewable energy can be available in one country and can therefore provide low-priced energy to an importing country when markets are coupled, generation and demand may be geographically far distanced. This effect is augmented by increasingly consolidated capacities of certain renewable energy technologies, such as offshore wind energy. This discrepancy between supply and demand can be counteracted by allowing greater exchanges across borders, enabled through a more integrated market. Also the abovementioned aspect of security of supply is not only underpinned by the readiness of national generation capacities to meet the demand, a sufficient network infrastructure and diversity of 
energy supplies (Helm, 2002 and Creti and Fabra, 2007). Instead, the reliance on available energy from neighboring countries, made available through trade, is becoming increasingly important. Thus, a secure supply of electricity becomes less of a national and more of a multilateral concern.

An integrated and interconnected European market is part of the solution to achieving the EU's energy political goals. However, it is important to consider that when power systems increasingly rely on renewable energy sources electricity trade itself and grid operation also gain complexity. As mentioned above, their weather dependency makes renewable energy sources subject to greater uncertainties, manifesting themselves in forecast errors (Wang et al., 2011). As a consequence, market participants have to make trading decisions and grid operators have to maintain a secure electricity grid with less certain information. Deviations from forecasts have to be balanced, stressing the role of system flexibility and higher short-term trade activity, especially in the intraday market to support the system balance (Koch and Hirth, 2019). For grid operators greater uncertainties have resulted in larger and more frequent corrective actions (BDEW, 2020).

The described challenges and uncertainties span a wide field of questions. These are divided into two parts within this dissertation. The first part looks at how the expansion of renewable energy affects Germany's electricity system in terms of price developments, the export balance and carbon emissions reductions. The three articles in this first, precursory part of the dissertation (Article 1-3, Section B.1 B.3) are subsumed under the title "Short- and mid-term interactions between renewable energy and electricity markets." The second part details how market coupling is realized between zones, specifically with the above-mentioned flow-based market coupling. Flow-based market coupling is a very current topic and of highest importance for many market participants, such as electricity trading companies, as well as grid operators and regulators. As the topic is very new, there is a large research gap, providing ample opportunities for innovative and relevant research. The gap is closed with five articles in the second part (Article 4-8, Section B.4 B.8), which focuses on how to represent flow-based market coupling within energy economic models and proposes approaches for key predictive parameters. It is titled "Modeling of and predictions within flow-based market coupling."

The next sections are structured as follow: Section A.2 provides an understanding regarding 1) price formation for electricity within a single country (A.2.1, 2) advantages of market coupling, explaining how trade across countries is enabled (A.2.2, 3) the prevention and curing of congestions in the grid (A.2.3, 4) the formation of cross-border trading capacities as limits to trade and as a form of preventative congestion management A.2.4 and 5) flow-based market coupling and how it combines the three prior aspects A.2.5. Also Section A.2.1 and A.2.5 derive the research questions, respectively for the two parts of this dissertation "Short- and mid-term interactions between renewable energy and electricity markets" as well as "Modeling of and predictions within flow-based market coupling." Section A.3 explains how the posed research questions are addressed, by 1) providing an overview of the articles as a part of this cumulative dissertation (A.3.1), 2) giving a brief overview of the used methods A.3.2, 3) detailing how the articles relate to each other (A.3.3), 4) elaborating the main findings of each article (A.3.4) and 5) concluding with final remarks and further necessary research activities A.3.5. 


\section{A.2 Fundamentals of electricity price formation, market coupling and congestion management}

This section gives a concise explanation of the basic mechanisms of electricity price formation, the coupling of electricity markets as well as congestion management, which is the process of preventing and resolving congestions to attain the compatibility of market results with the electricity grid's capacities. The last part of this section highlights the distinctiveness of flowbased market coupling, as the preferred market coupling algorithm. From these fundamental explanations the main research questions are derived.

\section{A.2.1 The merit order: Formation of electricity prices in a country}

The formation of electricity prices follows the merit order, an arrangement of available generation capacities in ascending order of their short-term marginal generation costs, forming the supply curve, i.e. $S_{\text {(merit order) }}$ (Cludius et al. 2014). This is depicted in Figure A.1. The panels describe two situations, one with high demand and one with low demand $\left(D_{\text {High }}\right.$ and $\left.D_{\text {Low }}\right) \cdot 3$ The intersections between the demand and generation capacities determine the prices $\left(\mathrm{P}_{\mathrm{High}}\right.$ and $\left.P_{\text {Low }}\right)$. This is a simplified, one-country example with three conventional technologies, constant technology-specific marginal costs, complete availability of conventional power plants, priceinelastic demand and no trade.

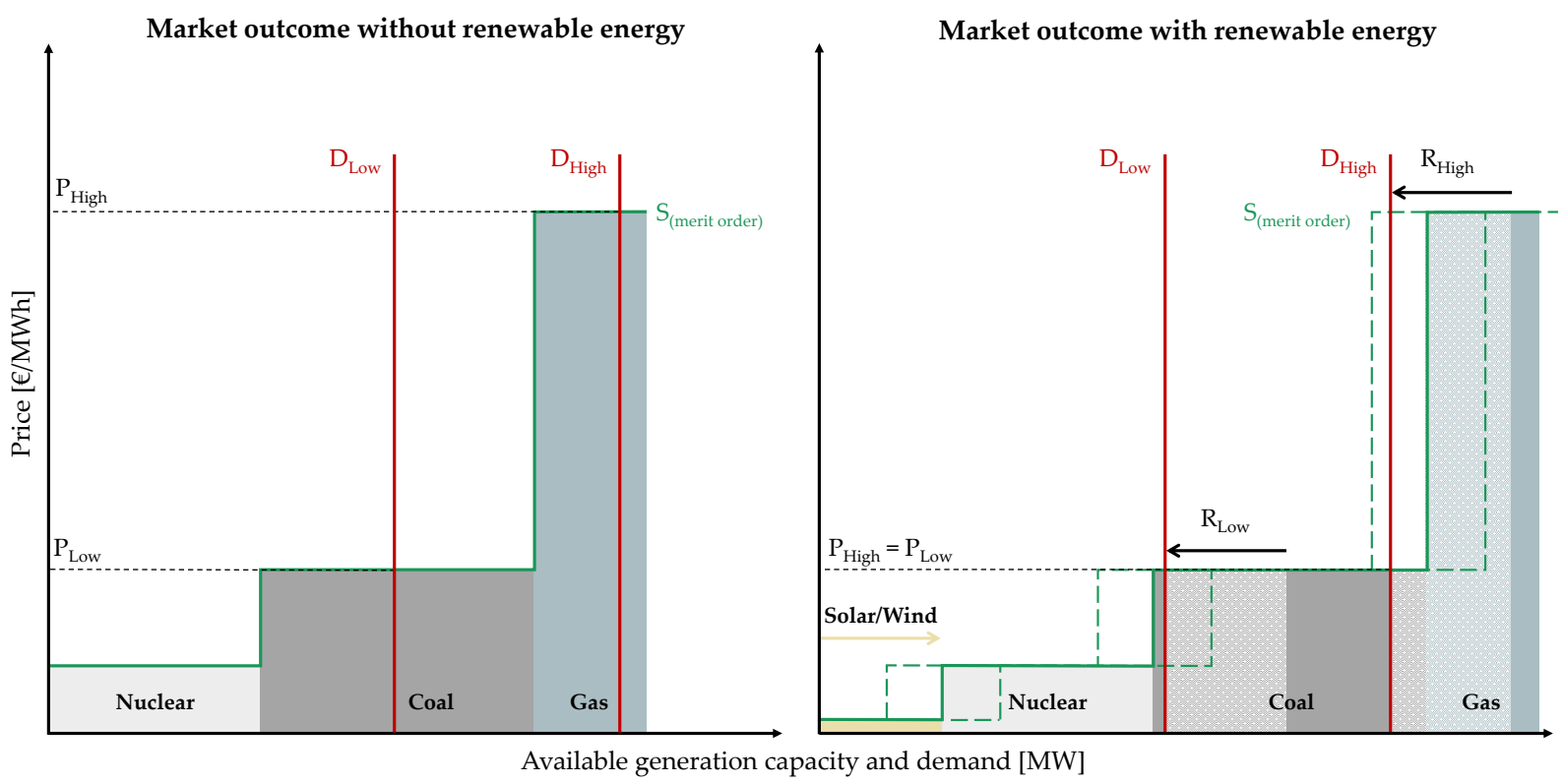

Figure A.1: Merit order with and without available renewable energy.

The left panel depicts a situation without renewable energy feed-in. Here, energy demand in the low load situation is covered by nuclear and coal-fired power plants. The latter one is the price setting technology, determining the price for the entire zone that all generating units receive. In the high load situation, gas-fired units are required to cover the demand and consequently set the price.

\footnotetext{
${ }^{3}$ Note that contrary to common microeconomic assumptions, demand for electricity is often assumed to be price-inelastic in power market models since there are no close substitutes for electricity.
} 
In the right panel, fluctuating renewable energy, e.g. wind and/or solar energy, is available and added at the beginning or left side of the merit order. This assumption is mainly based on the priority feed-in of renewable energy (European Parliament and Council of the EU, 2009) but also their low marginal costs $4_{4}^{4}$ This shifts the static, conventional part of the merit order to the right. The size of the shift (forward-facing yellow arrow) equals the replacement of conventional units (backward-facing black arrows and shaded areas). $R_{\text {High }}$ and $R_{\text {Low }}$ indicate the replacements and correspond with the "width" of the renewable energy feed-in. Both demand situations can now be covered by coal power plants and the price is the same in both situations. In theory, this shift in the merit order has several important effects.

The price declines. The real merit order consists of numerous blocks, not just three, so any addition of renewable energy will likely replace the price-setting unit and lead to a unit with lower marginal costs to determine the price, referred to as "merit order effect" (Cludius et al. 2014). In this simplified example, only the high demand situation entails a price shift. Generally, this effect of declining prices is more pronounced at the far end of the merit order due to its shape. Although this is a one-country example, at this point it is important to mention that the lower price due to renewable energy may spur electricity exports from the considered country to other countries.

Local carbon emissions are reduced (temporarily). Any conventional power generation is associated with carbon emissions. The exception is nuclear power plants, which are, however, rarely replaced by renewable energy due to their position in the merit order as well as their rather inflexible dispatch behavior $5^{5}$ Thus, in virtually all cases electricity from renewable energy with zero carbon emissions (at the point of generation) replaces conventionally generated electricity with non-zero emissions. In the example above, these replacements are indicated by $R_{H i g h}$ and $R_{\text {Low }}$. When considering more than one country and more than one time step, the emissions reduction effect may only be local and temporary. The overall cap of the EU Emissions Trading System sets the total emissions (European Commission, 2020). However, reduced emissions also decrease the carbon price and are therefore possibly emitted sometime or somewhere else (e.g. by another country, cf. "waterbed effect" and discussion by Anke et al. 2020).

More uncertainty is introduced into the system. As discussed above, renewable energy is intermittent, weather-dependent and difficult to predict. The majority of electricity is traded on the day-ahead market (EPEX SPOT, 2018) 6 Therefore, the amount of available renewable energy, i.e. the width of the block in the merit order, is uncertain a priori. Suppose two different kinds of false predictions, indicated by the dashed merit order (supply) curves in the right panel. If renewable energy is initially underestimated the merit order is later further shifted outward (cf. von Selasinsky, 2016). In the low demand case a small amount of additional available energy is enough to make nuclear power the price-setting technology and lower the price. Conversely, renewable energy can be overestimated. In consequence, some of the initially anticipated shift of the merit order is later reversed. In the high demand case an overestimation leads to a lower

\footnotetext{
${ }^{4}$ Solar and wind energy capacities do not have fuel costs but operating costs incur, e.g. due to maintenance, repairing, operational management and trading. Most of these components are fixed costs, however, so the marginal costs of generating electricity from these renewable energy sources are typically low or even zero.

${ }^{5}$ Note that this is a German perspective with small nuclear capacities relative to the entire system.

${ }^{6}$ Importantly, the intraday market has gained importance and volume in recent years (Koch and Hirth. 2019).
} 
amount of available renewable energy and therefore causes a higher price set by gas-fired units. The required overestimation for this to happen is larger than the hypothetical underestimation in the low demand case. However, the price change would be very large, i.e. the price uncertainty is large.

In summary, the electricity price is formed based on demand and the shape of the merit order that depends on the availability of conventional power plants, the availability of renewable energy and the marginal costs of power plants, determined by fuel prices and the carbon price. Also, the severity of the described forecast errors for renewable energy, causing further shifts of the merit order or partially reversing anticipated shifts, likely depends on the position within the merit order. The country-specific (or market zone-specific) merit orders will also affect price differences and thus trade across borders, the main focus of this dissertation that is addressed in the coming sections.

However, from the hitherto described effects several research questions can be derived. These describe major short- and mid-term effects but are, of course, not exhaustive. Article 1 (B.1) addresses Q1, Article 2 (B.2) deals with Q2 and Article 3 (B.3) is concerned with Q3:

Q1: How does renewable energy affect the electricity prices and trade surplus of Germany and are these effects different for solar and wind energy?

Q2: To what extent are carbon emissions and the electricity generation of conventional power plants in Germany affected by the availability of renewable energy?

Q3: How do short-term corrections in wind energy forecasts affect prices and do the effects vary in different market situations, i.e. in different merit order positions?

Article 1-3 B.1, B.2 and B.3) of this dissertation are combined in the first part "Short- and mid-term interactions between renewable energy and electricity markets." Although Article 1 and 3 address the trade surplus and power prices of Germany, respectively, they are not counted into the second part of this dissertation that broaches the issue of market coupling. The reason is that the analyses in Article 1 and 3 only consider Germany, taking on the perspective of a single country, and deal with outcomes of trade but not explicitly modeling market coupling or elements of market coupling, as done in all articles of the second part.

\section{A.2.2 Market coupling: Enabling cross-border trade of electricity}

Market coupling combines the bids of national exchanges and provides the opportunity to trade electricity across market zones. This goes along with the EU's goal of an interconnected market to preserve security of supply and attain competitive prices. But why is trading desirable and what are its limits?

On a general and theoretical level, trade theory, e.g. the Heckscher-Ohlin model, suggests that two trading countries will gain from trade, compared to a situation without trade (Markusen and Melvin, 1981). For the concrete example of electricity trading in Europe, the benefits of market integration are estimated to be several billion euros annually (Newbery et al. 2016). Figure A.2 explains the origin of these gains of electricity trade. 


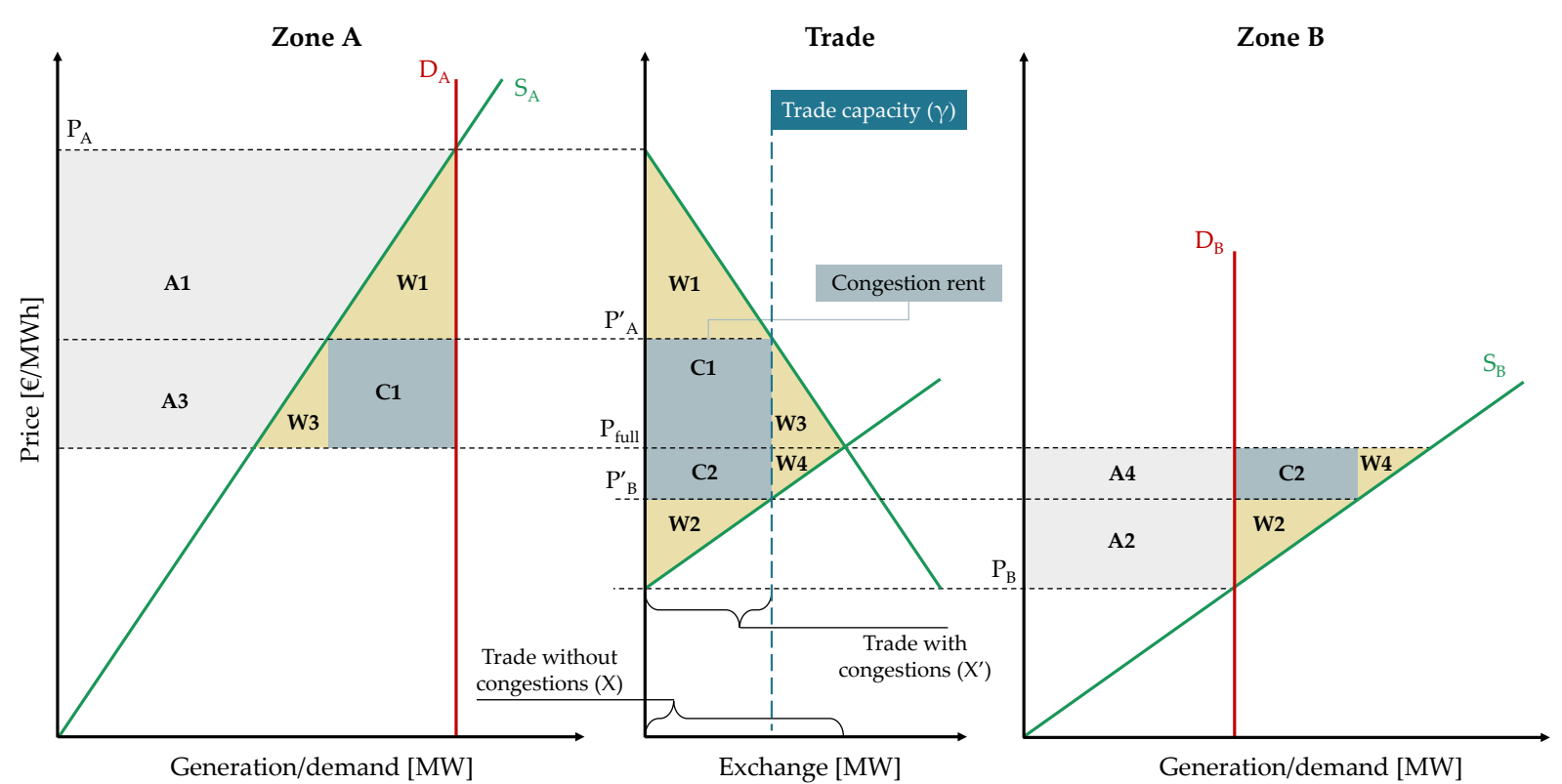

Figure A.2: Unlimited and limited trading of electricity between two zones.

The left and right panel of Figure A.2 (following Androcec et al., 2009 and 50 Hertz et al. 2018) consider the price formation within two zones, without the possibility for trade. Then, two zonal prices are formed, $\mathrm{P}_{\mathrm{A}}$ and $\mathrm{P}_{\mathrm{B}}$, resulting from the intersection of supply and demand, $D_{A}=S_{A}$ and $D_{B}=S_{B}$. Note that these examples assume complete price inelasticity of demand and the step-wise merit orders (cf. Figure A.1) are simplified as lines.

When allowing for trade, zone A reduces its generation and zone B increases its production, leading to an exchange $X$ between the zones, where zone $A$ is the importing zone and zone $B$ is the exporting zone. The middle panel displays that for an exchange, zone $B$ is the supplying zone, thus the supply line for exchange is identical to the supply line in zone B past the point of the demand of zone B. The reduction in supply in zone A, due to cheaper available energy in zone B, becomes "additional demand" for zone B, which is why the supply line of zone A, below the point of demand in zone $\mathrm{A}$, is mirrored and appears as a "demand" line for the exchange.

When there are no limiting trade capacities, i.e. when the capacity needed for an exchange of $X$ can be provided to the market due to sufficient transmission capacities (assumed to be lossless), the zonal prices can fully converge to $P_{\text {full }}$. In this case, the total welfare gain is the sum $(W 1+C 1+W 3)+(C 2+W 4+W 2)=\frac{1}{2} \cdot\left(P_{A}-P_{B}\right) \cdot X$. The welfare gain for zone $A$ is $W 1+C 1+W 3$, where $A 1+W 1+A 3+W 3+C 1$ is the gain in consumer surplus and $A 1+A 3$ the loss in producer surplus. $C 2+W 4+W 2$ is the welfare gain for zone $B$, where $\mathrm{A} 4+\mathrm{C} 2+\mathrm{W} 4+\mathrm{A} 2+\mathrm{W} 2$ is the gain in producer surplus and $A 4+\mathrm{A} 2$ the loss in consumer surplus.

When the desired exchange exceeds the trade capacity $\gamma$, exchange $X^{\prime}<X$ is realized and prices converge, but not fully, to $\mathrm{P}_{A}^{\prime}$ and $\mathrm{P}_{\mathrm{B}}^{\prime}$. The overall welfare gain for market participants is reduced to $W 1+W 2=\frac{1}{2} \cdot\left(P_{A}-P_{A}^{\prime}\right) \cdot X^{\prime}+\frac{1}{2} \cdot\left(P_{B}^{\prime}-P_{B}\right) \cdot X^{\prime} . W 1$ is the welfare gain for zone $A$, with $A 1+W 1$ being the gain in consumer surplus and $A 1$ the loss in producer surplus. $W 2$ is the welfare gain for zone $B$, with $A 2+W 2$ being the gain in producer surplus and $A 2$ the loss in consumer surplus. $\mathrm{C} 1+\mathrm{C} 2$ is the congestion rent, equal to $\left(\mathrm{P}_{A}^{\prime}-\mathrm{P}_{B}^{\prime}\right) \cdot \mathrm{X}^{\prime}$, collected by the 
system operator (cf. Hirth et al. 2019), because consumers pay more than producers receive (Weibelzahl, 2017). It indicates the economic value of transmission lines (Van den Bergh et al. 2014). W3 + W4 is the congestion-caused dead-weight loss, also referred to as "congestion cost."

Note that both, the uncongested and the congested case result in a welfare gain. Thus, both cases result in a larger overall welfare than a situation without any trade. It becomes evident that a larger trade capacity will shrink the dead-weight loss as well as increase the gains in welfare, i.e. $W 1 \underset{\gamma \rightarrow X}{\longrightarrow} \frac{1}{2} \cdot\left(P_{A}-P_{\text {full }}\right) \cdot X$ and $W 2 \underset{\gamma \rightarrow X}{\longrightarrow} \frac{1}{2} \cdot\left(P_{\text {full }}-P_{B}\right) \cdot X$.

Thus, from a market perspective the maximization of trading capacities and unhindered trade are advantageous. Also, from a standpoint of integrating renewable energy and security of supply, large trading capacities increase the possible trade of renewable energy and reliance on generation capacities in other countries. From a security of supply perspective this is especially important during times of low renewable energy feed-in. However, the main challenge is determining the correct trading capacities. The welfare gains, ensuing due to larger trading capacities, may be partially, fully or more than offset by higher amounts of corrective measures to ensure the secure operation of transmission systems when market results are incompatible with the electricity grid. This operative congestion management, which can be curative or preventative, is further described in Section A.2.3. Abating or avoiding grid-incompatible market outcomes before and during market coupling, specifically by providing correct trading capacities, is another dimension of preventative congestion management, detailed in Section A.2.4.

\section{A.2.3 Congestion management: Averting the violation of physical grid constraints}

While the clearing of markets finds the cost minimizing match of demand and supply, the market outcome, the so-called dispatch, may not be compatible with the grid. This means the committed amounts of power generation cannot be fully transported via the electrical lines without violating the physical limits of the grid elements. These events are referred to as congestions. To a large extent they are the result of a market setup with zonal market clearing ("zonal pricing") and subsequent grid operation, rather than considering all grid constraints during market coupling, as is done in so-called nodal pricing approaches. Nodal pricing is seen as the approach producing the optimal short-term price signals to market participants, while zonal pricing implies welfare losses (Androcec et al. 2009). Before and during grid operation, congested network elements have to be relieved-by reducing the electrical flow-to prevent the violation of grid constraints (Weibelzahl, 2017). In other words, zonal pricing comes at the cost of more frequent ex-post adjustments, i.e. congestion management, because grid constraints are imperfectly and incompletely anticipated and incorporated during market coupling.

Congestion management entails lowering the feed-in at points of overproduction and increasing the feed-in at points of undersupply. The first effect is achieved by so-called negative redispatch, which involves decreasing the power output of relevant generating units, or, alternatively, curtailing the feed-in of weather-dependent renewable energy sources, e.g. by altering the pitch angle of wind turbines (Jauch and Gloe, 2016) or inverter control of photovoltaics installations (Seuss et al., 2016). To balance demand and supply at all times, negative redispatch and curtailment have to be matched by positive redispatch, i.e. increasing the power output of 
relevant generating units. The relevance of units is decided by the effectiveness and grid compatibility of redispatch actions: Power has to be reduced at points "feeding into" the congestion and more power has to be fed in "behind" the congestion. For Germany, these network and system security measures are stipulated in $\$ 13$ EnWG and encompass redispatch, including the utilization of reserve capacity, curtailment as well as other adjustment measures, which play a minor role. It is important to note that redispatch ( $\$ 13$ paragraph 1 EnWG) is generally preferred over curtailment ( 13 paragraph 2 EnWG in conjunction with $\S 14$ EEG) (cf. 50Hertz, 2020 and Grimm et al., 2016).
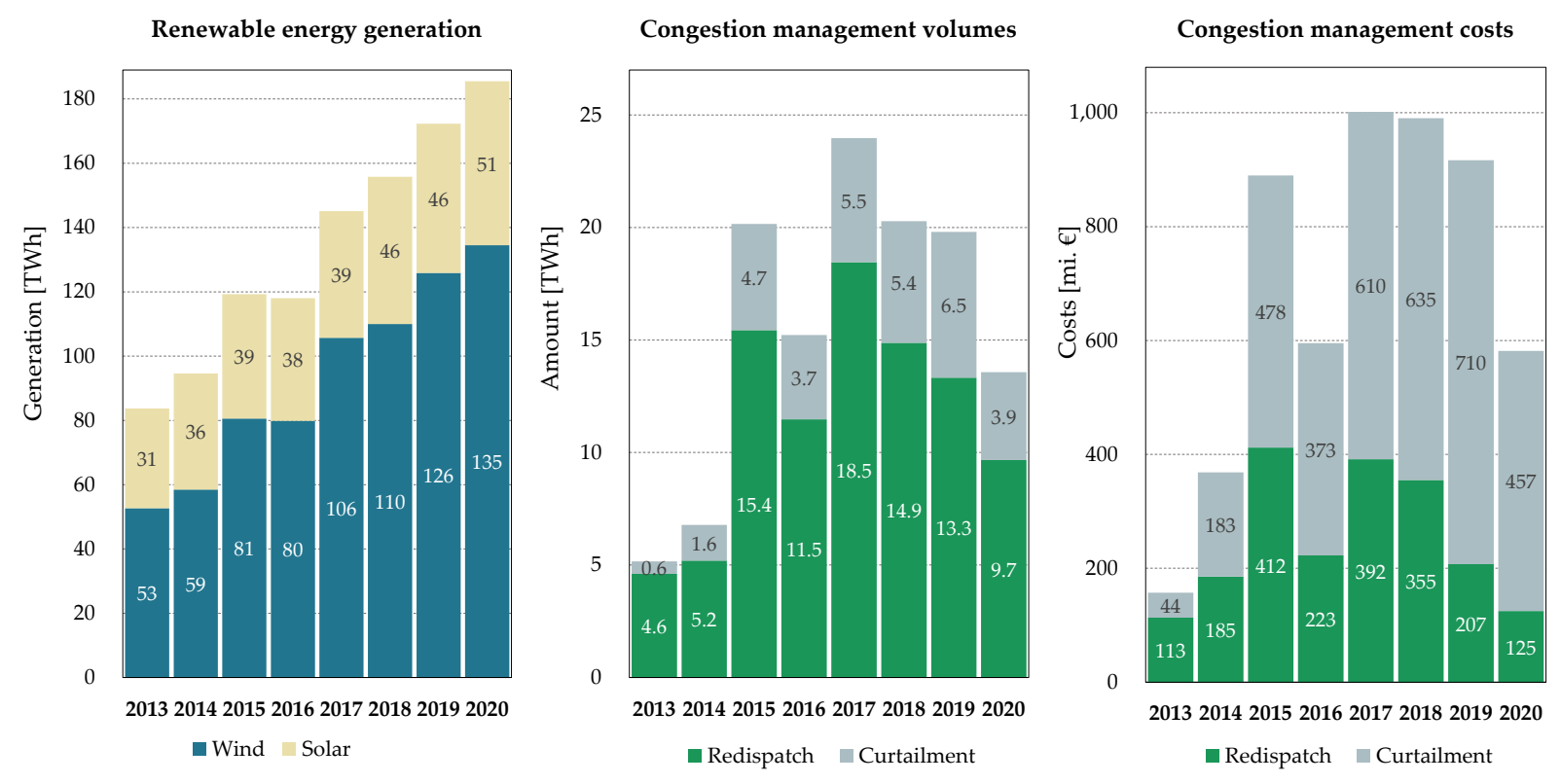

Figure A.3: Historical gross electricity generation from renewable energy sources (2013 to 2020) as well as congestion management amounts and costs in Germany (2013 to September 2020).

To illustrate the growing importance of congestion management, Figure A.3 displays the historical amounts and costs of redispatch and curtailment in juxtaposition with the electricity generation from solar and wind energy, the main weather-dependent renewable energy sources for power generation..$^{7}$ Notably, before 2015 the total amount of congestion management remained at low levels of around 5 TWh and 7 TWh in 2013 and 2014, respectively. Contemporaneous with the expansion of renewable energy capacities, the redispatch and curtailment amounts soared and with them the associated costs. Despite further increases in renewable energy feed-in after 2017, the congestion management costs and amounts slightly declined, attesting to the more efficient integration of renewable energy sources into the power system.

The above-described measures can be part of curative as well as preventative congestion management, mostly after market coupling and during grid operation. This kind of congestion management can be costly, especially the curtailment of renewable energy, whose operators are still remunerated even if curtailed (with limited exceptions). Hence, further preventative measures within congestion management are gaining importance. One important way of preventing congestions is to limit the amount of trade during market coupling to grid-compatible levels.

\footnotetext{
${ }^{7}$ Renewable energy generation: BMWi and AGEE-Stat 2020) (2013-19) and Destatis 2021) (2020; preliminary figures). Congestion management: $\operatorname{BDEW}(2020)$; for 2020, sums for Q1-Q3 (January to September) are displayed.
} 


\section{A.2.4 Trading capacities: Limiting cross-border exchange of electricity as a form of preventative congestion management}

Providing a grid-compatible amount of trading capacities attempts to send the right "congestion signals" to the market (cf. Weibelzahl, 2017). These congestion signals cannot fully avoid congestions, especially intrazonal ones, but can reduce or limit congestions caused by cross-zonal trade. Initially, auctioning cross-border capacities was separate from the trading of electricity. Implicit auctioning of capacities was introduced in 2006 in form of market coupling between France, Belgium and the Netherlands. In 2010, Germany joined this market coupling, which was based on available transfer capacities (ATCs) ${ }^{8}$ ATCs indicate the maximum bilateral exchange between two market zones, only considering bilateral trade activities. Therefore, transmission system operators (TSOs) have to split trading capacities between the involved borders (Kristiansen, 2020).

Flow-based market coupling (FBMC) was introduced in 2015 in Central Western Europe (CWE), after tests in parallel to the existing ATC method. It led to higher social welfare and larger trade volumes, accompanied by high levels of reliability, stability and robustness (Van den Bergh et al., 2016; Kristiansen, 2020; Lang et al., 2020). Thus, it is the preferred method to serve as a basis of calculating and providing cross-zonal capacities, stipulated by Commission Regulation (EU) 2015/1222 (European Commission, 2015). FBMC was supposed to be implemented in the Core Region-CWE and Central Eastern Europe-by the end of 2020 (Amprion, 2019), a process that will be delayed. More details regarding the method of flow-based market coupling follow in Section A.2.5.

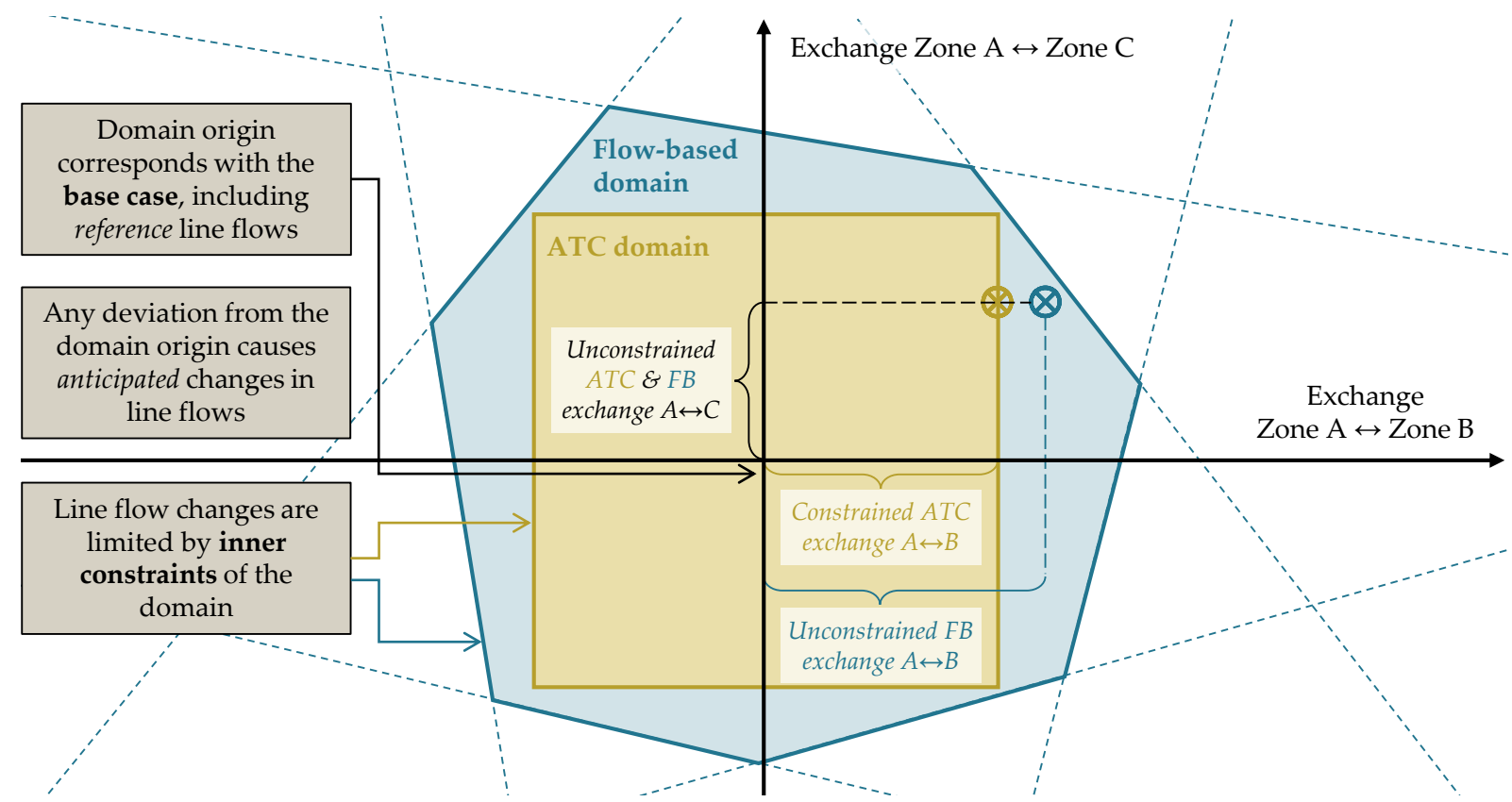

Figure A.4: Two-dimensional static (ATC, available transfer capacity) and dynamic (FB, flow-based) trading domain between three zones.

\footnotetext{
${ }^{8}$ For the remainder of the text, ATCs are used to describe the method based on available/net transfer capacities (ATCs/NTCs). ATCs are derived by subtracting already allocated (long-term) capacities from NTC values (Weber et al. 2010).
} 
Trading domains are exemplary visualized in Figure A.4 (based on Amprion et al., 2014 and 50 Hertz et al., 2017). In this form of depiction, the domain origin represents no trade and therefore exchanges of zero between the involved zones. The so-called base case, a congestion forecast done two days prior to the day of delivery and therefore the day before day-ahead market coupling (see Section A.2.1 and A.2.2), estimates the line flows in this situation of no trade. Any deviation from the origin means there is trade between at least two zones. Any trade activity is associated with line flow changes, which have to be anticipated. At points, where line flow changes utilize that maximum available grid capacity, an inner constraint limits the trading domain.

Note that while the ATC domain is box-shaped due to static exchange capacities, the flowbased market coupling domain is dynamic, exactly because it anticipates line flow changes (detailed in Section A.2.5). The desired market outcome, i.e. the resulting exchanges based on the coupling of national bids, is the blue point. With FBMC, this point can be cleared, which results in an unconstrained trade because the point does not reach the limits of the FBMC domain. With ATC, however, the desired market outcome cannot be cleared as it exceeds the inner constraints. Instead, the yellow point is cleared. This leads to a constrained trade between zone A and zone B. The trading between zone $\mathrm{A}$ and $\mathrm{C}$ is unconstrained in both cases.

The difference between ATC and flow-based in this example refers back to Figure A.2, in which there is trade with and without congestions. In this case, flow-based market coupling represents the case without congestions $(\gamma \geqslant X)$ and can provide the full gain in welfare, while ATC can provide only a partial gain in welfare $\gamma=X^{\prime}<X$.

It is important to note that the desired market outcome is the same in both cases. The difference is that, on average, flow-based market coupling better anticipates how the desired export-import positions of the zones translate into line flow changes. In this particular case, flow-based market coupling can clear the desired point because it anticipates that the limiting element (elements) of the grid is (are) affected to a smaller extent than under ATC. Drawing on the conclusions of Section A.2.2, the premise of cross-border capacity calculations remains to avoid excessive trading capacities. This means that the larger capacity provided by flow-based market coupling in the example above ideally preserves the same amount of grid security and does not increase the need for corrective or remedial actions, i.e. congestion management. The overall goal of flow-based market coupling is therefore an optimal utilization of existing grid capacities to provide the greatest amount of trade, constrained by a correct anticipation of congestions. The next section explains how flow-based market coupling anticipates changes in line flows and subsequently sets trading domain constraints.

\section{A.2.5 Flow-based market coupling: Combining trading capacities, market coupling and congestion management}

Flow-based market coupling combines the three main aspects of Section A.2.2, A.2.3 and A.2.4 Its algorithm provides cross-border trading capacities during market coupling, therefore carrying out preventative congestion management. For ease of understanding, this section purposely 
refrains from a mathematical notation of flow-based market coupling, since this is covered extensively, e.g. in Schönheit et al. (2020b) and Schönheit et al. (2020c).

The flow-based market coupling algorithm bases its resulting cross-border capacities on flow calculations, which is where it derives its name from. It does so for a subset of network elements that are deemed critical. This status is determined by estimating how much an individual grid element, e.g. a line, is affected by trade. For this, sensitivities are computed for every bilateral combination of involved market zones. These sensitivities are referred to as zone-to-zone PTDFs (power transfer distribution factors) and indicate what share of an additional amount of trade between two zones is allotted to a specific line. For instance, the value $\mathrm{PTDF}_{\mathrm{l}, 1 \rightarrow 2}=0.1$ means that $10 \%$ of additional trade between zone 1 and 2 are allotted to line l, i.e. with $1000 \mathrm{MW}$ additional export from zone 1 to 2, $100 \mathrm{MW}$ are anticipated to flow through line l. Importantly, the zone-to-zone PTDFs and allotted shares are of predictive nature, discussed further below. When the sensitivity surpasses a predefined threshold, e.g. $5 \%$, this element is considered to be critical, i.e. substantially affected by trade. It is crucial to mention and understand that critical network elements are not only cross-border elements but also zone-internal lines.

These critical network elements (CNEs) are monitored before and during market coupling. The above-mentioned base case estimates the flows on these CNEs for situations anticipated two days prior. These congestion forecasts mainly consist of predictions for electricity demand, trade positions, renewable energy feed-in as well as availability and output of conventional power plants. When trade deviates from the anticipated trade positions, expressed in so-called net positions of zones (exports minus imports), these are translated into flow changes. For this translation, the FBMC algorithm needs generation shift keys (GSKs). GSKs enable the creation of zonal PTDF matrices, whose elements indicate how a critical network element is affected by a unilateral increase of a zone's net position. From these, zone-to-zone PTDFs are computed (see above) to measure how a critical network element is affected by bilateral trade. GSKs represent an assumption and prediction, which units participate to what extent in net position changes. With GSKs, the anticipated change in power output (due to changes in net positions) can be expressed as nodal injections and subsequently translated into line flow due to a known grid topology.

Importantly, during market coupling, the (desired) net positions of all involved zones are taken into account and the consequent flow changes are estimated for every critical network element. This is a crucial particularity of flow-based market coupling and difference to the ATC method (see Section A.2.4). By taking into account all trade positions, market situations outside of the static ATC domain can be cleared. Referring back to Figure A.4 the trade between zone $\mathrm{A}$ and $\mathrm{B}$ can be augmented because of a low amount of trade between zone $\mathrm{A}$ and $\mathrm{C}$. The slope of the upper-right inner constraint exactly represents this trade-off between the exchanges: Flow-based market coupling detects that the low amount of trade between zone A and C leads to a lower degree of utilization of the constraining element and can therefore allow for a greater amount of trade between zone A and B, also affecting the same critical element. This fulfills the mentioned premise in Section A.2.2 and A.2.4 that larger trading capacities should not be excessive and lead to more remedial actions. Note that the dimension of the trading domains 
and constraints depends on the amount of involved zones. When three zones are involved (as is the case in Figure A.4, also the exchange between zone $B$ and zone $C$ has to be taken into account, so the domain is really a convex polyhedron and the mentioned constraint is a plane.

Constraints, as depicted in Figure A.4 are created because the flow changes are limited by the physical capacities of the network elements. From the physical maximum, security margins are deducted to account for (part of) the uncertain nature of the predicted flows and flow changes. This results in the maximum flow allowed during market coupling. As mentioned above, the base case results in a reference flow for every critical network element. The difference between reference flow and maximum flow is referred to as remaining available margin (RAM) and limits the allowed flow changes. RAMs exist for positive and negative flow changes. These RAMs result in the constraints of the trading domains in flow-based market coupling. Flow changes are not only estimated on a static basis but also by taking into account the (most relevant) outages of grid elements, also referred to as contingencies. This so-called n-1 security criterion (cf. Weinhold and Mieth, 2020) can substantially alter how line flows are expected to change with trade as it anticipates how grid elements are affected by trade if another element in the grid is not available anymore.

To summarize, the decisive aspects, subject to calculations and design choices of the TSOs, are the 1) nomination of critical network elements, determining which elements are monitored before and during market coupling, 2) construction of base cases, resulting in expected (reference) trade positions and flows, an indication of the expected grid utilization, 3) estimation of generation shift keys, anticipating how power plants behave during market coupling and translating zonal information (trade positions) into line flow changes during trade, and 4) consideration of the $n-1$ security criterion, factoring in how the line utilization changes due to outages/contingencies.

Ideally, all four aspects are anticipated correctly and congestions caused by trade can be anticipated and largely prevented. Especially base cases and generation shift keys are predictive elements of flow-based market coupling and naturally subject to great uncertainties. In addition to the inherently prediction-based and uncertain nature of flow-based market coupling, regulatory stipulations introduce further challenges to this methodology. Most noticeably, the introduction of minimum RAMs (minRAMs) will substantially shape flow-based market coupling estimations. These minRAMs stipulate that allowed flow changes during market coupling need to amount to at least $70 \%$ of line capacities (ACER, 2019b). In other words, 70\% of a line's capacity needs to be made available for trade. This can lead to the predicament that highly utilized lines, which hint at possible congestions caused by trade, need to be "artificially" relieved prior to market coupling. The resulting, possibly skewed trading domain allows for more trade but can also be a less realistic depiction of the true trade constraints. Ultimately, this can impede the effectiveness of cross-border trading capacities to prevent or reduce congestions with higher resulting amounts of congestion management volumes (cf. results by Matthes et al., 2019). The issue of internal grid constraints, which can be the limiting element of cross-zonal trade, are increasingly diverted to individual countries, with the possible consequence of necessary grid expansion. While stipulations like the minRAM criterion try to enhance trade, it is also worth mentioning that the implementation of flow-based market coupling is sometimes met with 
skepticism by market participants, especially by criticizing the supposed lack of transparency (e.g. Swedenergy et al., 2020).

Flow-based market coupling spans a wide array of research questions. The following are addressed by Article 4-8 (B.4 B.8) in the second part of this dissertation "Modeling of and predictions within flow-based market coupling." These research questions pertain to specific elements and the mathematical modeling of flow-based market coupling as well as predictions of parameters within the methodology. Article 4 (B.4) answers Q4, Article 5 (B.5) explores Q5, Article 6 (B.6) in concerned with Q6 and Article 7 (B.7) addresses Q7:

Q4: Do different generation shift keys substantially alter trading domains and the effect of trade on individual critical network elements?

Q5: What statistical or statistical learning methods are suited to predict the power output of generating units two days ahead as a basis for base cases?

Q6: How can a data-driven, dynamic and feasible statistical approach be designed to obtain generation shift keys?

Q7: Do larger minimum trading capacities lead to welfare losses and higher curative congestion management?

The last research question (Q8) takes on a more general and educational perspective and is addressed in Article 8 (B.8). Note that Article 8 largely builds upon the lessons learned of Article 4-7. Hence, it is put last in the order of this dissertation's articles. If the reader requires or appreciates an introduction to the topic of flow-based market coupling, s/he is advised to read Article 8 before Article 4-7.

Q8: How can the role and coherence of fundamental parameters within flow-based market coupling be communicated to students, researchers and operative users in an easy-tounderstand manner?

The posed research questions gain significance and importance when considering how scarcely researched and, at times, opaque the calculation process of flow-based market coupling is. This dissertation aims to contribute to the understanding of this complex, yet important methodology. 



\section{A.3 Addressing the research questions}

This section provides an overview of all articles that are a part of this cumulative dissertation, indicating the authors, titles as well as dates and places of submission or publishing. It briefly introduces the main methodological categories of the articles, explains the dissertation's structure and how the articles tie in with each other. For each article, a concise summary is provided, briefly outlining the structure, stating the main findings and showing how the posed research questions are answered. Lastly, the section provides concluding notes and highlights further needed research.

\section{A.3.1 Overview of articles as part of this cumulative dissertation}

Figure A.5 provides an overview of all submitted and published articles. It shows all articles within the two main parts: Article 1-3 in the first part "Short- and mid-term interactions between renewable energy and electricity markets" as well as Article 4-8 in the second part "Modeling of and predictions within flow-based market coupling." The relation of the articles are detailed in Section A.3.3.

Short- and mid-term interactions between renewable energy and electricity markets

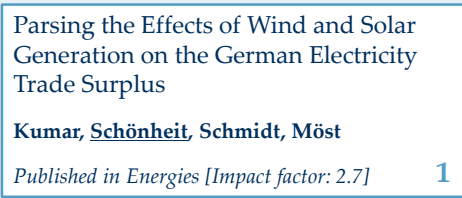

Modeling of and predictions within flow-based market coupling

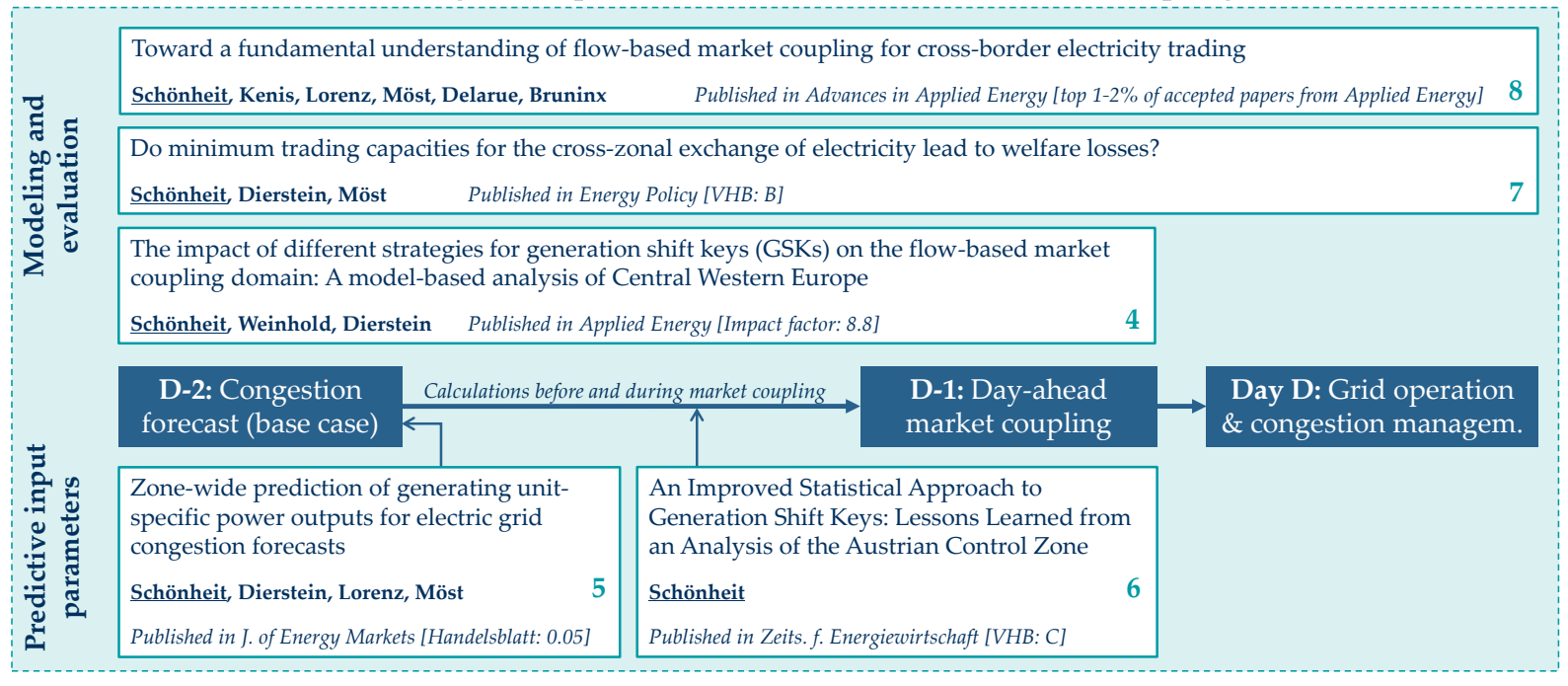

Figure A.5: Overview and structure of articles as part of this cumulative dissertation.

Below, all published and submitted articles are listed. The VHB-JOURQUAL3 (VHB) ranking is indicated. If the journal is not listed in VHB, the impact factor (IF), $\mathrm{H}$ index (H) and SCImago journal rank (SJR, with quartile in parentheses) are indicated, retrieved on 06.01.2021. For the journal of Article 5, Journal of Energy Markets, these metrics are unavailable, which is why the Handelsblatt Ranking is listed. The journal, in which paper 8 is published, Advances in Applied 
Energy, is a new sister journal of Applied Energy. The indicators of Applied Energy and the described selection process of Advances in Applied Energy serve as an indication of the ranking.

Short- and mid-term interactions between renewable energy and electricity markets

1. Kumar, S., Schönheit, D., Schmidt, M. \& Möst, D. (2019). Parsing the Effects of Wind and Solar Generation on the German Electricity Trade Surplus, Energies, 12(18), 3434 DOI: https://doi.org/10.3390/en12183434

Published on 06.09.2019 (online) in Energies (MDPI)

IF: 2.7, H: 78, SJR: 0.64 (Q2)

2. Anke, C.-P. \& Schönheit, D. (2020). What caused 2019's drop in German carbon emissions: Sustainable transition or short-term market developments?, Zeitschrift für Energiewirtschaft, 44(4), 275-284

DOI: https://doi.org/10.1007/s12398-020-00289-3

Published on 04.12.2020 in Zeitschrift für Energiewirtschaft (Springer)

VHB: C

3. Schönheit, D., Homann, L., Möst, D. \& Westgaard, S. (2020). The effect of corrective short-term updates for wind energy forecasts on intraday electricity prices

Currently being revised for new submission

\section{Modeling of and predictions within flow-based market coupling}

4. Schönheit, D., Weinhold, R. \& Dierstein, C. (2019). The impact of different strategies for generation shift keys (GSKs) on the flow-based market coupling domain: A model-based analysis of Central Western Europe, Applied Energy, 258, 114067 DOI: https://doi.org/10.1016/j.apenergy.2019.114067

Published on 09.11.2019 (online) in Applied Energy (Elsevier)

IF: 8.8, H: 189, SJR: 3.61 (Q1)

5. Schönheit, D., Dierstein, C., Lorenz, L. \& Möst, D. (2020). Zone-wide prediction of generating unit-specific power outputs for electric grid congestion forecasts, Journal of Energy Markets, 14(2), 1-32

DOI: https://doi.org/10.21314/JEM.2020.224

Published on 01.06.2021 in Journal of Energy Markets (Risk Journals)

Handelsblatt-Gewicht VWL 2015: 0.05

6. Schönheit, D. (2019). An Improved Statistical Approach to Generation Shift Keys: Lessons Learned from an Analysis of the Austrian Control Zone, Zeitschrift für Energiewirtschaft, 43(3), 193-212 DOI: https://doi.org/10.1007/s12398-019-00261-w

Published on 11.10.2019 in Zeitschrift für Energiewirtschaft (Springer) VHB: C

7. Schönheit, D., Dierstein, C. \& Möst, D. (2020). Do minimum trading capacities for the cross-zonal exchange of electricity lead to welfare losses?, Energy Policy, 149, 112030 DOI: https://doi.org/10.1016/j.enpol.2020.112030

Published on 20.11.2020 (online) in Energy Policy (Elsevier)

VHB: B 
8. Schönheit, D., Kenis, M., Lorenz, L., Möst, D., Delarue, E. \& Bruninx, K. (2020). Toward a fundamental understanding of flow-based market coupling for cross-border electricity trading, Advances in Applied Energy, 2, 100027

DOI: https://doi.org/10.1016/j.adapen.2021.100027

Published on 30.04.2021 in Advances in Applied Energy (Elsevier)

Top 1-2\% of accepted papers from Applied Energy

Note that the numbering of articles does not strictly follow the dates of completion, submission or publication but is geared to the logical succession of articles, described below.

\section{A.3.2 Brief overview of used methods to address the research questions}

Before detailing the articles, this section provides a brief overview of the methods, deployed to address the research questions. The models are described in greater depth in each article. The used methods can be divided into two parts, namely 1) statistical and econometric methods as well as 2) operations research and optimization models.

Statistical and econometric methods: The common theme of Article 1-3 as well as Article 6 is explaining the effects of certain explanatory variables on other dependent variables. Empirical ex-post analyses based on historical time series are conducted, which is why econometric approaches are the method of choice. The models generally assume this form:

$$
y=\alpha+\mathbf{X} \beta+\epsilon
$$

The goal is to isolate the effects or influence $(\boldsymbol{\beta})$ of explanatory variables $(\mathbf{X})$ on a dependent variable $(y)$, while allowing for a static term $(\alpha)$ and an error term $(\epsilon)$. The goal of Article 5 is the prediction of variables rather than interpreting the influence of specific factors. Hence, it explores more extensive forecasting techniques based on methods of statistical learning.

Operations research and optimization models: Article 4, 7 and 8 rely on optimization models to answer questions regarding electricity markets and grids. They generally follow this form:

$$
\begin{gathered}
\min _{\mathbf{x}} f(\mathbf{x}) \\
\mathbf{A x} \leqslant \mathbf{b}
\end{gathered}
$$

The used power system models map the economic and technical fundamentals of electricity markets and grids. They take on a "global planner" perspective with the objective of minimizing overall (or system) costs, i.e. $\mathbf{f}(\mathbf{x})$. This dissertation does not consider investment decisions, so system costs are comprised of power generation costs as well as subsequent costs for congestion management. Therefore, model-endogenous variables $(\mathbf{x})$ are typically the cost minimizing dispatch of power plants and congestion management activities. Important assumptions include that all market participants behave perfectly rational and that electricity demand is price inelastic. The system's restrictions (b) are technical constraints, most importantly the installed capacities of power plants, operative constraints of power plants, e.g. ramping up and down constraints, as well as physical limits of grid lines. The exogenous technical parameters (A) indicate how the model-endogenous variables "expend" the system's limitations. 
An important element of these power system models are so-called energy balances, based on the fact that electricity demand (consumption) and supply (generation) have to be balanced at all times. Importantly, these restrictions are equalities and not inequalities. When modeling trade, energy balances are imposed for countries (or bidding zones) with the possibility of trade, limited by cross-border capacities (see Section A.2.4). When considering the grid, energy balances are imposed for each grid node, with the possibility of exchanges between nodes via the electricity lines, considering the physical properties of load flow in form of Kirchhoff's circuit laws (Van den Bergh et al., 2014).

\section{A.3.3 Relation and coherence of articles}

This section provides a brief understanding how the articles relate to each other. This discussion is extended in Section A.3.4, where the individual articles are summarized.

The first main topic "Short- and mid-term interactions between renewable energy and electricity markets" addresses the challenges and questions posed in Section A.2.1. namely Q1, Q2 and Q3. The articles of the first topic answer overarching topics within energy economics, yet are all linked to the described effects along the merit order theory. The common goal of these articles is the isolation of certain effects based on historical time series, which is why regression analysis is used in all articles. Each article answers a different question but all look at the effect of electricity generated from renewable energy sources on power markets.

While Articles 1-3 are stand-alone articles, the articles of the second topic "Modeling of and predictions within flow-based market coupling" follow a succession. One of the first objectives within this dissertation was to create a model-based representation of flow-based market coupling with the goal of identifying the most important uncertain parameters. Beforehand, based on available literature and own studies, generation shift keys were singled out as a key parameter. This is why Article 4 specifically addresses the question if GSKs substantially affect the day-ahead trading domains (cf. Q4). Existing literature on this was (and is) not only scarce but also lacked a line-specific analysis of the effect of GSKs. Providing such an analysis was another main motivation for Article 4.

The results of Article 4 are detailed in Section A.3.4. At this point, however, it is useful to mention that these results were a leading reference for the remaining articles. A preliminary, theory-based analysis in Article 4 identifies base cases (two-days ahead congestion forecasts) as a crucial basis for all subsequent flow-based market coupling computations and results. While predictions for renewable energy and electricity demand are abundantly researched, there are very few contributions to the forecasting of the output of conventional power plants, especially when considering an entire country or bidding zone. This motivated Article 5 to explore various approaches for the task of generating unit-specific forecasts of power output, specifically for the construction of base cases (cf. Q5). The analysis does not aim at further FBMC computations and is therefore detached from optimization models, representing the power system. This provided the freedom to explore various statistical and statistical learning methods that can serve as input for energy system models. 
Importantly, Article 4 does indeed conclude that GSKs are a determining factor of flow-based market coupling results. Because most GSK computation methods are rather simple and/or static (see more in Section A.3.4), the goal was to construct GSKs based on historical dispatch data and provide a feasible and flexible approach (cf. Q6). This is taken on in Article 6 that was further motivated by exchanges with TSOs, some of which also see the need for improved GSK methods. Similar to Article 5, Article 6 is also detached from energy system models and its approach can be used to compute GSKs as one determining input to the flow-based market coupling method.

Article 4 also served as a motivation to extend the chair's (Chair of Energy Economics) electricity grid model ELMOD to incorporate the flow-based market coupling method, documented in Schönheit et al. (2020b). The goal of this model was to address changes in regulatory stipulations, specifically the requirement of providing minimum trading capacities to the market. This adds another important dimension to flow-based market coupling. Rather than "only" optimizing its parameters to maximize the quality of predictions, the stipulation is a substantial exogenous push toward greater trade activities. Therefore, the expected outcomes of the new requirements are larger trade volumes but also a reduced ability of the system to anticipate congestions (cf. Section A.2.5 and further in Section A.3.4). This motivated the creation of Article 7 with the goal of quantifying the effects of this stipulation on welfare and congestion management measures (cf. Q7).

Lastly, the results and lessons learned from Article 4-7, including the creation of a representation of flow-based market coupling (Schönheit et al. 2020b), motivated the creation of an open-access, easy-to-understand model to communicate the basics of flow-based market coupling (cf. Q8). This can serve as a starting point for research and teachings in this field that is likely going to gain importance over the next years. As shared in Section A.2.5, the interested reader is advised to read Article 8 before Article 4-7, if an introduction to flow-based market coupling is needed.

\section{A.3.4 Main findings of articles}

This section gives a brief summary of each article, regarding its motivation, approach and main results. It also indicates when the articles' results serve as a basis for a later article and when results are reaffirmed. For each article key insights are provided as well as one exemplary visualization with a short explanation and interpretation.

\section{Summary of first article}

The first article (B.1), Parsing the Effects of Wind and Solar Generation on the German Electricity Trade Surplus, addresses Q1 and deals with the effect of growing shares of renewable energy generation on electricity prices and, in effect, on power exports of Germany. An exploratory data analysis confirms the trade theory: With rising renewable energy generation, a downward shift of the supply curve occurs, which, on average, translates into lower prices at a given demand and greater export volumes. This confirms the merit order effect described in Section A.2.1. Based on this analysis, in order to separate the effects of wind and solar energy 
on the trade surplus (net position) in Germany, a regression analysis is conducted. Also, as flow-based market coupling is increasingly shaping cross-border trade volumes, the effect of its introduction in mid-2015 is evaluated. For this, a ridge regression is used to address the issue of high multicollinearity of the explanatory variables and their interaction terms.

While aspects of cross-border commercial exchanges are addressed by existing literature, the motivation for this analysis is the goal of empirically disaggregating the contribution of wind and solar generation to the German export surplus. Both technologies have increased in significance for the German power sector, especially over the last decade. Therefore, an analysis, based on the years 2012 to 2016, is the basis to separately estimate the effects of solar and wind power on prices and subsequently on Germany's net position.

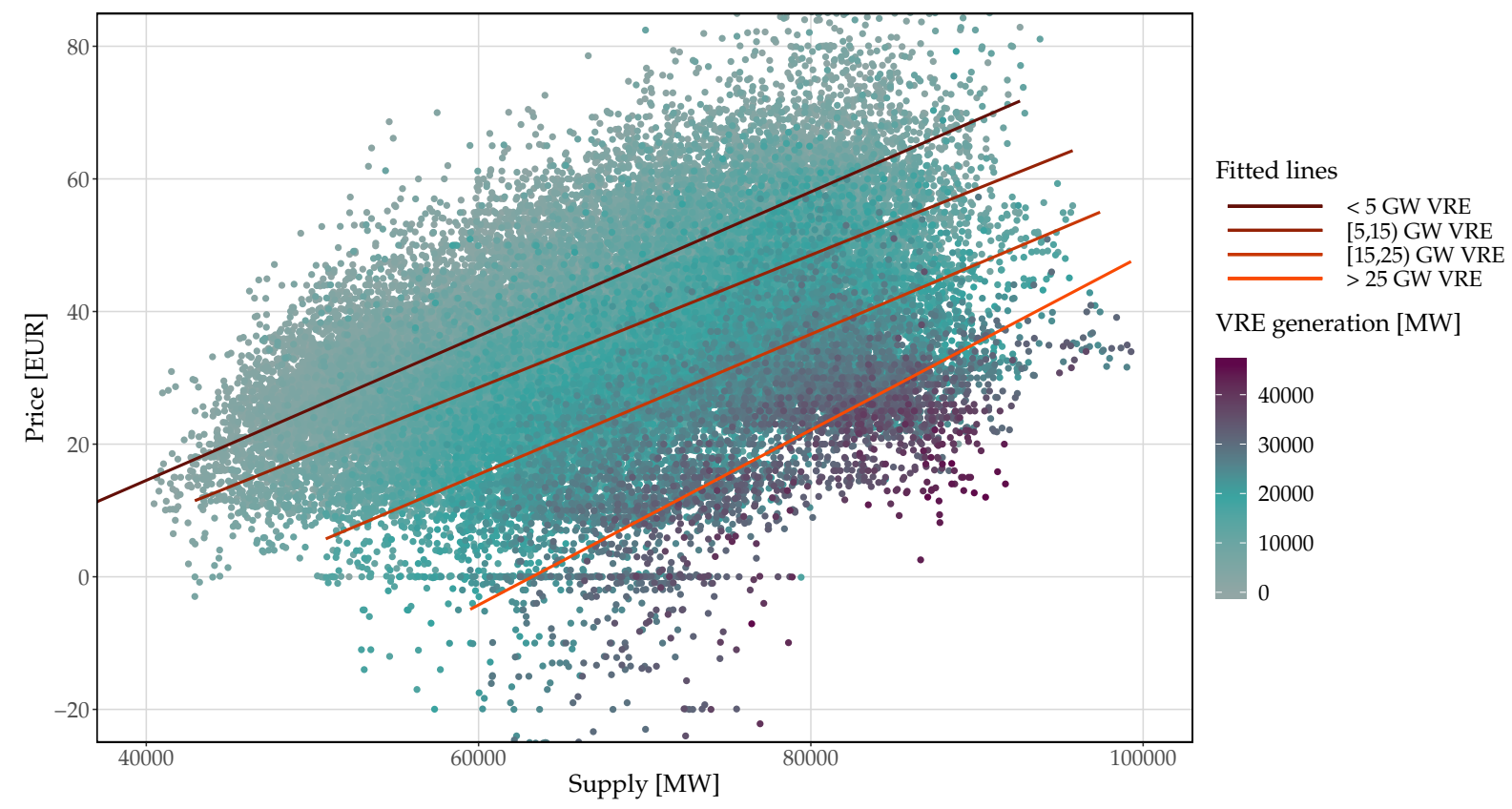

Figure A.6: Key result of Article 1 - Effect of power generation from renewable energy sources on electricity prices. Figure from Kumar et al. (2019).

Displayed is the hourly electricity price in relation to the overall energy supply in Germany for 2012-2016. The lines visualize the best fit for different feed-in categories of variable renewable energy (VRE), the sum of solar and wind generation. The color scale of the points also corresponds to the level of VRE feed-in. The graph shows that a drop or rightward shift of the supply line is clearly visible with growing shares of VRE. Thus, at a given supply the price drops or, conversely, a larger electricity supply is provided for a given price level with growing feed-in amounts of VRE.

The main findings include:

R1.1: Both, wind and solar energy positively affect the export position of Germany, confirming the trade theory as well as the conclusions of the fundamental data analysis.

R1.2: The marginal effect of solar generation on the net position is smallest when wind and solar feed-in are low and largest when wind and solar feed-in are high and is thus positively correlated with both, wind and solar generation. The marginal effect of wind energy on the net position is smallest when wind feed-in is high and solar feed-in is low and largest when wind feed-in is low and solar feed-in is high and is thus positively correlated with solar generation and negatively correlated with wind generation. Thus, 
growing levels of overall renewable energy supply lead to exports at an increasing rate. The exception is the negative effect of wind energy supply on the marginally exported share of wind energy. This may be rooted in decreasing cross-border capacities with rising wind generation, an explanation that is confirmed by the analysis.

R1.3: The impact of flow-based market coupling is positive, i.e. its introduction leads to higher trade surpluses, on average. This confirms one of the purposes of FBMC, namely allowing for greater amounts of trade and the possibility to export or import renewable energy-generated electricity. This effect is larger for wind energy, compared to solar energy. A possible explanation for this is the more pronounced contemporaneousness of solar generation and electricity demand, which may occur during more constrained trading domains, even with FBMC.

Key insight: In Germany, increasing power generation based on weather-dependent renewable energy leads to price decreases and consequent increases in exports; these effects are augmented by flow-based market coupling. The shares of exported power are different for solar and wind and largely depend on the present renewable electricity feed-in.

Own contribution: I contributed to this article by conceptualizing the study, in terms of topic and approach, together with the other authors. My main contribution was the data processing, the set-up and computation of the regression model as well as the evaluation and presentation of results. I created many of the visualizations. Lastly, I contributed to the writing of the paper and the revision process to a large degree.

\section{Summary of second article}

The second contribution (B.2), What caused 2019's drop in German carbon emissions: Sustainable transition or short-term market developments?, investigates Q2 and the effects of different factors on the recent reduction in carbon emissions. Because the emissions reduction was especially large in 2019, the article analyzes the drivers of carbon emissions and conventional power generation from 2016 to 2019 based on a regression model. It seeks to identify market-driven effects, mainly fuel prices, as well as endogenous (or transitional) effects, namely the $\mathrm{CO}_{2}$ price and the expansion of renewable energy capacities.

While the effects of renewable energy feed-in on carbon emissions has been researched before, this analysis focuses on the most recent substantial reductions. It determines what share of the observed reduction is due to persisting effects and what is caused by short-term dynamic market developments. Furthermore, the article discusses the impact of current climate policies on Germany's carbon emissions.

The article finds that:

R2.1: The stated hypotheses of the article are mostly confirmed, namely 1) renewable energy generation leads to carbon emissions reductions in Germany (confirming the theory in Section A.2.1 with different effects: wind energy replaces more carbon-intensive technologies, such as lignite and hard coal, compared to solar energy, 2) the gas price 
positively affects $\mathrm{CO}_{2}$ emissions and the coal price negatively affects $\mathrm{CO}_{2}$ emissions as well as 3) the carbon price has a negative effect on $\mathrm{CO}_{2}$ emissions.

R2.2: When comparing the emissions of 2018 and 2019, the large reduction in 2019 is mostly rooted in the large gas price decline. When comparing 2019 to 2016, long-term effects are more dominant, namely the expansion of renewable energy capacities and the rising $\mathrm{CO}_{2}$ price.

R2.3: To comply with reduction goals for greenhouse gas emissions, policies should focus on influenceable factors, such as renewable energy capacities and $\mathrm{CO}_{2}$ prices. Appropriate carbon prices indicate the EU Emissions Trading System's ability to mitigate emissions. A reliance on world market-driven factors, such as fuel prices, is not advised since their reduction effects are less foreseeable and not guaranteed.
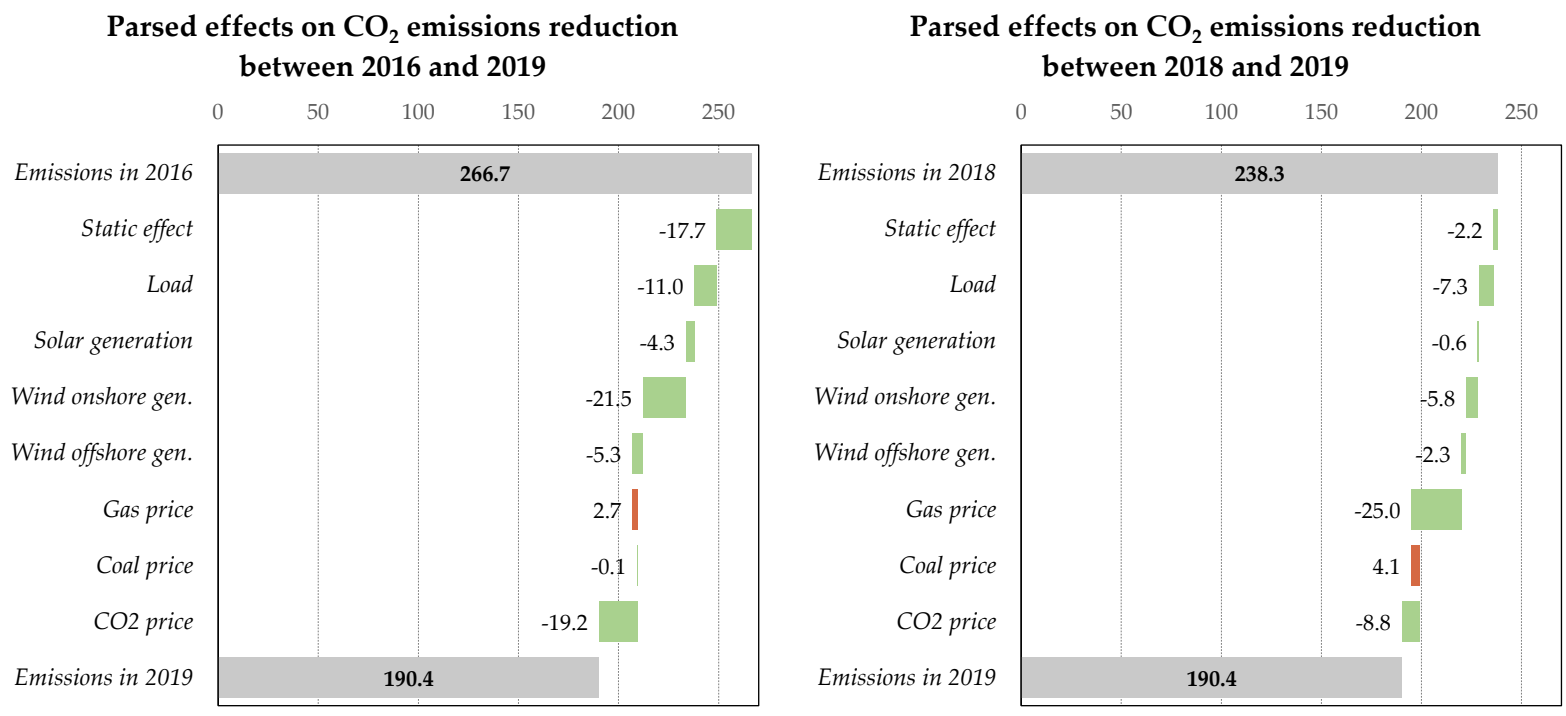

Figure A.7: Key result of Article 2 - Recent drivers of $\mathrm{CO}_{2}$ emissions reductions. Figure from Anke and Schönheit(2020).

Displayed are total carbon emissions in the power sector in a base year (left: 2016 and right: 2018) and emissions for 2019. All values are megatons of $\mathrm{CO}_{2}$ emissions. The horizontal bars indicate which driver contributed what amount to the decrease between the two respective years. The static effect is the effect not captured by any of the other included variables. The graph attests to the fact that in the short-run market factors, specifically the decline in gas price, affects emissions the most. In the long-run, the expansion of solar and wind energy capacities and a growing carbon price are the main emissions-reducing factors.

Key insight: Carbon emissions in Germany are driven by long-term transitions of the power sector, such as the expansion of renewable energy generation capacities and carbon prices, as well as short-term market factors like fuel prices, especially gas prices. The transition aspects are steerable and should therefore be the policy focus. To effectively implement a transition of the energy system, policy makers need to account for the fact that solar and wind energy replace different kinds of conventional technologies.

Own contribution: It is worth mentioning that the first author, Carl-Philipp Anke, and I contributed equally to this analysis. We collaborated on the conceptualization of the article. My main contribution was the processing and analysis of data, developing the regression model as 
well as the visualization, presentation and evaluation of its results. I wrote the chapters on data, methodology and results as well as parts of the conclusion. I provided changes and input to the remaining chapters before submission and during the reviewing process.

\section{Summary of third article}

The third paper (B.3), The effect of corrective short-term updates for wind energy forecasts on intraday electricity prices, addresses Q3. The goal of the article is to find out how short-term corrections in the predicted amount of available wind energy affect intraday prices. Further, it aims to quantify if this effect varies, depending on the position within the merit order, referring back to Section A.2.1. For this, several hypotheses are stated. The most important ones are that the effect of wind energy on prices is negative and that this effect is larger at the "fringes" of the merit order, namely for high and low residual loads. The residual load is the total load, from which the power generation of solar and wind energy is subtracted. To answer these hypotheses, exploratory and regression-based analyses are conducted. Two short-term wind energy forecasts, and thus updates in wind energy availability, are retrieved through processing and transformation of high-resolution wind speed forecasts at different times, one corresponding to the day-ahead market and one at midnight, i.e. at the very beginning of the day of delivery.

Previous research has addressed the effect of renewable energy feed-in on prices, but this analysis focuses on clearly explaining and deriving theory-based hypotheses as well as introducing two different forecasts for wind energy. With this novel approach, wind energy updates can be retrieved to be able to answer the theory-based research questions. Further, the analysis provides estimates for the price effects of wind energy at continuous levels of electricity demand rather than using categorical effects.

The following results are obtained, largely supporting the hypotheses:

R3.1: The exploratory data analysis confirms that the effect of wind energy updates on intraday prices is negative. Based on bi-variate correlations within several subsets, the effect is more pronounced for low and high residual load situations.

R3.2: A pronounced correlation between day-ahead and intraday prices is found. Switches from positive day-ahead prices to negative intraday prices, due to positive wind energy updates, occur more frequently than the reversed case.

R3.3: A linear regression model confirms that the negative effect of wind energy updates is largest in high residual load situations. In low residual load situations, the effect is weaker but increases when negative prices are considered.

R3.4: An extended linear regression model, with a quadratic term of the deviating load from the mean load, helps to quantify these varying effects. It shows that in high and low load situations the effect of wind updates on intraday prices is largest.

Key insight: The weather-dependency of wind energy introduces uncertainties, i.e. forecast errors, into the German power sector, which can assume large proportions and need to be balanced in the intraday market. The negative effect of wind energy on electricity prices 


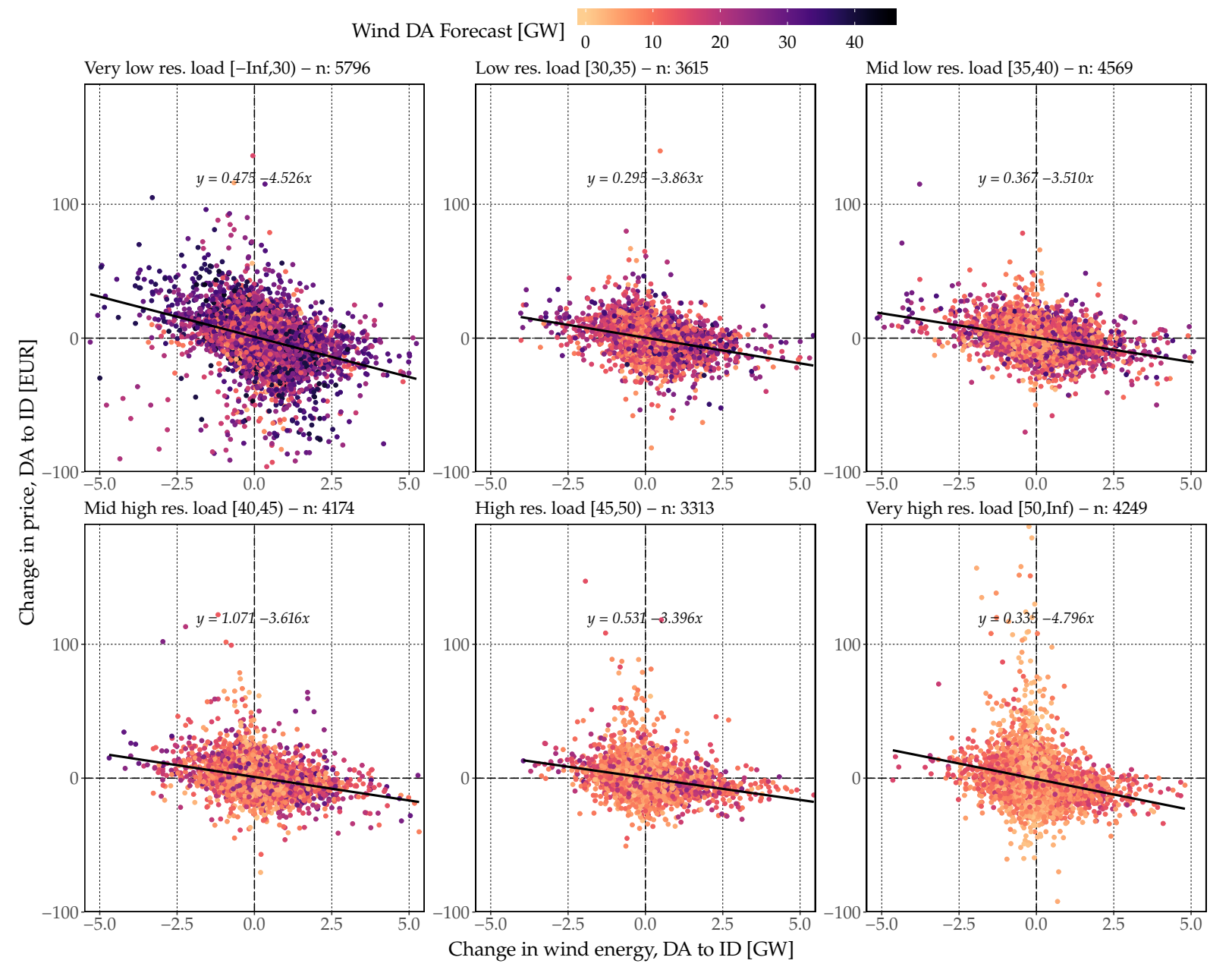

Figure A.8: Key result of Article 3 - Relation between available wind energy and intraday prices.

Displayed are the bi-variate correlation values between changes in wind energy and price changes for six different categories of residual load. The residual load is used as a proxy for the market situation, i.e. position within the merit order. All changes are differences between the day-ahead (DA) and intraday (ID) market. The color scale corresponds to the day-ahead wind energy forecast. The lines are estimates of best fit, along with the linear relation $(y=a-b \cdot x)$. The graph indicates that the sensitivity of prices to changes in wind energy (b) is largest in the very low and very high residual load category. This attests to the different effects of wind energy on prices, depending on the residual load.

largely depends on the composition of the merit order and can take on substantially different magnitudes, depending on the position, i.e. market situation, within the merit order. Thus, models linked to the merit order theory, as proposed in this analysis, can help to better anticipate and account for these uncertainties.

Own contribution: As first author, I coordinated the research of this article. All authors shared its conceptualization, for which I took on a leading role. My main contributions were part of the data collection (weather data), the data processing, developing the regression models, all visualizations of data and results as well as the evaluation and interpretation of results. I wrote the majority of the manuscript, in particular the exploratory data analysis, methodology, model description, results, conclusion and implications. I handled the submission and will handle the revision process. 


\section{Summary of fourth article}

In the fourth article (B.4), The impact of different strategies for generation shift keys (GSKs) on the flow-based market coupling domain: A model-based analysis of Central Western Europe, the effect of GSKs on the trading domain as well as on individual network elements is computed. It addresses $\mathbf{Q} 4$. The analysis details a novel approach for base case estimations, by means of a dispatch optimization model that complies with historical flows on critical network elements. Based on the computed base cases, several GSK strategies are used to create n-1 secure day-ahead market coupling domains. The effect of GSKs is statistically evaluated on the level of critical network elements.

The study is motivated by the general consensus that GSK strategies affect the trading domains, which stands in stark contrast to the small body of literature addressing this topic. The few existing studies focus on aggregated criteria to evaluate the effect of GSK strategies, such as welfare, costs or aggregated, fuel-specific generation. This highlights the need for a grid element-specific evaluation of the effect of GSK strategies. There is also a need for approaches to construct base cases based on publicly available data, which is realized in this study.

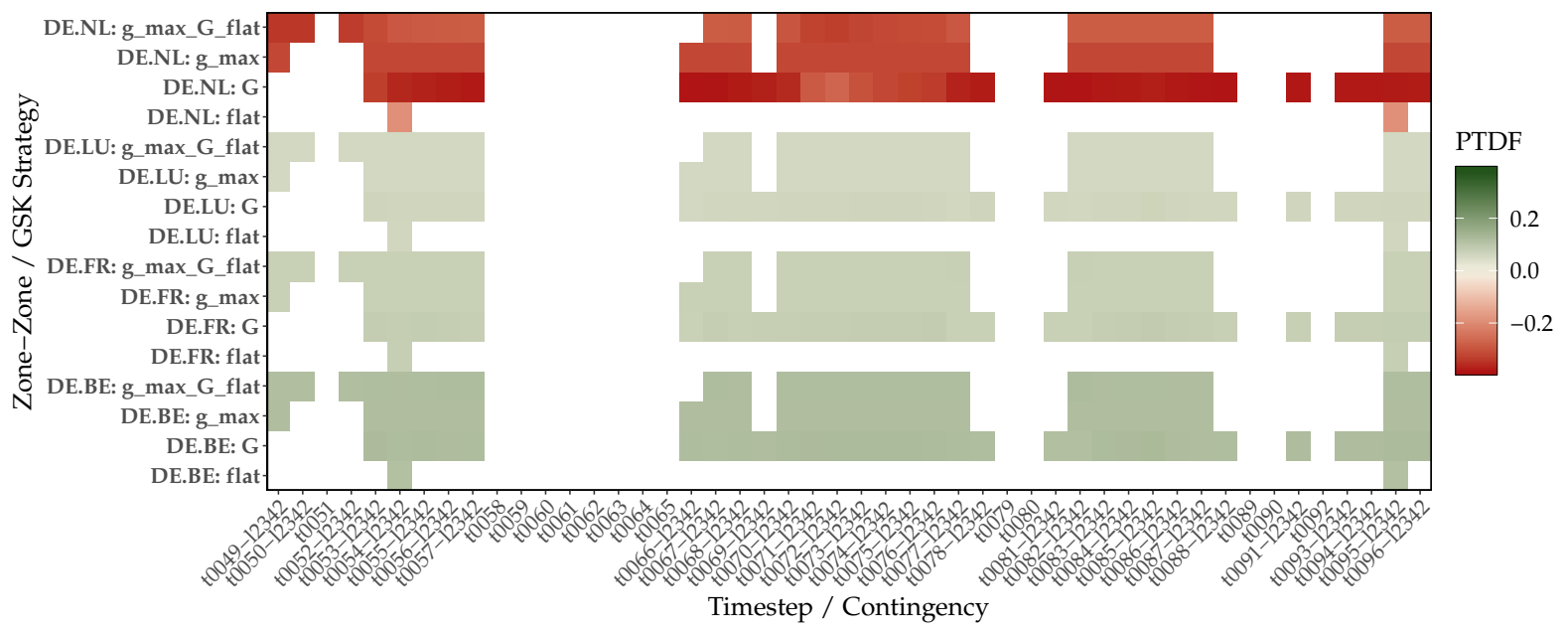

Figure A.9: Key result of Article 4-Effect of bilateral trade on an individual network element. Figure from Schönheit et al. (2020c).

The colored elements display the share of bilateral trade that is allotted to this critical network element (expressed by zone-to-zone PTDF values). The x-axis displays the timestep, e.g. t0049, as well as the outage, e.g. 12342, under which this network element becomes a constraint for the market coupling domain. The y-axis displays four different bilateral country-to-country combinations, e.g. DE.BE for Germany-Belgium, and four different GSKs (flat, G, g_max, g_max_G_flat). White fields indicate that this element does not constrain the domain for the given timestep, country-to-country combination and GSK. The graph exemplifies that the extent to which a grid element is affected by bilateral trade changes over time and is dependent on the chosen GSK, which is especially visible for the combination DE.NL (Germany-Netherlands). Also, the GSK often determines whether or not a grid element limits the trading domain (white vs. red/green fields for the same timestep and country-to-country combination).

The main results are the following:

R4.1: The main decisive and uncertain parameters for the construction of trading domains within flow-based market coupling are determined in this analysis, namely 1) construction of base cases, as the foundation of all subsequent computations, 2) estimation of GSKs, 3) nomination of critical network elements and 4) consideration of outages 
( $\mathrm{n}-1$ cases). The first three factors have to be determined deliberately. This stresses the importance of well-designed parameters by the TSOs to maximize the ability of flow-based market coupling to accurately anticipate line flows and congestions and, in turn, provide correct trading capacities. These identified factors require much more research activity.

R4.2: The proposed approach for constructing the base case is a valid, yet time- and dataintensive method for obtaining the relevant information from the two-days ahead congestion forecast.

R4.3: Generation shift key strategies can have a substantial effect on the size and shape of the trading domain. They are therefore a key determinant for the computation of cross-border capacities.

R4.4: GSKs and outages substantially and significantly affect how individual critical network elements are anticipated to be affected by changes in trade. As a novelty, the results are presented with so-called zone-to-zone PTDF values, the valid criterion to give an appropriate estimate for the effect on CNEs. This implies that detailed analyses like the conducted one can identify critically affected elements within the grid and quantify the effect of changing parameters on these elements.

Key insight: The efficacy of flow-based market coupling, i.e. its ability to correctly anticipate grid congestions and provide correct trading capacities to the market, is based on deliberately designed parameters by transmission system operators: Most notably the congestion forecasts, selection of critical network elements, consideration of outages and generation shift keys. The latter parameter needs to be carefully constructed, as it has a substantial effect on the cross-border capacities as well as individual network elements.

Own contribution: Together with the second author, Richard Weinhold, I coordinated the creation of this article. All authors shared the conceptualization of the article. My main contributions were the collection and processing of data (needed for the matching of historical flows in the base case), the computation of generation shift keys based on the optimization results (provided by the second author) and the statistical evaluation of critical network element-specific zone-to-zone PTDF values. I created all visualizations with the exception of market coupling domains. I wrote the vast majority of the article, handled the submission and coordinated the reviewing process.

\section{Summary of fifth article}

The fifth paper (B.5), Zone-wide prediction of generating unit-specific power outputs for electric grid congestion forecasts, sets out to predict the conventional power generation for base cases. For this, several statistical and statistical learning approaches are tested to descry which one is suited best for the task at hand to answer Q5. The analysis is done for 205 conventional generating units in Germany for the year 2017. It is based on publicly available data, using fundamental forecast variables, such as load, renewable energy and unavailabilities of conventional power plants, to predict power outputs of individual generating units. 
Result R4.1 and R4.2 stress the importance of feasible base case constructions. While renewable energy and load forecasts have been extensively researched, the available literature on short-term unit-specific forecasts of power output is scarce. This analysis seeks to close the research gap by finding a feasible and implementable approach for the stated forecasting task.

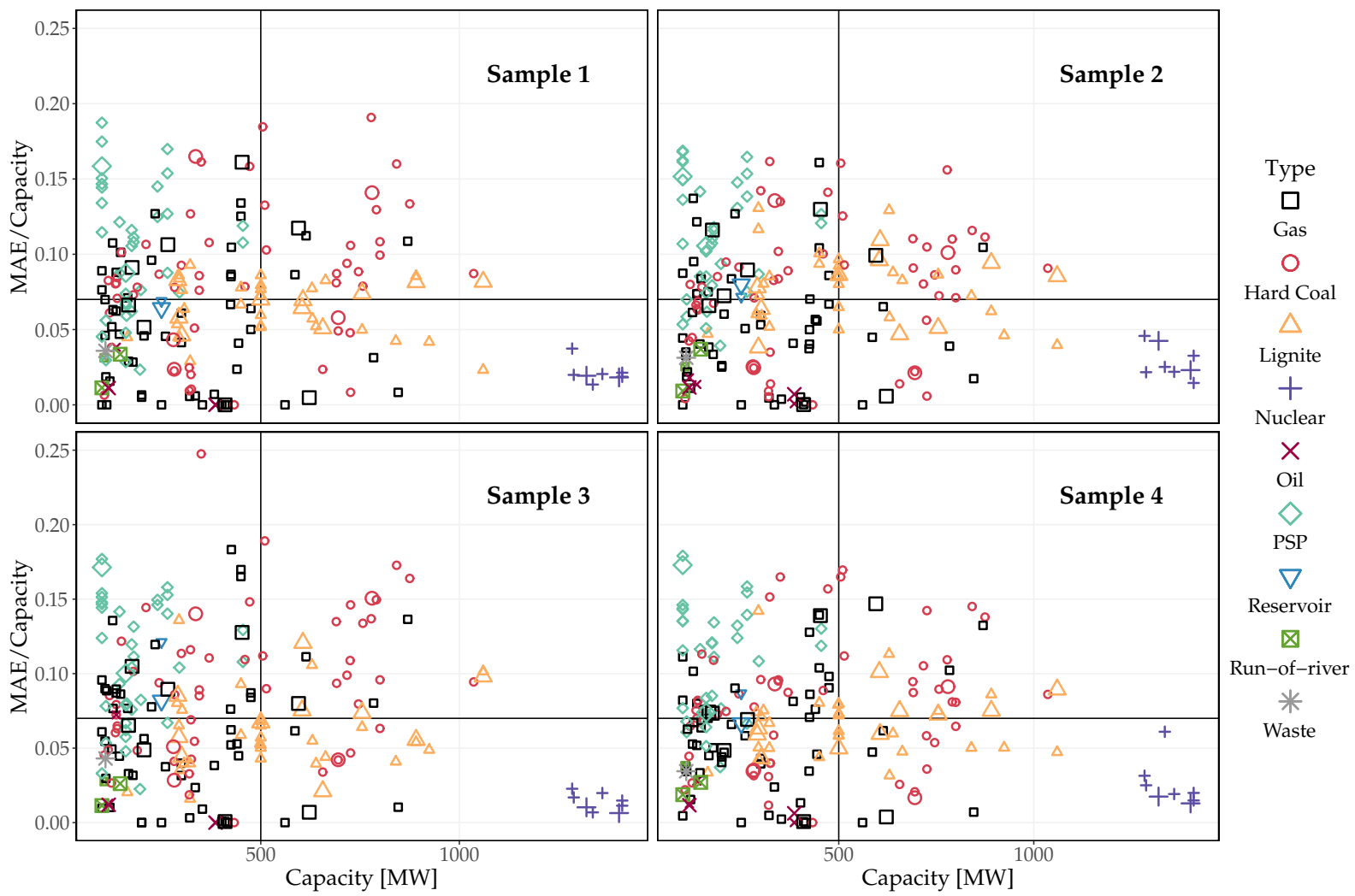

Figure A.10: Key result of Article 5 - Average forecast errors for each generating unit. Figure from Schönheit et al. (2021a).

Displayed are test results of the best-performing model (Extra Trees) to predict the power output of numerous generating units. Concretely, the figure shows for each tested generating unit the ratio of mean average error (MAE) to capacity (y-axis) in relation to its capacity (x-axis). The errors are computed by the difference between actual and predicted power output. This is visualized for the chosen model for four different combinations of training/test-subsets. The horizontal bar indicates the median MAE/capacity ratio. The vertical bar divides the units into "small" and "large" units. The shapes and colors correspond to different fuel types of the units. The graph indicates that most units can be predicted with rather low average errors. Mostly, pumped storage hydro power plants (PSPs), hard coal and gas power plants are in the upper spectrum of the panels, thus showing the largest forecast errors.

The main results describe how the forecasting task at hand can be approached:

R5.1: Due to the idiosyncratic nature of power output data-continuous but bound between 0 and the installed capacity - it is advantageous to split the prediction task into classification predicting the on and off status of units and a subsequent regression to forecast the power output based on the classification prediction.

R5.2: A combination of Extra Trees (Extremely Randomized Trees) classifier and Extra Trees regressor is suited best for this task. For most units, this combination achieves accuracy rates of over $90 \%$ and average error-to-capacity ratios of $10 \%$. 
R5.3: Flexible units, such as pumped-storage power plants and hard coal- and gas-fired units, are the hardest to predict. Part of the reason can be intraday behavior, which is unfavorably captured in the used data and is difficult to predict with fundamental variables.

R5.4: The power outputs on winter days appear harder to predict than on summer days. Also, an error analysis suggests that load and solar generation drive the prediction errors. Solar feed-in coincides with higher load and consequently with more extensive utilization of flexible power plants. The contemporaneousness of generation of flexible units and solar feed-in can explain this result.

Key insight: Statistical learning approaches can help to accurately forecast the unit-specific power output as an important element of base cases (two-days ahead congestion forecasts) in flow-based market coupling. It can be helpful to split up the forecasting task into classification and regression due to the on/off-status of power plants. Flexible units are hardest to predict and need to be considered with especial attention.

Own contribution: As the first author, I coordinated the research of this article and had a major role in its conceptualization. I coordinated the data collection and processed the data. My main contributions were the development of all used models as well the computation, interpretation and evaluation of their results. I created all visualizations and wrote the vast majority of the paper. I handled the submission and reviewing process.

\section{Summary of sixth article}

The sixth contribution (B.6), An Improved Statistical Approach to Generation Shift Keys: Lessons Learned from an Analysis of the Austrian Control Zone, proposes a regression modelbased approach to determine generation shift keys, along the lines of Q6. It is based on the approach developed by Schönheit and Sikora (2018). The article mainly results from a study for Austrian Power Grid, during which the approach was refined and improved. For this, two regression models are developed: The first model computes peak/off-peak, winter/summer GSK values, separately for workdays and weekends; the second one computes hourly GSK values, separately for winter and summer. Furthermore, the article suggests a selection process for determining which units participate in the GSKs. The developed unit selection process is based on the size of sensitivities, i.e. the marginal "reaction" of a unit's power output to changes in the net position, retrieved from the regression coefficients. This is seen as a proxy for economic significance, as very small amounts of participation are neglected.

The paper goes along with result R4.1, R4.3 and R4.4, highlighting the need for robust and accurate GSKs. Many existing approaches link power plant behavior, and in turn GSK values, to fixed generating unit characteristics, such as the installed capacity. Some strategies make even weaker assumptions and weight all grid nodes equally. Also, the selection process of units is mostly knowledge-based rather than linked to clear-cut criteria. Overall, the construction of GSKs is a rather opaque and non-harmonized process. However, there are requirements and efforts to implement a harmonized GSK approach (ACER, 2019a). Thus, the motivation is to 

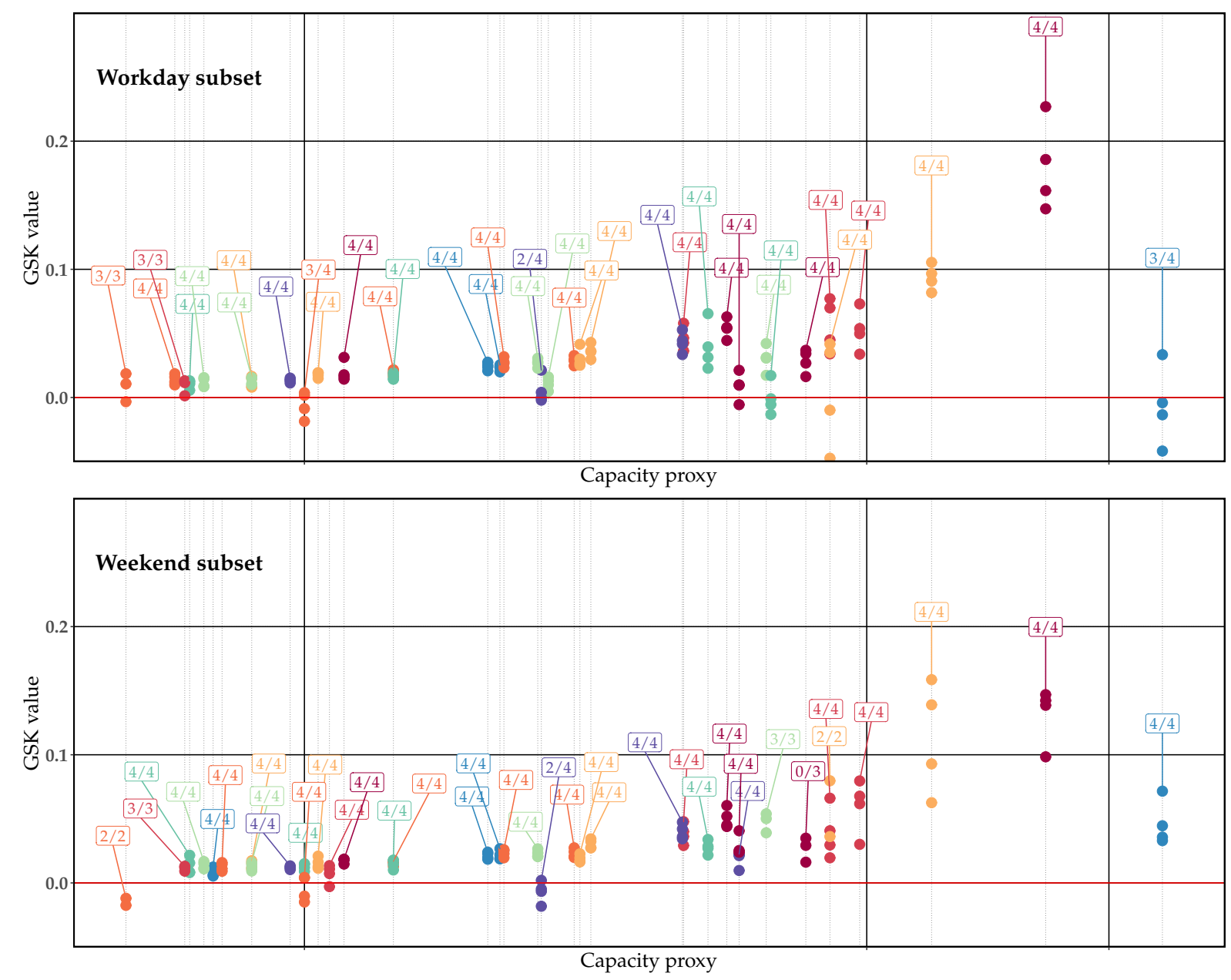

Figure A.11: Key result of Article 6-Computed generation shift keys with the statistical approach. Figure from Schönheit (2019).

Displayed are the GSK values for each analyzed unit in Austria for four different categories, namely peak/off-peak and summer/winter. These values are computed separately for two subsets, workdays and weekends (including holidays). The labels indicate how many of the GSK values are statistically significant wihin a subset (e.g. " $4 / 4$ "). Note that not necessarily four values are computed for every unit due to exclusion criteria for each category (hence, e.g. "3/3" can occur). The $x$-axis follows a logarithmic scale and is a proxy for installed capacities without numeric values to ensure the anonymity of the units. The graph demonstrates that GSKs assume different values across the categories (peak/offpeak and summer/winter) and the subset (workday/weekend). Also, it shows that a positive relation between capacities and GSK values exists but has a limited validity. This supports the construction of time-dependent and dispatch-based GSKs.

provide a transparent and feasible approach, which can be easily implemented in other control zones. By using regression analysis, the proposed method enables GSK estimations based on actual (historical) dispatch decisions of power plant operators. This decouples GSKs from fixed power plant characteristics and merit-order assumptions.

The main findings of the article are:

R6.1: The selection process includes units with statistically significant and robust GSK values in the majority of cases. Insignificant GSK values are very small or small in almost all cases. Consequently, the anticipated participation of units in these cases is very small, and therefore almost irrelevant from a system perspective. Also, very small 
sensitivities barely affect the other sensitivities, when all sensitivities are normalized to obtain GSK values with a sum of one.

R6.2: Based on the proposed approach, the resulting GSK values show large variation across time categories. This corroborates the bearing of estimating time-dependent GSKs. The two models show, however, that hourly GSK values are not necessarily advantageous. This conclusion is based on higher explanatory power of the peak/off-peak model, relative to model complexity, as well as more insignificant sensitivities when using the hourly resolution.

R6.3: There is a limited positive correlation between GSK values, i.e. participation of a unit in zonal changes, and installed capacities. This disputes the application of capacityweighted GSKs, as often done in reality.

Key insight: The proposed approach to compute generation shift keys is flexible, datadriven and can take into account historical dispatch decisions as well as day-to-day, operative information from the congestion forecasts. The approach not only indicates the participation of units within the GSK but also provides criteria to select units, the second important task of GSK computations within flow-based market coupling.

Own contribution: This is a single author paper. It is worth mentioning that the paper benefited from several discussions with Dr. Maria Aigner, Hans Hatz and Milan Vukasovic (Austrian Power Grid) as well as Prof. Dr. Dominik Möst (TU Dresden, Chair of Energy Economics).

\section{Summary of seventh article}

The title of the seventh paper (B.7), Do minimum trading capacities for the cross-zonal exchange of electricity lead to welfare losses?, entails $Q 7$ and broaches the issue of the stipulated minimum trading capacities within flow-based market coupling, so-called minRAMs. The criterion to reserve a certain amount of line capacities for trading was introduced in 2019 and increasingly affects the system in the years until 2025 (Section A.2.5). The paper analyzes the Central Western European area, in which flow-based market coupling is active since 2015, for two representative weeks of 2016. Three different levels of minRAMs are imposed, from the current $20 \%$ to the target value of $70 \%$ in 2025 , with one intermediate step at $45 \%$. The study not only evaluates changes in day-ahead market coupling welfare but also the incurring congestion management costs. It can therefore evaluate if increasing minRAMs are associated with overall welfare gains or losses. The ensuing costs are quantified for the three different GSK strategies, motivated by R4.3 and R4.4. This gives an indication which GSK strategy is overall cost-minimizing and what strategy is suited best for different situations of renewable energy feed-in and demand.

Research on flow-based market coupling so far has mainly focused on good representations of the electricity markets and grids. This entails the anticipation and consideration of changes in trade, accounting for the effects on the electricity grid and its limits. The minRAM criterion puts further constraints on congestion forecasts (base cases), in which the utilization levels of electricity grid elements are computed two days prior to the day of delivery and thus one day prior to the day-ahead market coupling. Effectively, elements can only be utilized to a certain 

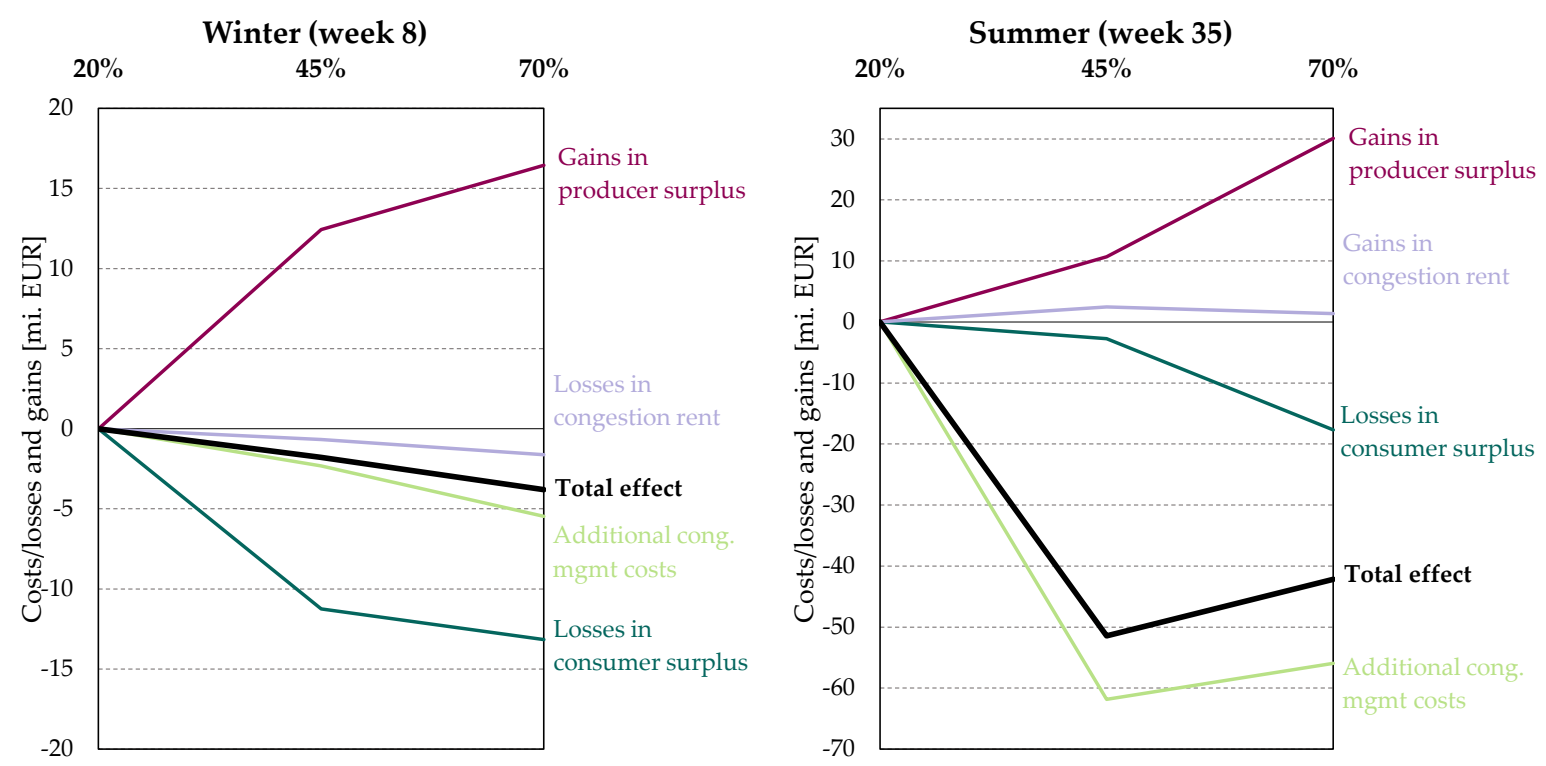

Figure A.12: Key result of Article 7 - Market and grid effects of growing minimum trading capacities. Figure from Schönheit et al. (2020a).

For the cost-minimizing GSK strategy (pro-rata), displayed are the changes in producer and consumer surplus, congestion rent and congestion management cost for different levels of minimum trading capacities (minRAM). Losses and additional costs are depicted in the negative spectrum. All changes are computed as differences between a minRAM of $20 \%$ and $45 \%$ or $70 \%$, respectively. The total effect is the summation of all individual effect and represents the loss in overall welfare. The analysis is conducted for two representative weeks in 2016. The graph shows that there is an overall negative effect with growing minRAMs in both weeks. The losses incur on the consumer side, with decreases in consumer surpluses and higher costs for congestion management measures.

extent under the minRAM criterion, whereas the remaining, unutilized capacity is reserved for market coupling. This is expected to impede the system's ability to correctly predict high utilization levels of grid elements, an indication for congestions, and appropriately limit the trading domain. This much-debated topic is not extensively researched and at the time of writing there were no existing recommendations on a cost-minimizing implementation of this criterion.

The paper finds that:

R7.1: With growing minRAMs the market coupling welfare increases but congestion management amounts and costs rise as well. The day-ahead welfare gains are more than offset by additional congestion management costs in all cases. Notably, the market coupling welfare gains are largely increases in producer surpluses, while consumer surpluses generally decrease, in addition to the higher congestion management costs borne by consumers.

R7.2: Because costs at minRAMs of $45 \%$ and $70 \%$ are similar, the greatest increases in costs are to be anticipated between $20 \%$ and $45 \%$. The study therefore recommends a "first phase" with smaller incremental steps from $20 \%$ to $45 \%$ and larger steps in a "second phase." This could be especially crucial because the geographical expansion of flowbased market coupling to encompass Central Western and Eastern Europe falls into the first phase, so the introduction of further, simultaneous uncertainties may necessitate a "slower" start of minRAM increases. 
R7.3: The choice for generation shift keys substantially affects market and grid results as well as overall welfare. Generally, it is advantageous to use base case information. In this analysis, this is mapped by the pro-rata strategy, anticipating shifts in generation proportional to the anticipated generation in the base case and making this the only dynamic strategy. It leads to lower costs compared to the other two, static GSK strategies (flat and capacity-weighted). This confirms R6.2 and R6.3.

R7.4: GSKs should be designed to be situation-dependent, thus changing based on the predicted demand and renewable energy feed-in. This can be realized through utilizing dynamic GSKs (pro-rata or e.g. the proposed approach in Article 6) or using static GSKs but re-estimating them for a given situation. The study also reveals that in extreme, less common situations of high and low residual load, static GSKs may prove to be more robust.

Key insight: Imposing minimum trading capacities on flow-based market coupling leads to overall welfare losses. The stipulation opens up market coupling domains, thus fostering price convergence and boosting market coupling welfare, but also impedes the system's ability to anticipate and account for grid congestions, which leads to higher costs for congestion management measures. Dynamic generation shift keys that take into account base case information are cost minimizing and should be preferred. GSKs should ideally be situation-dependent and based on the predicted demand and renewable energy feed-in.

Own contribution: As the first author, I coordinated the creation of the article and played a major role in its conceptualization. I processed all needed data and developed and implemented the necessary expansions to create flow-based market coupling results within the optimization model ELMOD. I created all visualization and wrote the vast majority of the paper. I handled the submission and reviewing process.

\section{Summary of eighth article}

Throughout the research and writing of this dissertation's articles a reoccurring realization was the scarcity of available literature and vastly different understandings regarding the flow-based market coupling methodology. This brought forth the idea for the final and eighth article (B.8): Toward a fundamental understanding of flow-based market coupling for cross-border electricity trading. The principal goal of this paper is to provide an intuitive understanding of the important elements of flow-based market coupling and ways to represent these elements in energy economic models, focusing on R4.1, R4.3, R4.4 and R7.3. Therefore, an open-access model was developed to address Q8. It is the result of discussions between the Chair of Energy Economics at TU Dresden and the Research Group Energy Systems Integration \& Modeling of KU Leuven. It benefited from the array of involved researchers and their different understandings of this topic and experience levels, ranging from an undergraduate student to professors.

The article and model can be a starting point for research and discussions for students, researchers and involved operative entities, such as energy utilities, grid operators and regulators. The article deviates in its style from the previous ones, especially because it poses superordinate 
learning goals, from which questions are derived for the reader that $\mathrm{s} /$ he is hopefully able to answer after reading the paper. The main "result" of this article is therefore the following:

R8.1: The paper provides an easy-to-understand introduction to the complex topic of flow-based market coupling. Beyond that, the exemplary model-based case studies in the article reconfirm R4.1, R4.4 and to a large extent $\mathbf{R} 4.3$ and $\mathbf{R} 7.3$ by providing a quantification for the effects of GSKs, the selection of critical network elements and the incorporation of flow security margins on market coupling costs, price zone formation, congestion management and line utilization.

To make the article relevant for a broader readership, the article also analyzes the effect of increasing shares of power generated from renewable energy sources (see Section A.1 and A.2.3) as well as the effect of the minRAM criterion (see Section A.2.5), with the following results:

R8.2: Growing shares of renewable energy lead to greater amounts of congestion management, i.e. redispatch and curtailment. These volumes can be reduced by either increasing the security margins on critical network elements or by monitoring more critical network elements. The first option simply constrains trade to a larger degree, the second option leads to a (more) complete representation of the electricity grid during market coupling. Flow-based market coupling parameters, including security margins and the selection of critical network elements, need to be chosen carefully to maximize overall welfare and find the optimal trade-off between enabling commercial exchanges and low (or acceptable) amounts of congestion management.

R8.3: In the analyzed case many critical network elements show utilization rates of over $20 \%$ (or even over $30 \%$ ) in situations of no trade during a substantial amount of hours during the year. Therefore, when imposing a security margin of 10\%, a minRAM of $70 \%$ (or even of $60 \%$ ) could not be fulfilled. Thus, the minRAM criterion necessitates adjustments of anticipated flows and is not automatically fulfilled, which is in line with the statements of Article 7.

Key insight: The readers learn that the methodology of flow-based market coupling is based on crucial parameters, most of which are of predictive nature, attempting to represent the most determining information of the electricity grid before and during market coupling. Further, the developed model helps to understand 1) how these crucial parameters affect market results and congestion management and 2) how flow-based market coupling can find a model-based representation for academic and operative activities, thus providing a useful starting point for further research.

Own contribution: As the first author, I coordinated the creation of the article and had a significant role in its conceptualization. I conducted part of and coordinated the data collection and processing. I developed the open-access model. I created all visualization and wrote the vast majority of the paper. I handled the submission and will handle the reviewing process. 



Figure A.13: Key result of Article 8 - Relation between considered critical network elements and domain size in flow-based market coupling. Figure from Schönheit et al. (2021b).

Displayed are domains for trade between zone 1 and 2 as well as zone 1 and 3 for a given hour for different thresholds $\alpha$. The threshold corresponds to the zone-to-zone PTDF values, at which a grid element is considered critical (see Section A.2.5). Concretely, at an $\alpha$-value of $10 \%$, each element, to which at least $10 \%$ of the flow caused by additional trade between any two zones is allocated, is considered critical. Critical network elements are displayed as blue line (constraints) and the feasible market coupling (trading) domain is marked as the green inner area. This analysis clearly shows that the domain shrinks with lower $\alpha$-values as more lines are considered critical and thus, more constraints are introduced.

\section{A.3.5 Concluding remarks and further research}

As detailed in Section A.2, the described challenges, which currently shape the German and European electricity markets and grids, spark a wide array of research questions. Naturally, the questions addressed in this dissertation are not exhaustive. Generally, a greater proliferation of weather-dependent renewable energy sources in the power system brings about substantial changes and greater uncertainties that affect prices, carbon emissions and energy exports, which link to overarching goals of the integration of renewable energy and carbon emissions reduction 
in the electricity sector. Especially the topic of flow-based market coupling is a fast developing and changing framework, yet most of its elements are scarcely researched. The actualization of the methodology and its stipulated aspects has vast implications for power markets and grids, in terms of market welfare, affordable electricity prices, volume and costs of congestion management measures, security of supply as well as the integration of renewable energy sources.

This dissertation makes important contributions to these fields by:

(a) isolating the effects of electricity generated from renewable energy sources on electricity exports, power prices, carbon emissions reductions as well as price levels and price uncertainties (Article 1-3);

(b) developing and using optimization model-based representations of flow-based market coupling to estimate the effects of the most important parameters within its methodology (Article 4, 7 and 8);

(c) providing first analyses regarding the anticipated effect of trade on the grid and on the detailed level of individual critical network elements within flow-based market coupling (Article 4);

(d) testing various statistical and statistical learning approaches for the prediction of power plant output (Article 5);

(e) developing a feasible, data-driven and dynamic approach for generation shift keys (Article 6);

(f) measuring the effects of minimum trading capacities on overall welfare and congestion management amounts and costs as well as providing recommendations on a costminimizing implementation of this regulation (Article 7);

(g) and providing an open-access model and easy-to-understand guide to flow-based market coupling as a starting point for students, researchers and operative users (Article 8).

In summary, this dissertation seeks to answer a variety of pressing research questions within two main topics, namely quantifying the impact of renewable energy on power markets and, in particular, the design and effects of flow-based market coupling. It provides novel modeling and computation approaches that can answer the posed research questions. These approaches can hopefully serve as a basis for further research. This is an important contribution since the described challenges need to be researched more extensively with a progressing decarbonization and profound transition of the energy system. This especially pertains to challenges within flowbased market coupling, some of which are almost uncharted topics. The imminent geographical expansion of this method to encompass Central Western and Eastern Europe brings forth the challenge of including many more countries for the calculation of cross-border trade capacities. At the same time, particularly between 2020 and 2025, the effects of regulatory stipulations, such as minimum trading capacities, will unfold their full effect. Although further requirements, like finding a common methodology for generation shift keys, will promote harmonization among the involved transmission system operators, they also necessitate more research on flow-based market coupling since the effects of such changes are unknown. Thus, research on the complex interrelations between the trade and transmission of electricity-namely providing clean and 
affordable energy within the European internal electricity market, on the one hand, and utilizing the existing grid to its full extent, on the other hand-will gain importance in the coming years. 


\section{References}

50Hertz (2020). Congestion management. https://www.50hertz.com/en/Transparency/GridData/Co ngestionmanagement, accessed on 01.06.2020.

50Hertz, Amprion, APG, Creos, ČEPS, ELES, Elia, HOPS, MAVIR, PSE, RTE, SEPS, TenneT, Transelectrica, and TransnetBW (2017). Explanatory note DA FB CC methodology for Core CCR: For Public Consultation. https://consultations.entsoe.eu/markets/core-da-ccm/user_uploads/explanatory-not e-for-core-da-fb-cc-public-consultation_fv.pdf, accessed on 07.06.2019.

50Hertz, Amprion, APG, Creos, Elia, EPEXSPOT, RTE, TenneT, and TransnetBW (2018). Documentation of the CWE FB MC solution - December 2018 - version 4.0. https://www.creg.be/sites/default/files/a ssets/Consult/2019/1891/PRD1891Annex1.pdf. accessed on 21.04.2020.

ACER (2019a). ACER Decision on Core CCM: Annex I - Day-ahead capacity calculation methodology of the Core capacity calculation region. https://www.creos-net.lu/fileadmin/dokumente/Creos_Luxem bourg/pdf_codes_reseaux/CORE_CCM_Day_ahead.pdf, accessed on 12.05.2020.

ACER (2019b). Decision No 02/2019 of the Agency for the Cooperation of Energy Regulators of 21 February 2019: On the Core CCR TSOs' proposals for the regional design of the day-ahead and intraday common capacity calculation methodologies. Agency for the Cooperation of Energy Regulators. https: //www.acer.europa.eu/Official_documents/Acts_of_the_Agency/Pages/Individual-decision.aspx. accessed on 25.01.2021.

Amprion (2019). Amprion Market Report 2019 - Flow Based Market Coupling: Development of the Market and Grid Situation 2015-2018. https://www.amprion.net/Dokumente/Dialog/Downloads/S tellungnahmen/Amprion-Market-Report-2019.pdf, accessed on 07.06.2019.

Amprion (2020). Multi Regional Coupling (MRC). https://www.amprion.net/Energy-Market/Conges tion-Management/Multi-Regional-Coupling-(MRC)-and-Cross-Border-Intraday-(XBID)/, accessed on 14.12.2020.

Amprion, APX, Belpex, Creos, Elia, EPEX SPOT, RTE, TenneT, and TransnetBW (2014). Documentation of the CWE FB MC solution: As basis for the formal approval-request. https://www.cre.fr/en/Documents/Public-consultations/Flow-Based-Market-Coupling-FB-MC-a nd-its-implementation-in-the-CWE-region, accessed on 07.06.2019.

Androcec, I., Wangensteen, I., and Krajcar, S. (2009). Impact of cross-border electricity trading on market participants. In 2009 International Conference on Power Engineering, Energy and Electrical Drives, pages 249-254. IEEE.

Anke, C.-P., Hobbie, H., Schreiber, S., and Möst, D. (2020). Coal phase-outs and carbon prices: Interactions between eu emission trading and national carbon mitigation policies. Energy Policy, 144:111647.

Anke, C.-P. and Schönheit, D. (2020). What caused 2019's drop in German carbon emissions: Sustainable transition or short-term market developments? Zeitschrift für Energiewirtschaft, 44(4):275-284.

Austrian Power Grid (2020). End of the German-Austrian electricity price zone - What does this mean? https://www.apg.at/en/Energiezukunft/Strompreiszone, accessed on 18.12.2020.

BDEW (2020). Redispatch in Deutschland: Auswertung der Transparenzdaten April 2013 bis einschließlich September 2020. https://www.bdew.de/service/anwendungshilfen/redispatch-deutschland/., accessed on 18.11.2020.

BMWi and AGEE-Stat (2020). Development of Renewable Energy Sources in Germany in the year 2019. https://www.erneuerbare-energien.de/EE/Navigation/DE/Service/Erneuerbare_Energien_i n Zahlen/Entwicklung/entwicklung-der-erneuerbaren-energien-in-deutschland.html, accessed on 23.01.2021. 
Cludius, J., Hermann, H., Matthes, F. C., and Graichen, V. (2014). The merit order effect of wind and photovoltaic electricity generation in Germany 2008-2016: Estimation and distributional implications. Energy Economics, 44:302-313.

Council of the EU and European Parliament (2019). Regulation (EU) 2019/943 of the European Parliament and of the Council of 5 June 2019 on the internal market for electricity. Official Journal of the European Union L, 158:54-124.

Creti, A. and Fabra, N. (2007). Supply security and short-run capacity markets for electricity. Energy Economics, 29(2):259-276.

Destatis (2021). Bruttostromerzeugung in Deutschland. https://www.destatis.de/DE/Themen/Branch en-Unternehmen/Energie/Erzeugung/Tabellen/bruttostromerzeugung.html, accessed on 23.01.2021.

ENTSO-E (2016). Advancing the merger of the CWE and CEE capacity calculation regions. https://www.entsoe.eu/news/2016/03/04/advancing-the-merger-of-the-cwe-and-cee-capac ity-calculation-regions/, accessed on 15.12.2020.

ENTSO-E (2019). Report on Capacity Calculation and Allocation. https://www.entsoe.eu/news/2019/ 09/03/two-new-entso-e-reports-on-market-network-codes-implementation-now-released/, accessed on 15.12.2020.

EPEX SPOT (2018). Trading on EPEX SPOT. http://static.epexspot.com/document/38579/Epex_Tradi ngBrochure_180129_Web.pdf, accessed on 01.07.2020.

European Commission (2015). Commission Regulation (EU) 2015/1222 of 24 July 2015 establishing a guideline on capacity allocation and congestion management. Official Journal of the European Union L, 197:24-72.

European Commission (2019a). Clean energy for all Europeans. Luxembourg: Publications Office of the European Union, https://www.doi.org/10.2833/21366.

European Commission (2019b). The European Green Deal. Brussels, https:/ /ec.europa.eu/info/strategy /priorities-2019-2024/european-green-deal_en, accessed on 17.07.2020.

European Commission (2020). EU Emissions Trading System (EU ETS). https://ec.europa.eu/clima/pol icies/ets_en, accessed on 14.12.2020.

European Parliament and Council of the EU (2009). Directive 2009/28/EC of the European Parliament and of the Council of 23 April 2009 on the promotion of the use of energy from renewable sources and amending and subsequently repealing Directives 2001/77/EC and 2003/30/EC. Official Journal of the European Union L, 140:16-62.

Grimm, V., Rückel, B., Sölch, C., and Zöttl, G. (2016). Zur Reduktion des Netzausbaubedarfs durch Redispatch und effizientes Einspeisemanagement: Eine modellbasierte Abschätzung. In List Forum für Wirtschafts-und Finanzpolitik, volume 41, pages 465-498. Springer.

Helm, D. (2002). Energy policy: security of supply, sustainability and competition. Energy Policy, 30(3):173184.

Hirth, L., Schlecht, I., et al. (2019). Redispatch Markets in Zonal Electricity Markets: Inc-Dec Gaming as a Consequence of Inconsistent Power Market Design (not Market Power). Working paper, ZBW - Leibniz Information Centre for Economics, https://www.econstor.eu/handle/10419/194292/, accessed on 17.07.2020.

Huber, M., Dimkova, D., and Hamacher, T. (2014). Integration of wind and solar power in Europe: Assessment of flexibility requirements. Energy, 69:236-246.

Jauch, C. and Gloe, A. (2016). Improved feed-in management with wind turbines. In Proceedings of the 15th Wind Integration Workshop, Vienna, Austria, pages 15-17. 
Jessen-Thiesen, P., Schönheit, D., Hladik, D., Dierstein, C., Zöphel, C., and Möst, D. (2019). Dauer und Häufigkeit von Dunkelflauten in Deutschland. Energiewirtschaftliche Tagesfragen, $69 \mathrm{Jg}$. Heft 1/2.

Koch, C. and Hirth, L. (2019). Short-term electricity trading for system balancing: An empirical analysis of the role of intraday trading in balancing Germany's electricity system. Renewable and Sustainable Energy Reviews, 113:109275.

Kommission "Wachstum, Strukturwandel und Beschäftigung" (2019). Abschlussbericht. https://www.bmwi.de/Redaktion/DE/Publikationen/Wirtschaft/abschlussbericht-kommiss ion-wachstum-strukturwandel-und-beschaeftigung.html, accessed on 17.06.2020.

Kost, C., Shammugam, S., Jülch, V., Nguyen, H.-T., and Schlegl, T. (2018). Levelized Cost of Electricity Renewable Energy Technologies. Fraunhofer Institute for Solar Energy Systems ISE, https://www.is e.fraunhofer.de/en/research-projects/stromgestehungskosten-erneuerbare-energien.html, accessed on 09.07.2020.

Kristiansen, T. (2020). The flow based market coupling arrangement in Europe: Implications for traders. Energy Strategy Reviews, 27:100444.

Kumar, S., Schönheit, D., Schmidt, M., and Möst, D. (2019). Parsing the Effects of Wind and Solar Generation on the German Electricity Trade Surplus. Energies, 12(18):3434.

Lang, L. M., Dallinger, B., and Lettner, G. (2020). The meaning of flow-based market coupling on redispatch measures in Austria. Energy Policy, 136:111061.

Markusen, J. R. and Melvin, J. R. (1981). Trade, factor prices, and the gains from trade with increasing returns to scale. Canadian Journal of Economics, pages 450-469.

Matthes, B., Spieker, C., Klein, D., and Rehtanz, C. (2019). Impact of a Minimum Remaining Available Margin Adjustment in Flow-Based Market Coupling. In 2019 IEEE Milan PowerTech, pages 1-6. IEEE.

Neukirch, M. (2016). Protests against German electricity grid extension as a new social movement? A journey into the areas of conflict. Energy, Sustainability and Society, 6(1):4.

Newbery, D., Strbac, G., and Viehoff, I. (2016). The benefits of integrating European electricity markets. Energy Policy, 94:253-263.

Pepermans, G. (2019). European energy market liberalization: experiences and challenges. International Journal of Economic Policy Studies, 13(1):3-26.

Schill, W.-P. (2014). Residual load, renewable surplus generation and storage requirements in Germany. Energy Policy, 73:65-79.

Schönheit, D. (2019). An Improved Statistical Approach to Generation Shift Keys: Lessons Learned from an Analysis of the Austrian Control Zone. Zeitschrift für Energiewirtschaft, 43(3):193-212.

Schönheit, D., Dierstein, C., Lorenz, L., and Möst, D. (2021a). Zone-wide prediction of generating unitspecific power outputs for electricity grid congestion forecasts. Journal of Energy Markets, 14(2):1-32.

Schönheit, D., Dierstein, C., and Möst, D. (2020a). Do minimum trading capacities for the cross-zonal exchange of electricity lead to welfare losses? Energy Policy, page 112030.

Schönheit, D., Hladik, D., Hobbie, H., and Möst, D. (2020b). ELMOD documentation: Modeling of flow-based market coupling and congestion management. Working paper of the Chair of Energy Economics (TU Dresden), Version of May 20, 2020, ZBW - Leibniz Information Centre for Economics, https://www.econstor.eu/handle/10419/217278, accessed on 20.05.2020.

Schönheit, D., Kenis, M., Lorenz, L., Möst, D., Delarue, E., and Bruninx, K. (2021b). Toward a fundamental understanding of flow-based market coupling for cross-border electricity trading. Advances in Applied Energy, 2:100027. 
Schönheit, D. and Sikora, R. (2018). A Statistical Approach to Generation Shift Keys. In 2018 15th International Conference on the European Energy Market (EEM), pages 1-6. IEEE.

Schönheit, D., Weinhold, R., and Dierstein, C. (2020c). The impact of different strategies for generation shift keys (GSKs) on the flow-based market coupling domain: A model-based analysis of Central Western Europe. Applied Energy, 258:114067.

Seuss, J., Reno, M. J., Lave, M., Broderick, R. J., and Grijalva, S. (2016). Advanced inverter controls to dispatch distributed PV systems. In 2016 IEEE 43rd Photovoltaic Specialists Conference (PVSC), pages 1387-1392. IEEE.

Swedenergy, Fortum, and Vattenfall (2020). Current Flowbased implementation plan a risk for a well-functioning Nordic power market. Stockholm, 28th of May 2020, https://www.fortum.com/sites/default/files/documents/20200528_flowbased_implementat ion_plan_risk_to_well-functioning_market.pdf, accessed on 16.07.2020.

Van den Bergh, K., Boury, J., and Delarue, E. (2016). The Flow-Based Market Coupling in Central Western Europe: Concepts and Definitions. The Electricity Journal, 29(1):24-29.

Van den Bergh, K., Delarue, E., and D'haeseleer, W. (2014). DC power flow in unit commitment models. TME Working Paper - Energy and Environment, WP EN2014-12. https://www.mech.kuleuven.be/en/tm e/research/energy_environment/Pdf/wpen2014-12.pdf, accessed on 14.12.2020.

von Selasinsky, A. (2016). The integration of renewable energy sources in continuous intraday markets for electricity. PhD thesis, Series of the Chair of Energy economics, TU Dresden.

Wang, Q., Guan, Y., and Wang, J. (2011). A chance-constrained two-stage stochastic program for unit commitment with uncertain wind power output. IEEE Transactions on Power Systems, 27(1):206-215.

Weber, A., Graeber, D., and Semmig, A. (2010). Market coupling and the CWE project. Zeitschrift für Energiewirtschaft, 34(4):303-309.

Weibelzahl, M. (2017). Nodal, zonal, or uniform electricity pricing: how to deal with network congestion. Frontiers in Energy, 11(2):210-232.

Weinhold, R. and Mieth, R. (2020). Fast Security-Constrained Optimal Power Flow through Low-Impact and Redundancy Screening. IEEE Transactions on Power Systems. 


\section{Chapter B}

\section{Published and submitted articles}

This chapter contains all published and submitted articles that are part of this cumulative dissertation. Each section contains one article and will list the authors, title, journal and the date of submission or, if applicable, the date of publication. Furthermore, the VHB ranking or, alternatively, the impact factor (IF), H index (H) and SCImago journal rank (SJR) are listed. For already published papers, only a DOI is provided. Papers not yet published are included in the version when this dissertation was submitted for grading. For all papers with co-authors, an authorship declaration is included.

Article 1: Parsing the Effects of Wind and Solar Generation on the German Electricity Trade Surplus (Section B.1. Published version)

Article 2: What caused 2019's drop in German carbon emissions: Sustainable transition or short-term market developments? (Section B.2 Published version)

Article 3: The effect of corrective short-term updates for wind energy forecasts on intraday electricity prices (Section B.3. Version submitted for grading of this dissertation)

Article 4: The impact of different strategies for generation shift keys (GSKs) on the flow-based market coupling domain: A model-based analysis of Central Western Europe (Section B.4. Published version)

Article 5: Zone-wide prediction of generating unit-specific power outputs for electric grid congestion forecasts (Section B.5. Published version)

Article 6: An Improved Statistical Approach to Generation Shift Keys: Lessons Learned from an Analysis of the Austrian Control Zone (Section B.6. Published version)

Article 7: Do minimum trading capacities for the cross-zonal exchange of electricity lead to welfare losses? (Section B.7 Published version)

Article 8: Toward a fundamental understanding flow-based market coupling for cross-border electricity trading (Section B.8: Published version) 



\section{B.1 Parsing the Effects of Wind and Solar Generation on the German Electricity Trade Surplus}

Authored by Kumar, S., Schönheit, D., Schmidt, M. \& Möst, D.

Published on 06.09.2019 (online) in Energies, 12(18), 3434

IF: 2.7, H: 78, SJR: 0.64 (Q2)

DOI: https://doi.org/10.3390/en12183434

Declaration of authorship for Article 1

\section{TECHNISCHE}

UNIVERSITÄT

DRESDEN

Fakultät Wirtschaftswissenschaften, Lehrstuhl für Energiewirtschaft

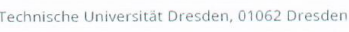

Lehrstuhl für Energiewirtschaft

Prof. Dr. Dominik Möst

Münchner Platz 3,

Lehrstuhlinhaber

01069 Dresden

Kontakt: Linda Schwabe

phone: $\quad+4935146333297$

e-mail: $\quad+4935146339763$ rax.

ERKLÄRUNG AUTORENSCHAFT

Am folgenden Beitrag:

Parsing the Effects of Wind and Solar Generation on the German Electricity Trade Surplus

haben folgende Personen:

$$
\begin{array}{ll}
\text { Autor 1: } & \text { Samarth Kumar (SK) } \\
\text { Autor 2: } & \text { David Schönheit (DS) } \\
\text { Autor 3: } & \text { Matthew Schmidt (MS) } \\
\text { Autor 4: } & \text { Dominik Möst (DM) }
\end{array}
$$

die Autorenschaft. Die Reihenfolge der Autoren richtet sich dabei nach den anteiligen Beiträgen. Die Beiträge der einzelnen Autoren, die die Veröffentlichung verantwortlich mittragen, gliedern sich nach den Kriterien der DFG (2013) zur guten wissenschaftlichen Praxis dabei wie folgt:

- Konzeption der Studie:

- Literaturrecherche:

- Erarbeitung der Daten:

DM, SK, DS, MS

MS, SK, DS

- Modellierung und Analyse

SK, DS

- Interpretation der Rohdaten

DS, SK

- Interpretation der Ergebnisse

SK, DS, MS

- Formulierung des Manuskripts:

SK, DS, MS, DM

$M S, D S, S K, D M$

Die Autoren stimmen mit Ihrer Unterschrift unter diesem Dokument einer Veröffentlichung des Beitrages sowie einer Nutzung des Beitrages zur wissenschaftlichen Qualifikation im Rahmen des Promotionsvorhabens durch andere Autoren zu.

Ort und Datum: Dresden, 5. September 2019
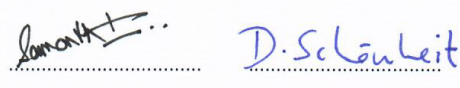

Autor 1

Autor 2
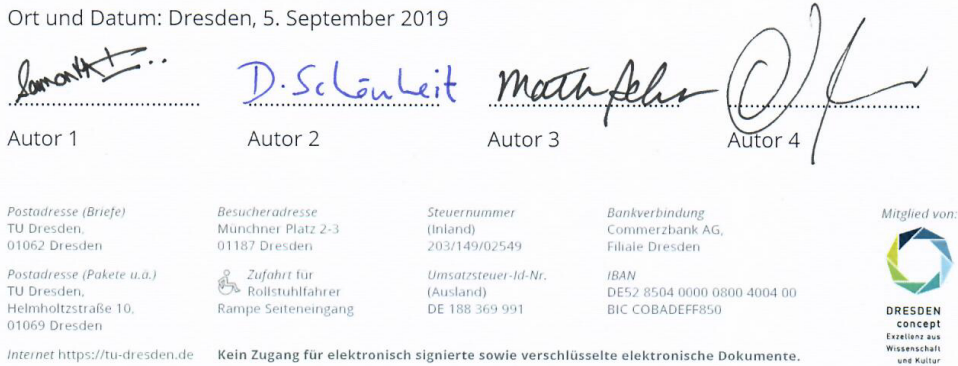



\section{B.2 What caused 2019's drop in German carbon emissions: Sustainable transition or short-term market developments?}

Authored by Anke, C.-P. \& Schönheit, D.

Published on 04.12.2020 in Zeitschrift für Energiewirtschaft, 44(4), 275-284

VHB: C

DOI: https://doi.org/10.1007/s12398-020-00289-3

Declaration of authorship for Article 2

\section{TECHNISCHE \\ UNIVERSITÄT \\ DRESDEN}

Fakultät Wirtschaftswissenschaften, Lehrstuhl für Energiewirtschaft

Technische Universität Dresden, 01062 Dresden

Lehrstuhl für Energiewirtschaft

Prof. Dr. Dominik Möst

Münchner Platz 3 ,

01069 Dresden

Lehrstuhlinhaber

Kontakt: Linda Schwabe

phone: $\quad+4935146333297$

fax: $\quad+4935146339763$

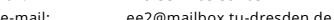

\section{ERKLÄRUNG AUTORENSCHAFT}

Am folgenden Beitrag:

What caused 2019's drop in German carbon emissions: Sustainable transition or short-term market developments?
haben folgende Personen:
Autor 1:
Carl-Philipp Anke (CPA)
Autor 2:
David Schönheit (DS)

die Autorenschaft. Die Reihenfolge der Autoren ist dabei alphabetisch. Die Autoren haben in gleichem Umfang zu der Veröffentlichung beigetragen. Die Beiträge der einzelnen Autoren, die die Veröffentlichung verantwortlich mittragen, gliedern sich nach den Kriterien der DFG (2013) zur guten wissenschaftlichen Praxis dabei wie folgt:

- Konzeption der Studie:

CPA, DS

- Erarbeitung der Daten

CPA

- Analyse der Daten:

- Interpretation der Daten:

- Interpretation der Rohdaten

- Interpretation der Ergebnisse

- Formulierung des Manuskripts:

CPA, DS

CPA, DS

CPA, DS

Die Autoren stimmen mit Ihrer Unterschrift unter diesem Dokument einer Veröffentlichung des Beitrages sowie einer Nutzung des Beitrages zur wissenschaftlichen Qualifikation im Rahmen des Promotionsvorhabens durch andere Autoren $z u$.

Ort und Datum: Dresden, 2. Oktober 2020

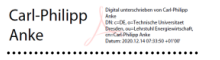

D. Sclonkeit

Autor 1

Autor 2
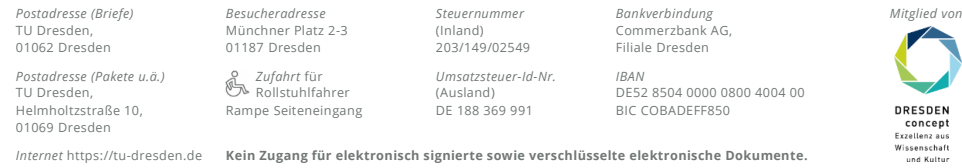



\section{B.3 The effect of corrective short-term updates for wind energy forecasts on intraday electricity prices}

Authored by Schönheit, D., Homann, L., Möst, D. \& Westgaard, S.

Version submitted for grading of this dissertation. Currently being revised for new submission.

Declaration of authorship for Article 3

\section{TECHNISCHE \\ UNIVERSITÄT \\ DRESDEN}

Fakultät Wirtschaftswissenschaften, Lehrstuhl für Energiewirtschaft

Technische Universität Dresden, 01062 Dresden

Lehrstuhl für Energiewirtschaft

Prof. Dr. Dominik Möst

Münchner Platz 3,

Lehrstuhlinhabe

01069 Dresden

Kontakt: L Linda Schwabe

phone (fax): $\quad+4935146333297(39763)$

e-mail: $\quad$ ee2@mailbox.tu-dresden.de

\section{ERKLÄRUNG AUTORENSCHAFT DECLARATION OF AUTHORSHIP}

Am folgenden Beitrag:

For the following contribution:

The effect of corrective short-term updates for wind energy forecasts on intraday electricity prices

haben folgende Personen:

the following persons:

Autor (Author) 1 :

Autor (Author) 4: $\quad$ Sjur Westgaard (SW)

die Autorenschaft. Die Reihenfolge der Autoren hold authorship. The order of authors follows the proportionate contributions. The contributions of Die Beitrage der einzelnen Autoren, die die Ver- the idual authors, who assume responsöffentlichung verantwortlich mittragen, gliedern bility for the publication, are structured as sich nach den Kriterien der DFG (2013) zur follows, according to the criteria of DFG (2013) guten wissenschaftlichen Praxis dabei wie folgt: $\quad$ regarding good scientific practice:

- Konzeption der Studie (Conceptual design of the study): DS, LH, DM, SW

- Literaturrecherche und Theorie (Literature research and theory): $\quad$ LH, DM, SW, DS

- Erarbeitung/Aufbereitung der Daten (Compilation/processing of data): DS, LH

- Modellierung und Analyse der Daten (Modeling and analysis of data): DS

- Interpretation der Ergebnisse (Interpretation of results): DS, LH, DM, SW

- Formulierung des Manuskripts (Formulation of the manuscript): $\quad$ DS, LH, DM, SW

Die Autoren stimmen mit Ihrer Unterschrift unter With their signature on this document, the authors diesem Dokument einer Veröffentlichung des Beitrages sowie einer Nutzung des Beitrages Weitrages sowie einer Nutzung des Beitrages zur ahmen des Promotionsvorhabens durch andere Autoren zu. as a utilization of this contribution as part of an academic qualification within a dissertation academic qualification within
project of the other authors.

Ort / Datum: Dresden, 20. September 2020
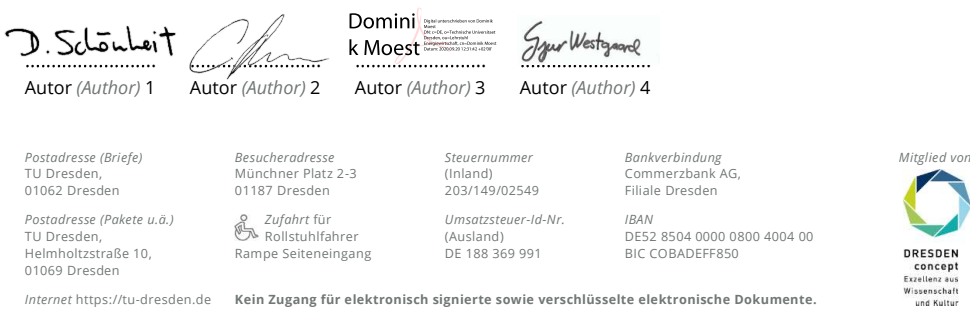



\title{
The effect of corrective short-term updates for wind energy forecasts on intraday electricity prices
}

\author{
David Schönheit* $\quad$ Lasse Homann ${ }^{\ddagger} \quad$ Dominik Möst $\ddagger^{\ddagger \dagger} \quad$ Sjur Westgaard ${ }^{\ddagger}$ \\ Manuscript of September 20, 2020 - Submitted to International Journal of Forecasting
}

\begin{abstract}
Transitioning towards a decreased reliance on conventional energy sources subjects electricity markets to greater uncertainties due to the weather dependency of renewable energy sources. Wind energy in Germany has experienced a tremendous expansion, especially over the past decade. This analysis quantifies how updates in predicted wind energy affect intraday electricity prices. It outlines the merit order theory and derives hypotheses, tested by means of exploratory and regression analyses. Wind speedbased wind energy forecasts are computed to obtain forecasts at two points before the time of delivery and measure the effect of the short-term update between them. The analysis finds that wind energy updates negatively affect intraday prices. The effect's magnitude depends on the position within the merit order approximated by the level of residual load. It is largest for high residual loads, because of the merit order's steeper shape. In situations of low residual load, the price effect and uncertainty is augmented because of negative prices and larger average forecast errors for wind energy. The results imply that varying predicted residual loads necessitate different risk assessments, for which merit order-based models can help to anticipate and account for the magnitude of price uncertainties due to (updates for) wind energy forecasts.

Keywords: wind energy forecasts, forecast corrections, intraday prices, merit order effect, asymmetric price effects, negative prices
\end{abstract}

JEL classifications: C01, C55, Q41, Q43, Q47

\section{Introduction}

Renewable energy covers a large proportion of German gross electricity consumption. In the first half year of 2020 more than $55 \%$ of the electricity was produced by non-conventional energy sources of which wind and solar power are the most important. Unexpected renewable generation can cause large price variation and enhances the occurrence of negative prices, observed in both the day-ahead and intraday market. A consequence of the growing renewable feed-in is that market participants have to increasingly rely on forecasts when placing their bids in the day-ahead auction. Naturally, updated forecasts become available closer to the time of delivery and position imbalances arise. If actual generation and consumption are not aligned, TSOs use control energy to stabilize the net frequency. Control energy is costly and can be avoided by extensive trading close to delivery. For this purpose, the intraday market offers continuous trading in hourly, 30minute, and 15-minute contracts until 5 minutes before the start of delivery.

\footnotetext{
*Corresponding author, david.schoenheit@tu-dresden.de, +49 35146339766

${ }^{\dagger}$ Technische Universität Dresden, Chair of Energy Economics, Münchner Platz 3, 01069 Dresden, Germany

¥lasseclas95@web.de, dominik.moest@tu-dresden.de, sjur.westgaard@ntnu.no

§NTNU, Department of Industrial Economics and Technology Management, 7491 Trondheim, Norway
} 
The impact of power generation from renewable energy sources on electricity prices is especially pronounced because (i) their marginal costs are low and production enters the electricity supply curve in the lower end, (ii) electricity sourcing from renewable generation is the subject of government support schemes and guaranteed priority feed-in and (iii) production needs to be forecasted and is dependent on weather and other meteorological conditions. The merit order theory predicts that the effect of forecast errors on the intraday price varies across different market conditions. In steeper regions of the merit order, the effect is supposed to be more pronounced, because marginal production cost is set by expensive generation technologies, e.g. fossil gas and oil. Similarly, a large effect is expected for the case in which prices are driven into negative regions as a result of must-run and ramping constraints as well as opportunity cost considerations.

The effect of renewable energy production on the day-ahead price has been extensively studied in the literature, but rather little attention has been paid to varying effects of forecast errors on intraday prices, depending on the steepness of the intraday supply curve. This analysis clearly outlines the merit order theory and the theoretical implications of wind energy feed-in and updates for wind energy forecasts on intraday prices. From this, hypotheses are formulated, regarding the effect of corrective short-term updates for wind energy forecasts on intraday prices which is hypothesized to be dependent on the position within the merit order. The results provide evidence that the intraday price formation depends on the residual load profile. The findings support the predictions derived from the shape of the merit order and suggest that accounting for varying impacts of forecast errors might prove useful in forecasting applications.

This paper proceeds as follows. Section 2 introduces the relevant literature and Section 3 explains the theoretical effect of forecast errors on the supply and the demand in the German electricity market. Section 4 presents the data, that serves as a basis for exploratory analyses in in Section 5 and the regression model-based quantification of the effect of wind energy updates on intraday prices in Section 6. Section 7 concludes this analysis.

\section{Review of related literature}

The research on electricity prices is heavily driven by the need to forecast future prices and price distributions. Consequently, there is a vast amount of forecasting models applied. The main focus lies on the prediction of the day-ahead electricity price, because, although a lot of electricity is traded in bilateral contracts, the day-ahead price is the main reference for electricity spot trading. Forecasts are needed since electricity prices do not follow a pure random motion, as observed in traditional financial markets, but exhibit patterns like mean reversion and seasonality at multiple levels. Many papers include forecasts of wind and solar and show that both are important drivers of day-ahead prices. Notably, there is also a recent turn towards the intraday electricity market in the forecasting literature. Among the first are Uniejewski et al. (2019) and Narajewski and Ziel (2020), who point-forecast the $\mathrm{ID}_{3}$-index, a volume-weighted average price of intraday contracts close to delivery.

However, besides the practical implementation of forecasting models at the corporate level, it is very important to understand the integration of power from renewable energy sources in the context of market design and regulatory framework. With the German electricity market hav- 
ing been liberalized for only 25 years it has been subject to constant structural remodeling. The direction is clear: A movement away from conventional generation and towards green energy. These interventions have important implications for the market and must be evaluated before next steps in the "Energiewende" (energy transition) are taken in order to guarantee grid stability and market-efficient pricing of electricity. One of the well-known consequence of the subsidized capacity expansion of green energy is the dampening effect in the level of prices, commonly known as the merit order effect. The mechanism, though being nonlinear, is easy and intuitive. Renewables with a marginal cost close to zero push expensive technologies out of the market.

For the Danish market, Jónsson et al. (2010) estimate the impact using a non-parametric secondorder polynomial regression technique and find that prices are not only suppressed but also their distribution changes due to increasing wind power penetration. Ketterer (2014) document similar results for the German market by showing that the price level decreases, whereas volatility increases when wind feed-in is high. In a more recent study, Maciejowska (2020) applies a quantile regression to account for non-linearities and to reveal differences between wind and solar. The author notes that the impact of renewables always has to be conditioned on the level of total demand, a manner ignored in many empirical studies. Eising et al. (2020) are showing that with a further increasing share of renewables a continued decline in market values of renewables with increasing regional discrepancies can be expected. Thereby, the price declining effect can be expected to be much more pronounced for photovoltaic than wind energy, especially due to the simultaneity of feed-in.

The merit order effect has been investigated for several markets that are differing in the regulatory framework and design (e.g Woo et al., 2011; Gelabert et al., 2011; Clò et al., 2015), but little of the underlying theory has been applied to intraday markets. von Roon and Wagner (2009) are the first who lay emphasis on the errors that are inherent to renewable forecasts. The authors investigate the quality of the wind power forecasts which are published by the four transmission system operators for the German market. They regress the difference of the day-ahead price and the intraday price on the forecast error and find only a weak relationship. Nevertheless, von Roon and Wagner (2009) note that high positive/negative forecast errors tend to be accompanied by a negative/positive price difference. The point estimate of the effect is $-1 € /$ MWh per $1 \mathrm{GWh}$ forecast error. In a similar manner, Hagemann (2015) investigates how changes in demand and supply after the day-ahead gate closure affect intraday prices. He considers plant outages, forecast errors of renewables, load forecast errors as well as cross-border transmission. Very important, the author notes that not only fundamentals may cause the day-head and intraday price to deviate, but also the strategic bidding behavior of market participants.

Ziel (2017) models the intraday price for a period of January 2011 through December 2015. The variation of the last price of the 60-minute intraday contracts is explained using a large time series model which includes terms for forecast errors of wind and solar. The estimated effect of wind forecast errors, depending on the hour, varies between $-4 € / \mathrm{MWh}$ and $-7 € / \mathrm{MWh}$ and is statistically significant. The author does not find evidence for an asymmetric impact of positive and negative errors. Kiesel and Paraschiv (2017) study the relationship between renewable forecast errors and 15-minute intraday electricity prices using a threshold model. By doing so, the au- 
thors claim to identify two regimes that cause a non-linear response of the price difference. In one regime conventional capacity is expected to cover the forecasted demand, whereas in the other regime market participants have higher expectations on renewable feed-in which causes excess demand pressure. However, in their results, as noted by Ziel (2017), the relevant coefficients for wind are not statistically different from each other, suggesting that the impact is the same across regimes. Gürtler and Paulsen (2018) use a panel regression to analyze the price effect of wind and solar forecast errors and confirm the magnitude of the estimates of Kiesel and Paraschiv (2017).

The intuition behind the non-linear impact is well-formed in theoretical considerations. Depending on the available information set at the time of the day-ahead auction, the day-ahead price is set somewhere along the merit order curve by the price-setting power plant. The marginal effect of a forecast error, due to the shift of the supply curve, is then determined (assuming inelastic demand) by the slope of the merit order, evaluated at the position of the price-setting power plant. The non-linearities emerge from the varying slope of the merit order as marginal-production cost rise for increasing electricity generation.

Kremer et al. (2019) refine the work of Kiesel and Paraschiv (2017) and explicitly include the estimated slope of the merit order in their model. Kulakov (2020) model the varying effects by shifting the day-ahead supply curve according to the forecast error and the total level of wind feed-in to arrive at the intraday price. The authors find that the shift in the supply curve is larger for negative forecast errors, but they also report that the influence of negative forecast errors decreased over the year 2017. Similar decreasing effects were found by Gürtler and Paulsen (2018). The use of the day-ahead merit order and its slope to investigate the intraday pricing mechanism is not undisputed and could be erroneous as the intraday supply curve is steeper, reflecting higher short-term marginal cost and ramping-up constraints. In contrast, Goodarzi et al. (2019) study the non-linearities utilizing quantile regression. They find that wind has a larger impact on the intraday price compared to solar. Although the quantile regression approach is promising to reveal the non-linearities, the estimated coefficients for wind forecast errors are rather constant over the quantiles.

This analysis extents the current literature by further dismantling the effect of renewable forecast errors on intraday prices. In particular, we propose to model the impact of forecast errors on the intraday price as a function of residual load, defined by the total load forecast minus forecasts of wind and solar energy. The contribution of this analysis is threefold. First, it provides evidence that threshold models, where only two-demand profiles are considered, lack the ability to detect the quadratic-like pattern in the effect of wind forecast errors on prices and explains why previous studies only find insignificant threshold effects. Second, the findings provide evidence that the intuition provided by the merit order theory is well applicable to the intraday price formation and varying effects of forecasts on prices should be considered when building an intraday pricing model. Third, this analysis is based on two different wind forecasts for wind energy before the point of delivery in the intraday market. This way, the effect of updates in wind energy forecasts on intraday prices can be quantified. 


\section{Theoretical background: How wind energy affects the merit order}

The classic merit order effect describes that an increasing supply by renewables tends to lower the average price per unit of electricity. This price decreasing effect depends on the additional renewable feed-in and the magnitude of the load. In steeper regions of the merit order, the effect is supposed to be more pronounced, because marginal production cost is set by expensive generation technologies, e.g. fossil gas and oil. Similarly, a small effect is expected for the case at base load (see Figure 1). But also larger price effects may occur at intersections of the merit order, where a technology shift (e.g. from nuclear to coal) due to different marginal costs appears. In a mathematical understanding, the classical merit order effect (of a small or infinitesimal additional feed-in of renewables) can be determined with the help of the derivative of the supply curve.

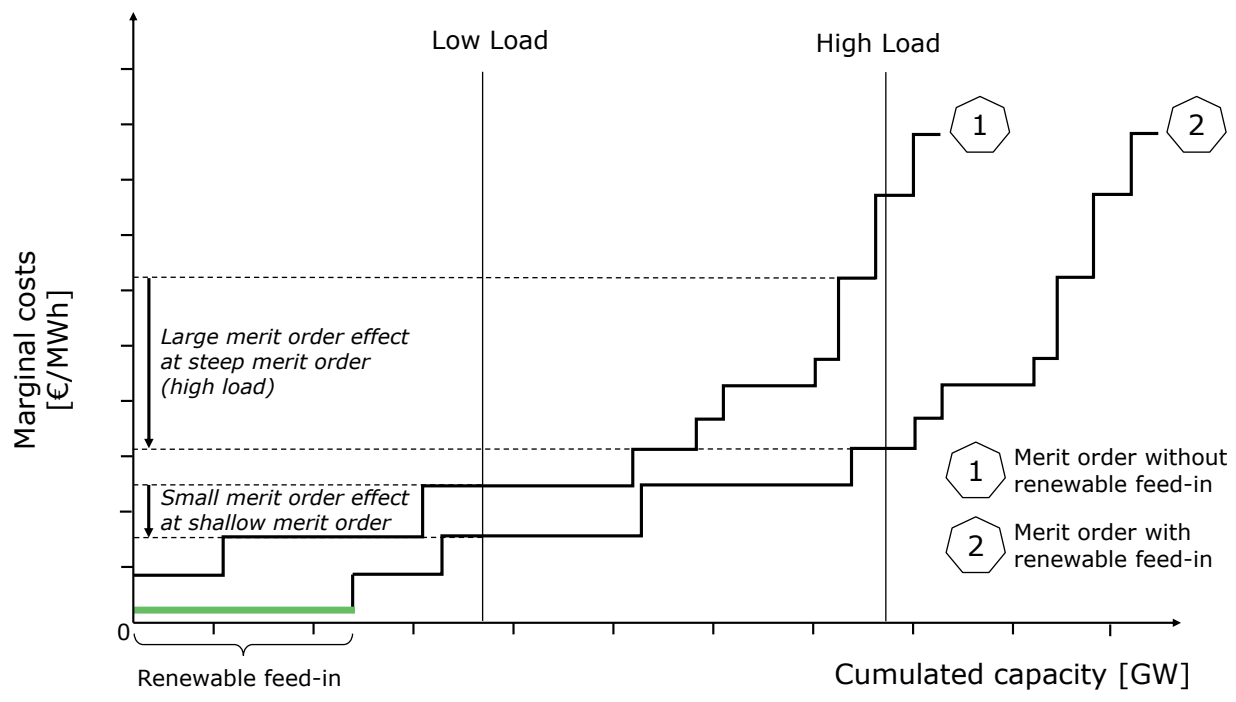

Figure 1: Classic merit order effect depending on electricity demand

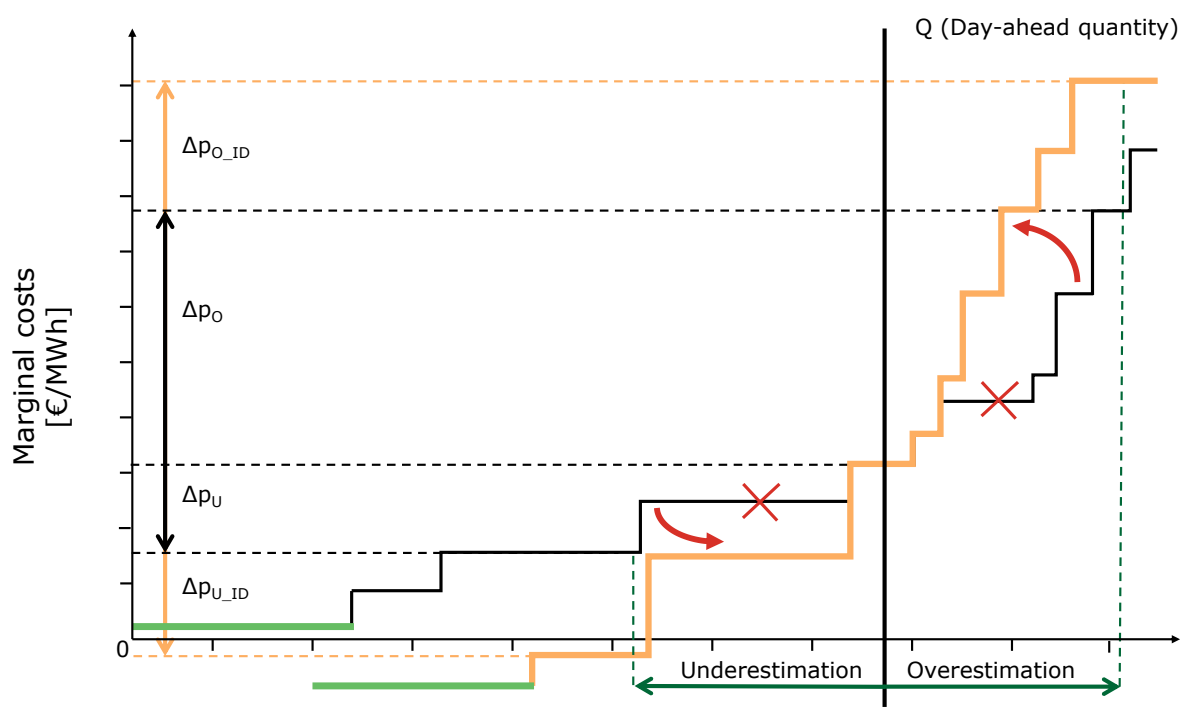

Figure 2: Price effect due to over-/underestimation of renewable feed-in 
This classical merit order effect has been extensively studied in the literature. However, the merit order effect on intraday markets and the relation with forecast errors has been paid little attention. In the following, a theoretical background is illustrated which is the basis for the subsequently formulated hypothesis. These hypotheses will be tested using historical data in the consequent sections.

First of all, it has to be noted that there is no unique intraday price for a given hour as continuous trading takes place. In consequence, intraday prices for a given hour are volume-weighted averages of the continuous trading within the considered hour. Starting from the day-ahead price, an overestimation of the feed-in from renewable energies leads to an expected higher price on the intraday market, since more conventional generation is required to compensate the lower-thanexpected renewable feed-in. This price increase is illustrated with $\Delta \mathrm{p}_{\mathrm{O}}$ in Figure 2. Accordingly, an underestimation of the feed-in from renewable energies leads to an expected lower price $\left(\Delta \mathrm{p}_{\mathrm{U}}\right.$ in Figure 2) on the intraday market, since less conventional generation is required.

However, the merit order curve was assumed to be identical to the day-ahead merit order curve and also the demand curve is considered as inflexible. ${ }^{1}$ The described price effect, $\Delta \mathrm{p}_{\mathrm{O}}$ and $\Delta \mathrm{p}_{\mathrm{u}}$, just result from the over- or underestimation of renewable energy feed-in. In general, it can be assumed that the merit order curve between day-ahead and intraday market may change due to the following facts: 1 . Some generators may not react to short-term market changes and thus do not participate in the intraday market due to lacking flexibility. This inflexibility may result from technical purposes (e.g. longer lead times are necessary) or from organisational matters (e.g. missing market connection). 2. Additional, strategic behaviour may also change the bidding behavior on intraday markets (see von Selasinsky, 2016).

Independent of the reasons for the changes in the merit order curve, it is comprehensible that the expected price is identical when there is no new additional information or, in other words, if there is no deviation from the day-ahead market results. ${ }^{2}$ Hence, day-ahead price and intraday price should be the same in the case if no forecast error (or any other deviation) occurs, as illustrated with $Q$ in Figure 2. If a deviation occurs, the intraday merit order curve is generally steeper as in the day-ahead market due to the above mentioned reasons (see Figure 2). In consequence, an additional price effect results from the change of the merit order curve which is illustrated with $\Delta \mathrm{p}_{\mathrm{O}_{-} \mathrm{ID}}$ in the case of overestimation and $\Delta \mathrm{p}_{\mathrm{U}_{-} \mathrm{ID}}$ in the case of underestimation. In general, this increases the price effect resulting from an over- or underestimation of renewable energy feed-in. Besides these described effects, the shape of the merit order curve (or in other words the derivative of the curve) has a strong impact on the merit order effect.

The described price effect can significantly increase if flexibility is very low. In general this is the case, if the residual load is very low and there are hardly any plants which can provide the flexibility in the case of an underestimation. Then no operator is willing to leave the market which can result in extreme price decreases up to extreme negative prices.

These considerations are the basis for the following hypotheses:

\footnotetext{
${ }^{1}$ In the short-term, demand of electricity is very inflexible as there are nearly no measures for price response. Although, industry may react to prices, reactions mainly happen when significant price changes occur.

${ }^{2}$ This means, no renewable forecast error, no plant failure, no load forecast error or any other deviation with regard to the supply and demand curve. In the following, it is assumed that only forecast errors of renewable feed-in occurs, while plant failures and load forecast errors are not considered.
} 
H1: Increased wind energy negatively affects electricity prices and vice versa (this corresponds to the described situation of under- and overestimation in Figure 2).

H2: The effect of short-term corrective updates of available wind energy on intraday prices depends on the residual load. (These hypotheses are derived from the general shape of the merit-order-curve depicted in Figure 1).

H2a: Wind energy updates at high loads have a stronger impact than at medium loads due to the steep increase of the merit order.

H2b: Wind energy updates at low loads have a stronger impact than at medium load due to inflexibility of conventional power plants and resulting negative prices.

H3: Changes from positive day-ahead prices to negative intraday prices occur regularly in situations of low residual load and wind energy underestimations. Changes from negative day-ahead prices to positive intraday prices occur regularly in situations of low residual load and wind energy overestimations, but overall less often than the first described situation. (As additional downward flexibility is required in situations with low residual loads in cases of underestimation, this statement is intuitive).

H4: The effect of short-term corrective updates on intraday prices is asymmetrical, i.e. different for positive and negative wind updates.

Besides these hypotheses, renewable operators or more precisely marketers of renewable capacity may have an incentive to deviate from there real day-ahead forecast as overestimations probably result in higher additional costs for the marketer. In consequence, marketers of renewable capacity may have an incentive to underestimate renewable feed-in on the day-ahead market.

\section{Data description}

This section describes the retrieval and processing of the used data. The sample period is from January 2017 to December 2019. The electricity prices and the available capacity forecasts are obtained from the EEX Transparency platform, accessed via the Montel excel feeder. The capacity forecasts cover the available capacity of nuclear, hard coal, lignite, and gas. For the intraday price, the last price of the 60-minute contracts is used. The day-ahead price is the market clearing price of the day-ahead auction. Total load forecasts and wind and solar generation forecasts, as well as their realized values, are collected from the ENTSO-E Transparency platform (ENTSO-E, 2020).

Table 1: Data sources

\begin{tabular}{lcc}
\hline Data & Source & Granularity \\
\hline Day-ahead price (PriceDA) & EPEX SPOT SE & hourly \\
Intraday price (PriceID) & EPEX SPOT SE & hourly \\
Renewable forecasts (WindDA and SolarDA) & ENTSO-E Transparency & quarter-hourly \\
Load forecasts (LoadDA) & ENTSO-E Transparency & quarter-hourly \\
Actual generation & ENTSO-E Transparency & quarter-hourly \\
Available capacity forecasts & EEX Transparency & daily \\
(AvailLignite, -HardCoal, -Gas, -Nuclear) & & \\
Wind energy forecasts (WindDA and WindUpdate) & ECMWF (see Appendix A) & hourly \\
\hline
\end{tabular}


Table 1 lists the data and their source together with the original frequency. Series that are recorded in quarter-hourly resolution, such as wind and solar forecasts, are aggregated to hourly means to match the frequency of the pricing data. Capacity forecasts are only available in a daily resolution and refer to the average capacity for the entire next day. To approximate the available capacity of a single hour, it is set to the day's average.

Importantly, renewable energy forecasts from ENTSO-E are used for the exploratory analysis in Section 5. The model-based analysis in Section 6 seeks to quantify how updates in wind energy affect intraday prices. Since the goal is to measure the effect on all hours of the day of delivery (D), the necessity arises not only for a day-ahead (D-1) wind energy forecast but also a second wind energy forecast that is closer to the intraday hours and times of delivery. Thus, two wind energy forecasts, 1) D-1 at 12:00 and 2) D at 0:00, are retrieved from high-resolution wind speed data. The method for retrieving these from ECMWF-based wind speed data is described in Appendix A. Thus, it is important to distinguish that in Section 5 "day-ahead wind energy" and "intraday wind energy" refer to the ENTSO-E day-ahead forecast and intraday values. In Section 6 these terms refer to the wind speed-derived day-ahead and intraday forecast (D-1 at 12:00 and D 0:00), retrieved from the ECMWF data. These relations are summarized in Figure 3.

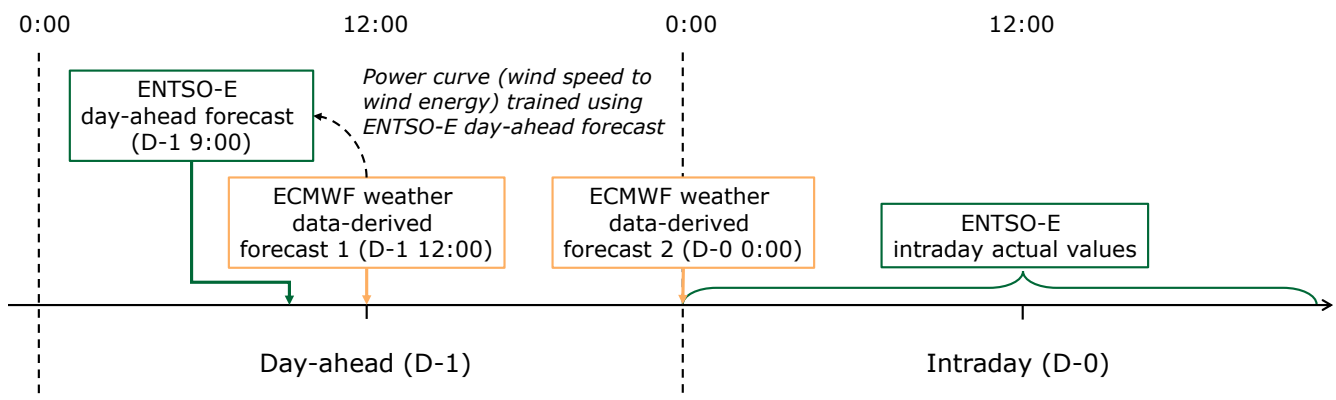

Figure 3: Data sources and times of forecast for wind energy.

Table 2 and 3 provide the summary statistics for all variables, separately for variables used in Section 5 and 6. As described in Appendix A, the wind speed dataset is limited to two years (with one month missing in each year) and only available for eight of the 24 hours. Thus, the number of observations used for the regression models drops to around 5300.

Table 2: Summary statistics for exploratory analysis in Section 5

\begin{tabular}{llrrrrrrr}
\hline & Statistic & $\mathrm{N}$ & Mean & St. Dev. & \multicolumn{1}{c}{ Min } & 25th. perc. & 75th perc. & Max \\
\hline Intraday & WindID & 26190 & 12.749 & 9.339 & 0.165 & 5.358 & 17.957 & 45.085 \\
& PriceID & 26190 & 38.856 & 24.443 & -479.000 & 28.400 & 49.400 & 700.000 \\
\hline Day-ahead & WindDA & 26028 & 12.659 & 9.196 & 0.292 & 5.392 & 17.692 & 44.227 \\
& PriceDA & 26190 & 38.784 & 17.547 & -90.010 & 30.170 & 47.950 & 163.520 \\
& Residual load & 25716 & 38.542 & 11.730 & -4.612 & 31.025 & 46.478 & 72.549 \\
\hline Differences & Price difference & 26190 & 0.073 & 17.755 & -395.690 & -7.470 & 6.600 & 624.510 \\
& Wind difference & 26028 & 0.108 & 1.071 & -11.023 & -0.404 & 0.581 & 8.002 \\
\hline
\end{tabular}

\section{Exploratory data analysis}

This section serves as a preliminary exploratory analysis of the data at hand. It lays the foundation for the model-based estimations in the following section. 
Table 3: Summary statistics for model-based analysis in Section 6

\begin{tabular}{|c|c|c|c|c|c|c|c|c|}
\hline & Statistic & $\mathrm{N}$ & Mean & St. Dev. & Min & 25th perc. & 75th perc. & $\operatorname{Max}$ \\
\hline Intraday & PriceID & 5336 & 38.197 & 22.423 & -162.100 & 27.500 & 49.000 & 300.000 \\
\hline \multirow[t]{9}{*}{ Day-ahead } & WindDA & 5336 & 11.852 & 8.909 & 0.853 & 5.037 & 16.186 & 43.968 \\
\hline & PriceDA & 5336 & 38.071 & 17.105 & -83.030 & 29.620 & 47.560 & 124.290 \\
\hline & LoadDA & 5328 & 56.023 & 9.516 & 34.585 & 48.027 & 64.055 & 75.912 \\
\hline & SolarDA & 5296 & 4.467 & 6.745 & 0.000 & 0.000 & 7.267 & 28.625 \\
\hline & AvailLignite & 5336 & 16.926 & 1.201 & 12.359 & 16.191 & 17.804 & 19.652 \\
\hline & AvailGas & 5336 & 7.449 & 1.176 & 3.838 & 6.563 & 8.453 & 9.647 \\
\hline & AvailHardCoal & 5336 & 11.590 & 1.849 & 4.722 & 10.359 & 12.856 & 15.931 \\
\hline & AvailOil & 5336 & 1.486 & 0.321 & 0.441 & 1.308 & 1.789 & 1.826 \\
\hline & AvailNuclear & 5336 & 8.481 & 1.250 & 5.048 & 7.776 & 9.368 & 10.353 \\
\hline$\overline{D-0} 0: 00$ & WindUpdate & 5336 & 0.132 & 1.276 & -9.044 & -0.422 & 0.652 & 17.138 \\
\hline
\end{tabular}

To provide an overview of the target variable of this analysis, Figure 4 shows the distributions of intraday prices for different levels of residual load. The data set is split into six subsets according to different levels of residual load, i.e. the forecasted electricity demand, from which the forecast for solar and wind generation is subtracted. Low to high residual load situations are characterized by narrower intraday price distributions, with seldom negative or extremely high prices. For very low residual loads, the occurrence of negative prices substantially increases. The median and 25th percentile of the distribution are also much lower, compared to the other residual load categories. The reverse is true for very high residual loads. Here, extreme prices occur much more frequently and the median and 75th percentile are much higher.

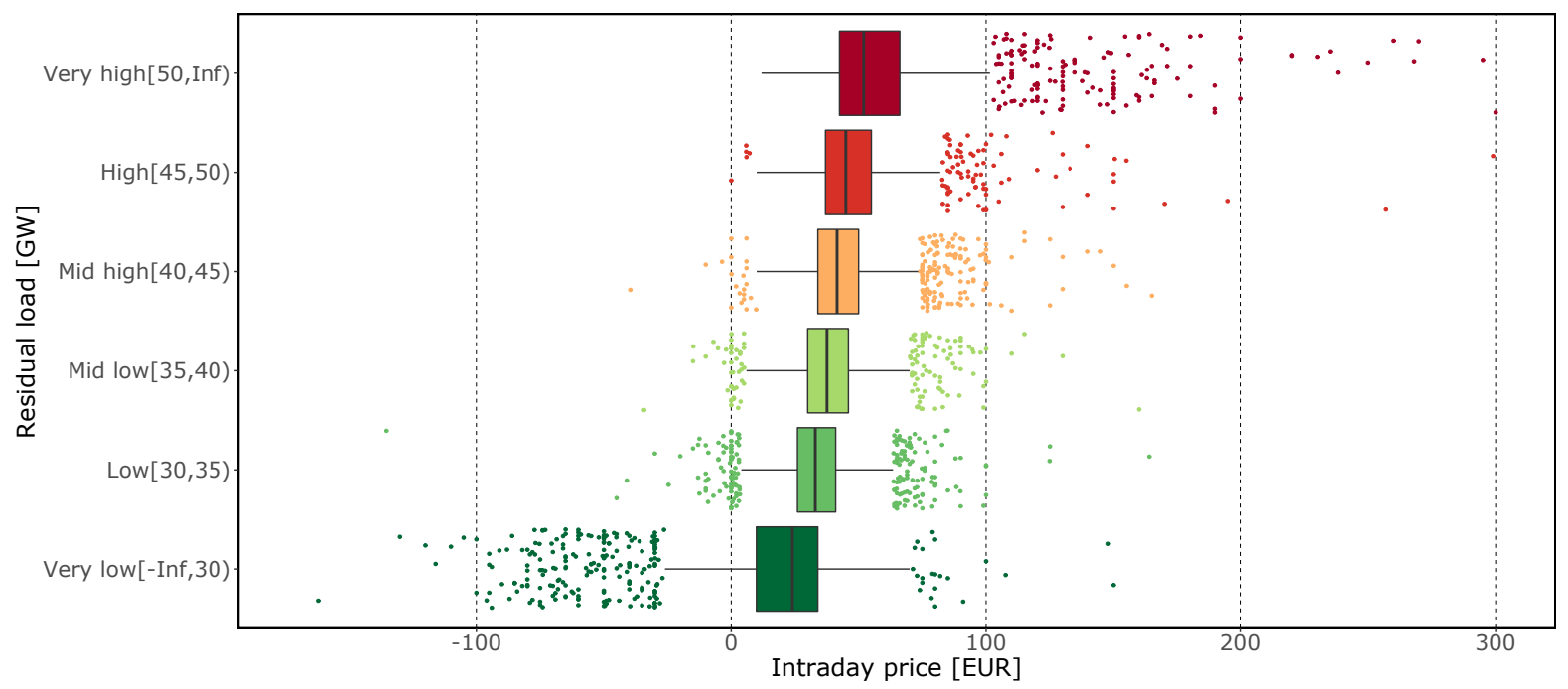

Figure 4: Distribution of intraday prices per category of residual load. All categorical boxplots follow the median, 25th/75th percentile, 1.5 times interquartile range and jittered outliers. Ten observations are out of the displayed range.

To explore the interaction between wind energy availability and prices, Figure 5 depicts the relation between price changes (y-axis) and deviations in wind energy forecasts ( $x$-axis). For both variables, the differences between day-ahead and intraday values are used (day-ahead subtracted from intraday). The bivariate relation is displayed for different categories of residual load. The black solid lines indicate the correlation between price changes (y) and wind forecast changes (x), taking the best fit when regressing $\mathrm{y}$ on $\mathrm{x}$. Complementary, the relation of $\mathrm{y}$ in dependence 


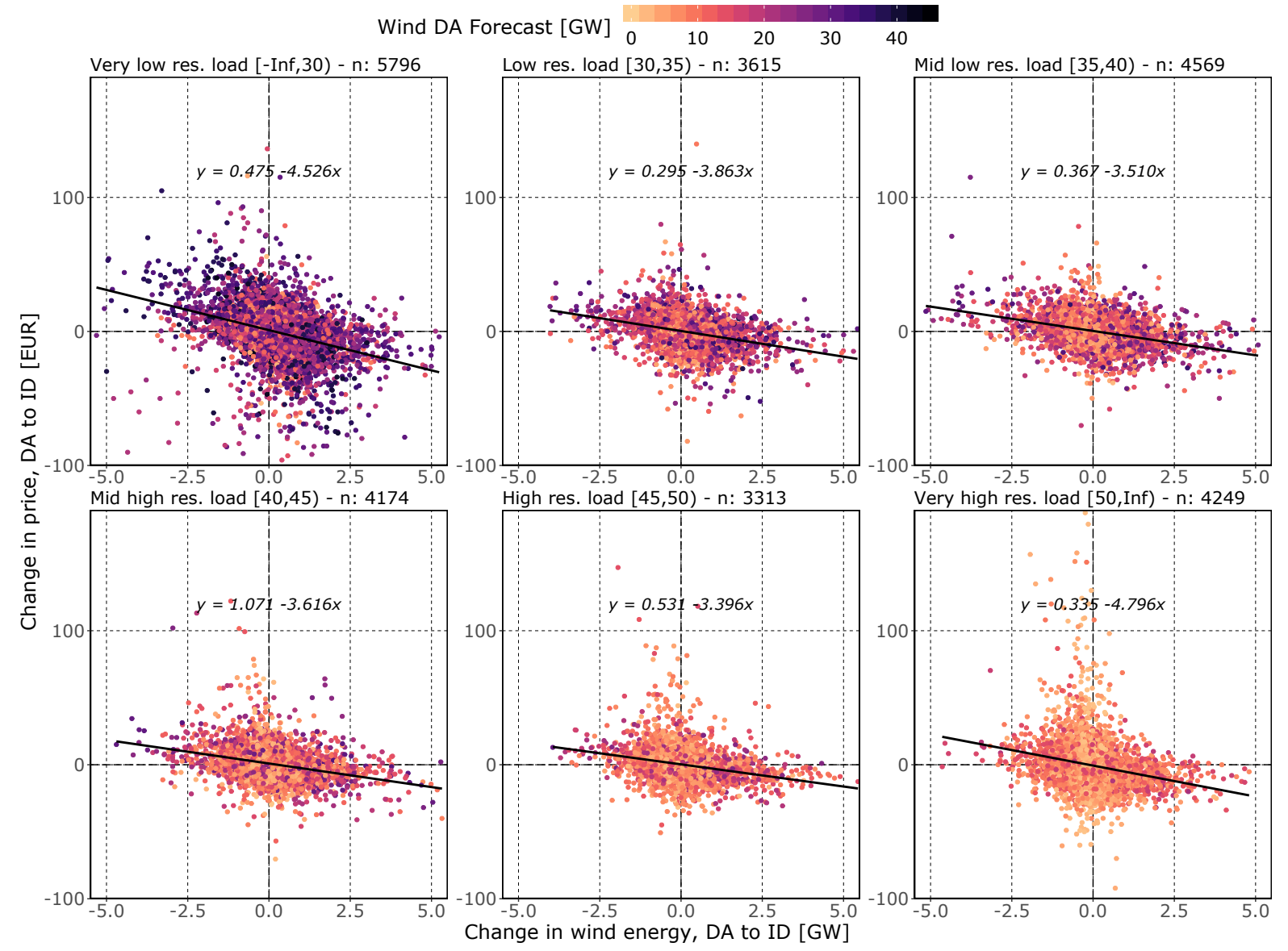

Figure 5: For Germany: Price change between day-ahead (DA) to intraday (ID) in relation to changes in wind energy forecasts (DA to ID) for different categories of residual load (in GW). The color scale corresponds to the WindDA energy forecast.

on $\mathrm{x}$ is noted. The color scale corresponds to the day-ahead wind energy forecast. Noticeably, low residual load observations are often characterized by high amounts of available wind energy. The reverse is true for high residual load situations. Several aspects can be observed from this depiction. First, the relation is always negative, i.e. positive changes in available wind energy are generally associated with negative price changes and vice versa, thus affirming hypothesis $\mathbf{H 1}$. Second, the negative relation differs depending on the residual load. The effect is most pronounced for very low and very high residual load situations, along the lines of hypothesis $\mathbf{H 2}$.

Tying in the results with Section 3, for very low residual loads, the stronger effect could be explained by an increased incidence of negative prices which can occur when the availability of renewable energy sources is high (H2a). Hence, a further increase in availability "push" prices from positive to negative. For very high residual loads, the large negative effect can be derived from the shape of the merit order. High residual loads mean that conventional peak units are participating in the market. In this "latter part" of the merit order, marginal price increases are steeper due to larger price differences in dispatched generating units, e.g. when gas-fired units are dispatched, following hard coal-fired units $(\mathbf{H} 2 \mathbf{b})$. In these situations, the price effect of additional renewable energy is larger. Thus, positive updates in available wind energy have a greater negative effect on prices. 


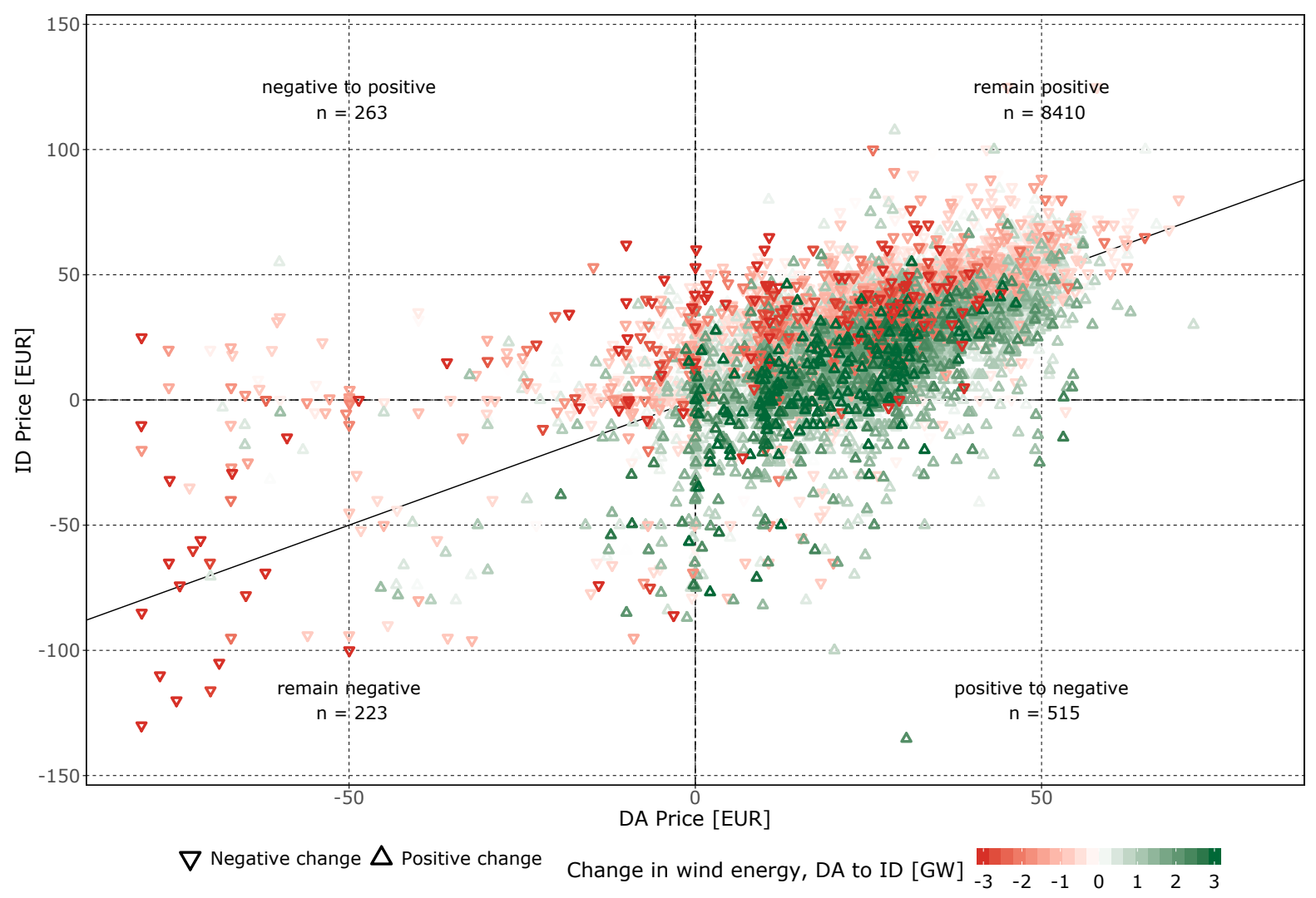

Figure 6: Intraday prices in relation to day-ahead prices with indication of differences in available wind energy between day-ahead and intraday.

Keeping in mind the occurrence of negative prices as well as the effect of changes in wind energy availability, it is useful to analyze the frequency of changes in the sign of prices. The description above assumes a "push" from positive to negative prices with additional availability in wind energy. For this, Figure 6 depicts intraday prices in relation to the day-ahead prices for very low and low residual load situations (<35 GW). The upward triangles indicate positive changes in wind energy availability (i.e. more wind during intraday than day-ahead) and the downward triangles indicate negative changes. The color spectrum also indicates how severe these changes are. ${ }^{3}$ The diagonal line indicates equal prices. Generally, positive updates lead to price drops and vice versa, again supporting H1. The frequency of observations in the four quadrants vastly differs. Day-ahead prices are often positive and remain positive (positive values include 0). Out of the other three quadrants, most observations are in the bottom right. Here, positive DA price "turn negative" on the ID market and almost always there is an underestimation and therefore a positive update of wind energy. Situations with remaining negative prices and changes from negative to positive prices occur less than half as often as the described positive-tonegative changes, confirming $\mathbf{H 3}$.

\footnotetext{
${ }^{3}$ Note that the observations are plotted in ascending order of absolute wind differences which means the observations with the highest wind differences are plotted "on top" and many observations with low wind differences are "hidden below". Also note that the color spectrum is limited to -3 to +3 GW. Observations exceeding these values are assigned the minimum and maximum value, respectively, and thus "squished" into the color scale. As Figure 5 shows, changes in wind energy below $-3 \mathrm{GW}$ and above $+3 \mathrm{GW}$ exist for very low and low residual loads. The majority of observations, however, is limited to the chosen range.
} 


\section{Model description and results}

The exploratory analysis focused on differences in the two markets, day-ahead and intraday. The overarching goal of this work is to quantify how updates in forecasts affect intraday prices. This necessitates having two wind energy forecasts and a model which can isolate the effect of the updates on prices. The retrieval of these two forecasts, used in this section, are described in Section 4 and Appendix A. This section details the regression models used to parse and quantify these effects for different residual load situations. As a preliminary step, Section 6.1 discusses the presence of heteroskedasticity, autocorrelation and multicollinearity. Section 6.2 and 6.3 describe the models and their results. Section 6.4 describes their implications.

\subsection{Preliminaries for the regression analyses}

All regressions described in Section 6.2 and 6.3 suffer from heteroskedasticity and almost all display positive autocorrelation, determined with the Breusch-Pagan test (with and without normality assumption) and the Durbin-Watson test. ${ }^{4}$ Thus, to account for the presence of heteroskedasticity and positive autocorrelation, robust Newey-West standard errors are applied with a lag of 24 hours to capture the daily patterns of the dependent and independent variables and possible time-lagged dependencies. The variance inflation factors (VIFs) for the continuous explanatory variables range from roughly 1.1 to 8 , with load being the most affected variable in the majority of cases. ${ }^{5}$ Although most VIFs are not very high, it is important to keep in mind that the presence of multicollinearity may reduce the significance of the affected variables' regression coefficients.

\subsection{Linear model for different subsets of residual load}

As a first step a linear OLS regression model is set up, following this equation:

$$
\begin{aligned}
\text { Price }_{t}^{\text {ID }}= & \beta_{0}+\beta_{1} \text { Wind }_{t}^{\text {DA }}+\beta_{2} \text { Wind }_{t}^{\text {Update }}+\beta_{3} \text { Load }_{t}^{\text {DA }}+\beta_{4} \text { Solar }_{t}^{\text {DA }}+\beta_{5} \text { Price }_{t}^{\text {DA }}+ \\
& \beta_{6} \text { Avail } \\
& \mathbf{H} \eta+M \mu+\epsilon_{t}^{\text {Lignite }}+\beta_{7} \text { Avail }_{t}^{\text {HardCoal }}+\beta_{8} \text { Avail }_{t}^{\text {Nuclear }}+\beta_{9} \text { Avail }_{t}^{\text {Gas }}+
\end{aligned}
$$

The intraday price serves as a dependent variable in all cases. The independent variables are the day-ahead forecast for wind and solar energy as well as load. The variable Wind $\mathrm{t}_{\mathrm{t} \text { date }}$ is the deviation between the day-ahead forecast at 12:00 and the wind forecast made on the day of delivery (D) at 0:00. Thus, positive values express additional expected available wind energy. Further, the available capacity of lignite, hard coal, nuclear and gas power plants serve as explanatory variables to better describe the configuration of the merit order. Lastly, dummy variables for hours and months are included to capture temporal, structural price patterns.

The day-ahead price is also included as an independent variable. There are two main reasons. First, the intraday price process is considered as a process that departs from the day-ahead price

\footnotetext{
${ }^{4}$ The Breusch-Pagan test's null hypothesis of homoskedastic error terms is rejected at the $0.1 \%$ significance level for all regressions, either with or without the normality assumption and often with both. The Durbin-Watson test's hypothesis of uncorrelated error terms is rejected at the $0.1 \%$ significance level for almost all regressions.

${ }^{5} \mathrm{~A}$ possible explanation for this is the high level of predictability of load due to the inclusion of hourly and monthly dummy variables which likely explain a substantial amount of the load's variance.
} 
and becomes first observable at the start of the intraday trading. Including the day-ahead price simultaneously controls for a variety of unobserved variables that effect both, the day-ahead and intraday market. Second, when including the day-ahead price residuals are found to be stationary. Thus, by including the day-ahead price the co-integration relationship between both price series is modeled. Importantly, this captures the shared seasonality of both prices. Therefore the interpretation of the dummy variables for hours and months should be adjusted as they capture the seasonality of the intraday price that deviates from that of the day-ahead price. The model can be viewed as a more general version of an analogous model where the price difference between the intraday and day-ahead market serves as dependent variable (see Kulakov, 2020, for a similar discussion). Notably, exploring the effect of wind energy forecast errors is a grateful applications as limited dependency towards other unobserved variables can be expected. Hence, when interpreting the coefficient of $\mathrm{Wind}_{\mathrm{t}}^{\mathrm{Update}}$ the presence of an omitted-variable bias is unlikely.

The regression analysis following Eq. 2 is conducted for four different subsets of residual load listed below. The correlation matrix for all continuous variables, separately for each of the follwing subset can be found in Table 8 in Appendix B.

1. High: All observations with high residual load, i.e. above the second tercile cut-off point (45 GW). This includes two observations with negative intraday prices.

2. Medium: All observations with medium residual load, i.e. larger or equal to the first tercile cut-off point $(35.6 \mathrm{GW})$ and below the second tercile cut-off point. This includes nine observations with negative intraday prices.

3. Low (w/ negative prices): All observations with low residual load, , i.e. below the first tercile cut-off, including observations with negative intraday prices.

4. Low (w/o negative prices): All observations with low residual load, excluding observations with negative intraday prices.

Table 4 displays the results of all regressions. Generally, more than a third of the intraday price's variation can be explained by the model. When considering low residual loads with negative prices, the explanatory power is highest at above $45 \%$. Noticeably, the effect wind energy updates on intraday prices is always negative (H1) but larger for high residual load situations $(-1.58$ $\left.\frac{\mathrm{EUR} / \mathrm{MWh}_{\mathrm{el}}}{\mathrm{GW}_{\text {Wind }}}\right)$, compared to medium and low residual load situations $\left(-1.31\right.$ and $-0.79 \frac{\mathrm{EUR} / \mathrm{MWh}_{\mathrm{el}}}{\mathrm{GW}_{\text {Wind }}}$, respectively) which confirms $\mathbf{H 2}$. The effect in low residual load situations, however, changes when negative prices are taken into account. Then, the effect increases in magnitude to -1.06 $\frac{\mathrm{EUR} / \mathrm{MWh}_{\mathrm{el}}}{\mathrm{GW}_{\mathrm{Wind}}}$. These effects are similar in magnitude compared to von Roon and Wagner (2009).

Thus, the effect of wind energy updates is substantial in all residual load situations but for different reasons. The higher coefficients in the high and medium residual load categories confirm the theory of a steeper shape at the higher end of the merit-order, corroborating H2a. Here, prices react more sensitively to renewable energy updates and consequent shifts in the merit order. The effect in low residual load situations is also substantial but emphasized because of negative prices which predominantly occur at the low end of the residual load spectrum (cf. Figure 4). Here, wind availability and updates can cause large price shifts from positive to negative. Hence, including 
Table 4: Results for linear regressions for four different subsets of residual load

\begin{tabular}{|c|c|c|c|c|}
\hline \multirow[b]{2}{*}{$\begin{array}{l}\text { Subset of } \\
\text { residual load }\end{array}$} & \multicolumn{4}{|c|}{ Dependent variable: Intraday price (PriceID) } \\
\hline & $\begin{array}{c}\text { High } \\
\text { (w/ neg. prices) }\end{array}$ & $\begin{array}{c}\text { Medium } \\
\text { (w/ neg. prices) }\end{array}$ & $\begin{array}{c}\text { Low } \\
\text { (w/ neg. prices) }\end{array}$ & $\begin{array}{c}\text { Low } \\
\text { (w/o neg. prices) }\end{array}$ \\
\hline WindDA & $\begin{array}{c}0.095 \\
(0.126)\end{array}$ & $\begin{array}{l}-0.006 \\
(0.131)\end{array}$ & $\begin{array}{c}-0.380^{* * *} \\
(0.126)\end{array}$ & $\begin{array}{c}-0.217^{* *} \\
(0.104)\end{array}$ \\
\hline WindUpdate & $\begin{array}{c}-1.584^{* * *} \\
(0.324)\end{array}$ & $\begin{array}{c}-1.311^{* * *} \\
(0.353)\end{array}$ & $\begin{array}{c}-1.062^{* * *} \\
(0.332)\end{array}$ & $\begin{array}{c}-0.790^{* *} \\
(0.318)\end{array}$ \\
\hline LoadDA & $\begin{array}{c}0.008 \\
(0.154)\end{array}$ & $\begin{array}{c}0.154 \\
(0.133)\end{array}$ & $\begin{array}{c}0.645^{* * *} \\
(0.166)\end{array}$ & $\begin{array}{c}0.534^{* * * *} \\
(0.138)\end{array}$ \\
\hline SolarDA & $\begin{array}{l}-0.264 \\
(0.256)\end{array}$ & $\begin{array}{c}-0.268^{* *} \\
(0.125)\end{array}$ & $\begin{array}{c}-0.723^{* * *} \\
(0.186)\end{array}$ & $\begin{array}{c}-0.474^{* * *} \\
(0.138)\end{array}$ \\
\hline PriceDA & $\begin{array}{c}0.888^{* * * *} \\
(0.072)\end{array}$ & $\begin{array}{c}0.895^{* * *} \\
(0.050)\end{array}$ & $\begin{array}{c}0.713^{* * *} \\
(0.073)\end{array}$ & $\begin{array}{c}0.501^{* * *} \\
(0.079)\end{array}$ \\
\hline AvailLignite & $\begin{array}{l}-0.224 \\
(0.495)\end{array}$ & $\begin{array}{c}0.329 \\
(0.410)\end{array}$ & $\begin{array}{l}-0.998 \\
(0.655)\end{array}$ & $\begin{array}{l}-0.550 \\
(0.540)\end{array}$ \\
\hline AvailHardCoal & $\begin{array}{c}0.265 \\
(0.464)\end{array}$ & $\begin{array}{l}-0.461 \\
(0.394)\end{array}$ & $\begin{array}{c}0.341 \\
(0.538)\end{array}$ & $\begin{array}{l}-0.645 \\
(0.445)\end{array}$ \\
\hline AvailNuclear & $\begin{array}{l}-1.020^{* *} \\
(0.519)\end{array}$ & $\begin{array}{l}-0.557 \\
(0.417)\end{array}$ & $\begin{array}{l}-0.003 \\
(0.616)\end{array}$ & $\begin{array}{l}-0.189 \\
(0.521)\end{array}$ \\
\hline AvailGas & $\begin{array}{c}-0.844^{*} \\
(0.507)\end{array}$ & $\begin{array}{c}0.239 \\
(0.401)\end{array}$ & $\begin{array}{l}-0.080 \\
(0.724)\end{array}$ & $\begin{array}{l}-0.745 \\
(0.592)\end{array}$ \\
\hline Hour 03 & $\begin{array}{c}1.267 \\
(1.316)\end{array}$ & $\begin{array}{l}-0.273 \\
(0.865)\end{array}$ & $\begin{array}{l}1.389 \\
(1.034)\end{array}$ & $\begin{array}{l}0.488 \\
(0.875)\end{array}$ \\
\hline Hour 06 & $\begin{array}{l}-2.545^{*} \\
(1.385)\end{array}$ & $\begin{array}{c}0.481 \\
(1.043)\end{array}$ & $\begin{array}{l}2.569^{*} \\
(1.544)\end{array}$ & $\begin{array}{l}2.947^{* *} \\
(1.287)\end{array}$ \\
\hline Hour 09 & $\begin{array}{l}1.269 \\
(2.098)\end{array}$ & $\begin{array}{c}2.291 \\
(1.511)\end{array}$ & $\begin{array}{c}6.537^{* * *} \\
(2.103)\end{array}$ & $\begin{array}{c}5.255^{* * *} \\
(1.831)\end{array}$ \\
\hline Hour 12 & $\begin{array}{l}6.443^{* *} \\
(3.278)\end{array}$ & $\begin{array}{l}3.816^{* *} \\
(1.724)\end{array}$ & $\begin{array}{l}5.796^{* *} \\
(2.545)\end{array}$ & $\begin{array}{l}4.760^{* *} \\
(2.156)\end{array}$ \\
\hline Hour 15 & $\begin{array}{l}4.636^{* *} \\
(2.085)\end{array}$ & $\begin{array}{l}2.864^{*} \\
(1.523)\end{array}$ & $\begin{array}{l}4.738^{* *} \\
(2.125)\end{array}$ & $\begin{array}{l}3.552^{*} \\
(1.875)\end{array}$ \\
\hline Hour 18 & $\begin{array}{l}-0.026 \\
(2.045)\end{array}$ & $\begin{array}{c}0.818 \\
(1.348)\end{array}$ & $\begin{array}{l}-3.095 \\
(2.305)\end{array}$ & $\begin{array}{l}-0.723 \\
(1.626)\end{array}$ \\
\hline Hour 21 & $\begin{array}{l}-0.711 \\
(1.627)\end{array}$ & $\begin{array}{c}0.571 \\
(1.322)\end{array}$ & $\begin{array}{c}-5.026^{* *} \\
(2.243)\end{array}$ & $\begin{array}{l}-2.702 \\
(1.820)\end{array}$ \\
\hline Month 02 & $\begin{array}{l}-0.154 \\
(1.828)\end{array}$ & $\begin{array}{l}-0.599 \\
(1.733)\end{array}$ & $\begin{array}{c}5.473 \\
(3.407)\end{array}$ & $\begin{array}{l}3.647 \\
(3.744)\end{array}$ \\
\hline Month 03 & $\begin{array}{l}-0.435 \\
(2.081)\end{array}$ & $\begin{array}{c}0.181 \\
(2.209)\end{array}$ & $\begin{array}{l}8.485^{*} \\
(4.416)\end{array}$ & $\begin{array}{c}4.762 \\
(3.595)\end{array}$ \\
\hline Month 04 & $\begin{array}{l}-1.030 \\
(2.765)\end{array}$ & $\begin{array}{l}-1.691 \\
(2.190)\end{array}$ & $\begin{array}{c}7.424^{* *} \\
(3.448)\end{array}$ & $\begin{array}{c}4.065 \\
(2.808)\end{array}$ \\
\hline Month 05 & $\begin{array}{c}0.975 \\
(3.017)\end{array}$ & $\begin{array}{l}1.540 \\
(2.400)\end{array}$ & $\begin{array}{c}10.748^{* * * *} \\
(3.763)\end{array}$ & $\begin{array}{l}5.259^{*} \\
(3.017)\end{array}$ \\
\hline Month 06 & $\begin{array}{c}4.274 \\
(3.325)\end{array}$ & $\begin{array}{l}1.221 \\
(2.447)\end{array}$ & $\begin{array}{c}7.922^{* *} \\
(3.595)\end{array}$ & $\begin{array}{c}2.925 \\
(3.135)\end{array}$ \\
\hline Month 07 & $\begin{array}{c}1.579 \\
(3.213)\end{array}$ & $\begin{array}{c}0.460 \\
(2.812)\end{array}$ & $\begin{array}{l}9.131^{* *} \\
(3.677)\end{array}$ & $\begin{array}{l}5.121^{*} \\
(3.058)\end{array}$ \\
\hline Month 08 & $\begin{array}{c}9.087^{* * *} \\
(3.208)\end{array}$ & $\begin{array}{l}3.640 \\
(2.401)\end{array}$ & $\begin{array}{c}13.668^{* * * *} \\
(3.748)\end{array}$ & $\begin{array}{l}8.576^{* *} \\
(3.641)\end{array}$ \\
\hline Month 09 & $\begin{array}{l}-0.308 \\
(2.519)\end{array}$ & $\begin{array}{c}2.634 \\
(2.202)\end{array}$ & $\begin{array}{l}6.570^{* *} \\
(2.964)\end{array}$ & $\begin{array}{c}2.991 \\
(2.747)\end{array}$ \\
\hline Month 10 & $\begin{array}{c}2.655 \\
(2.711)\end{array}$ & $\begin{array}{l}3.024 \\
(2.371)\end{array}$ & $\begin{array}{c}10.634^{* * *} \\
(3.119)\end{array}$ & $\begin{array}{c}8.732^{* * *} \\
(2.857)\end{array}$ \\
\hline Month 11 & $\begin{array}{c}0.676 \\
(2.678)\end{array}$ & $\begin{array}{c}0.616 \\
(1.987)\end{array}$ & $\begin{array}{c}8.151^{* *} \\
(3.341)\end{array}$ & $\begin{array}{l}6.141^{* *} \\
(3.086)\end{array}$ \\
\hline Month 12 & $\begin{array}{l}2.213 \\
(2.486)\end{array}$ & $\begin{array}{l}-1.895 \\
(1.756)\end{array}$ & $\begin{array}{l}5.445^{*} \\
(3.202)\end{array}$ & $\begin{array}{l}5.224^{*} \\
(2.815)\end{array}$ \\
\hline Constant & $\begin{array}{c}19.319 \\
(12.573) \\
\end{array}$ & $\begin{array}{c}-2.208 \\
(10.924) \\
\end{array}$ & $\begin{array}{l}-12.255 \\
(11.272) \\
\end{array}$ & $\begin{array}{l}10.652 \\
(9.427) \\
\end{array}$ \\
\hline Observations & 1,762 & 1,767 & 1,759 & 1,625 \\
\hline $\mathrm{R}^{2}$ & 0.396 & 0.396 & 0.457 & 0.389 \\
\hline Adjusted $R^{2}$ & 0.386 & 0.386 & 0.449 & 0.379 \\
\hline Res. Std. Error & $16.6(\mathrm{df}=1734)$ & $12.2(\mathrm{df}=1739)$ & $16.7(\mathrm{df}=1731)$ & $13.3(\mathrm{df}=1597)$ \\
\hline F Statistic & $42.060^{* * *}$ & $42.160^{* * *}$ & $54.014^{* * *}$ & $37.649^{* * *}$ \\
\hline Note: & & & ${ }^{*} \mathrm{p}<0.1$ & ${ }^{*} \mathrm{p}<0.05 ;{ }^{* * *} \mathrm{p}<0.01$ \\
\hline
\end{tabular}

the negative prices substantially increases the effects of both variables. Even when considering negative prices, however, the effect is not as strong as for medium residual loads, hence only partially confirming $\mathbf{H} \mathbf{2 b}$. 
It is also important to consider that not only the effect of wind updates differs across the residual load categories, but also the distributions of wind updates differ. This is due to the fact that low residual loads are associated with (and caused by) higher renewable energy feed-in (refer back to Figure 7). For high and medium residual load, the distributions are somewhat similar with $0.196 \pm 1.203$ and $0.178 \pm 1.151$ (mean \pm standard deviation). For low residual loads, however, the distributions are wider: $0.032 \pm 1.452$ when including negative prices and $0.002 \pm 1.397$ when excluding negative prices. This stems from the fact that larger amounts of wind energy (as is the case in lower residual load situations, on average), go along with wider error distributions, i.e. more frequent large over- or underestimations. This implies that the smaller effect of wind updates in the low residual load category may be augmented into an overall larger effect due to more frequent larger over- or underestimations of wind energy. It is noticeable that the average wind energy update is always positive (also see Table 2 and 3). This is due to right-skewed distributions of wind energy update. Beyond that, positive updates are in fact more common than negative updates, with 2968 observations with positive updates, compared to 2368 with negative updates. This can hint at a tendency to underestimate the available wind energy in the day-ahead market.

Table 4 also reveals that the dependency of intraday prices on day-ahead prices is much more pronounced during high and medium residual loads, with coefficients close to 0.9 . These coefficients drop to 0.5 and 0.7 for low residual loads without and with negative prices, respectively. This goes along with Figure 6 which shows large deviations of intraday prices from day-ahead prices in very low and low residual load situations. More intraday activity may be needed when renewable energy feed-in is high due to large uncertainties regarding available energy and greater subsequent balancing activity in the intraday market.

Noticeably, the dummy variables for morning and mid-day hours exhibit statistical significance most often. Thus, the intraday prices in these hours are fundamentally most different from the reference category (hour 0 ). Also, mostly summer months differ from the reference month (month 1, January) and their dummy variables are often of substantial size and significance. For instance, August exhibits large and significant coefficients which may rooted in the German school holiday system. In August, most regions are on holidays, especially the industry-heavy South, which may alter load and price patterns.

As an exploratory analysis, Figure 6 in Section 5 discusses positive and negative updates. It suggests that positive updates can turn positive day-ahead into negative intraday prices more frequently than the reversed case. To quantify if positive and negative updates affect intraday prices differently, i.e. if there are asymmetric price effects of positive and negative updates, the regression according to Eq. 2 is re-conducted for the same subsets. The difference is that negative and positive changes are considered as two separate variables. Both kinds of updates are considered as positive values which has to be kept in mind when interpreting the coefficients.

$$
\begin{aligned}
& \text { Price }_{t}^{\text {ID }}=\beta_{0}+\beta_{1} \text { Wind }_{t}^{D A}+\beta_{2 a} W_{i n d}^{\text {Update,pos }}+\beta_{2 b} \text { Wind }_{t}^{\text {Update,neg }}+ \\
& \beta_{3} \operatorname{Load}_{\mathrm{t}}^{\mathrm{DA}}+\beta_{4} \text { Solar }_{\mathrm{t}}^{\mathrm{DA}}+\beta_{5} \operatorname{Price}_{\mathrm{t}}^{\mathrm{DA}}+ \\
& \beta_{6} \text { Avail }_{t}^{\text {Lignite }}+\beta_{7} \text { Avail }{ }_{t}^{\text {HardCoal }}+\beta_{8} A v a i l_{t}^{\text {Nuclear }}+\beta_{9} A v a i l_{t}^{\text {Gas }}+ \\
& \mathbf{H} \boldsymbol{\eta}+\mathbf{M} \boldsymbol{\mu}+\epsilon_{\mathrm{t}}
\end{aligned}
$$


Table 5: Results for linear regressions for four different subsets of residual load, with separate positive and negative wind updates

\begin{tabular}{|c|c|c|c|c|}
\hline \multirow[b]{2}{*}{$\begin{array}{l}\text { Subset of } \\
\text { residual load }\end{array}$} & \multicolumn{4}{|c|}{ Dependent variable: Intraday price (PriceID) } \\
\hline & $\begin{array}{c}\text { High } \\
\text { (w/ neg. prices) }\end{array}$ & $\begin{array}{c}\text { Medium } \\
\text { (w/ neg. prices) }\end{array}$ & $\begin{array}{c}\text { Low } \\
\text { (w/ neg. prices) }\end{array}$ & $\begin{array}{c}\text { Low } \\
\text { (w/o neg. prices) }\end{array}$ \\
\hline WindDA & $\begin{array}{c}0.108 \\
(0.130)\end{array}$ & $\begin{array}{c}0.049 \\
(0.134)\end{array}$ & $\begin{array}{c}-0.380^{* * *} \\
(0.127)\end{array}$ & $\begin{array}{c}-0.220^{* *} \\
(0.105)\end{array}$ \\
\hline WindUpdatePos & $\begin{array}{l}-1.688^{* * *} \\
(0.347)\end{array}$ & $\begin{array}{l}-2.190^{* * *} \\
(0.592)\end{array}$ & $\begin{array}{l}-1.119^{* *} \\
(0.541)\end{array}$ & $\begin{array}{l}-0.647 \\
(0.535)\end{array}$ \\
\hline WindUpdateNeg & $\begin{array}{l}1.313^{*} \\
(0.773)\end{array}$ & $\begin{array}{c}0.129 \\
(0.586)\end{array}$ & $\begin{array}{l}0.998^{*} \\
(0.543)\end{array}$ & $\begin{array}{l}0.935^{* *} \\
(0.432)\end{array}$ \\
\hline LoadDA & $\begin{array}{c}0.009 \\
(0.153)\end{array}$ & $\begin{array}{c}0.148 \\
(0.133)\end{array}$ & $\begin{array}{c}0.646^{* * *} \\
(0.166)\end{array}$ & $\begin{array}{c}0.533^{* * *} \\
(0.137)\end{array}$ \\
\hline SolarDA & $\begin{array}{l}-0.264 \\
(0.256)\end{array}$ & $\begin{array}{c}-0.265^{* *} \\
(0.124)\end{array}$ & $\begin{array}{l}-0.724^{* * * *} \\
(0.187)\end{array}$ & $\begin{array}{l}-0.473^{* * *} \\
(0.138)\end{array}$ \\
\hline PriceDA & $\begin{array}{c}0.888^{* * *} \\
(0.072)\end{array}$ & $\begin{array}{c}0.899^{* * *} \\
(0.050)\end{array}$ & $\begin{array}{c}0.713^{* * *} \\
(0.073)\end{array}$ & $\begin{array}{c}0.501^{* * * *} \\
(0.079)\end{array}$ \\
\hline AvailLignite & $\begin{array}{l}-0.233 \\
(0.495)\end{array}$ & $\begin{array}{c}0.301 \\
(0.406)\end{array}$ & $\begin{array}{l}-1.001 \\
(0.654)\end{array}$ & $\begin{array}{l}-0.546 \\
(0.542)\end{array}$ \\
\hline AvailHardCoal & $\begin{array}{c}0.261 \\
(0.464)\end{array}$ & $\begin{array}{l}-0.444 \\
(0.396)\end{array}$ & $\begin{array}{c}0.339 \\
(0.539)\end{array}$ & $\begin{array}{l}-0.643 \\
(0.444)\end{array}$ \\
\hline AvailNuclear & $\begin{array}{l}-1.021^{* *} \\
(0.519)\end{array}$ & $\begin{array}{l}-0.565 \\
(0.415)\end{array}$ & $\begin{array}{l}-0.005 \\
(0.615)\end{array}$ & $\begin{array}{l}-0.185 \\
(0.519)\end{array}$ \\
\hline AvailGas & $\begin{array}{l}-0.837 \\
(0.510)\end{array}$ & $\begin{array}{c}0.316 \\
(0.403)\end{array}$ & $\begin{array}{l}-0.076 \\
(0.721)\end{array}$ & $\begin{array}{l}-0.758 \\
(0.591)\end{array}$ \\
\hline Hour 03 & $\begin{array}{c}1.279 \\
(1.313)\end{array}$ & $\begin{array}{l}-0.294 \\
(0.864)\end{array}$ & $\begin{array}{l}1.396 \\
(1.025)\end{array}$ & $\begin{array}{c}0.476 \\
(0.872)\end{array}$ \\
\hline Hour 06 & $\begin{array}{l}-2.541^{*} \\
(1.384)\end{array}$ & $\begin{array}{c}0.454 \\
(1.046)\end{array}$ & $\begin{array}{l}2.580^{*} \\
(1.538)\end{array}$ & $\begin{array}{l}2.927^{* *} \\
(1.280)\end{array}$ \\
\hline Hour 09 & $\begin{array}{c}1.271 \\
(2.095)\end{array}$ & $\begin{array}{l}2.490^{*} \\
(1.509)\end{array}$ & $\begin{array}{c}6.555^{* * *} \\
(2.113)\end{array}$ & $\begin{array}{c}5.217^{* * * *} \\
(1.842)\end{array}$ \\
\hline Hour 12 & $\begin{array}{l}6.486^{* *} \\
(3.266)\end{array}$ & $\begin{array}{l}4.126^{* *} \\
(1.716)\end{array}$ & $\begin{array}{l}5.817^{* *} \\
(2.576)\end{array}$ & $\begin{array}{l}4.719^{* *} \\
(2.180)\end{array}$ \\
\hline Hour 15 & $\begin{array}{l}4.669^{* *} \\
(2.088)\end{array}$ & $\begin{array}{l}3.079^{* *} \\
(1.523)\end{array}$ & $\begin{array}{l}4.762^{* *} \\
(2.141)\end{array}$ & $\begin{array}{l}3.497^{*} \\
(1.896)\end{array}$ \\
\hline Hour 18 & $\begin{array}{l}-0.014 \\
(2.045)\end{array}$ & $\begin{array}{l}1.013 \\
(1.347)\end{array}$ & $\begin{array}{l}-3.078 \\
(2.302)\end{array}$ & $\begin{array}{l}-0.754 \\
(1.631)\end{array}$ \\
\hline Hour 21 & $\begin{array}{l}-0.690 \\
(1.623)\end{array}$ & $\begin{array}{c}0.816 \\
(1.364)\end{array}$ & $\begin{array}{l}-5.009^{* *} \\
(2.244)\end{array}$ & $\begin{array}{l}-2.722 \\
(1.824)\end{array}$ \\
\hline Month 02 & $\begin{array}{l}-0.204 \\
(1.842)\end{array}$ & $\begin{array}{l}-0.965 \\
(1.720)\end{array}$ & $\begin{array}{l}5.445 \\
(3.395)\end{array}$ & $\begin{array}{c}3.707 \\
(3.698)\end{array}$ \\
\hline Month 03 & $\begin{array}{l}-0.459 \\
(2.079)\end{array}$ & $\begin{array}{c}0.018 \\
(2.161)\end{array}$ & $\begin{array}{l}8.468^{*} \\
(4.391)\end{array}$ & $\begin{array}{c}4.809 \\
(3.546)\end{array}$ \\
\hline Month 04 & $\begin{array}{l}-1.058 \\
(2.769)\end{array}$ & $\begin{array}{l}-1.759 \\
(2.188)\end{array}$ & $\begin{array}{l}7.417^{* *} \\
(3.448)\end{array}$ & $\begin{array}{c}4.082 \\
(2.777)\end{array}$ \\
\hline Month 05 & $\begin{array}{c}0.925 \\
(3.017)\end{array}$ & $\begin{array}{l}1.515 \\
(2.362)\end{array}$ & $\begin{array}{c}10.734^{* * *} \\
(3.753)\end{array}$ & $\begin{array}{l}5.286^{*} \\
(2.988)\end{array}$ \\
\hline Month 06 & $\begin{array}{c}4.261 \\
(3.320)\end{array}$ & $\begin{array}{l}1.229 \\
(2.411)\end{array}$ & $\begin{array}{l}7.914^{* *} \\
(3.595)\end{array}$ & $\begin{array}{l}2.937 \\
(3.114)\end{array}$ \\
\hline Month 07 & $\begin{array}{l}1.567 \\
(3.209)\end{array}$ & $\begin{array}{l}0.735 \\
(2.722)\end{array}$ & $\begin{array}{l}9.124^{* *} \\
(3.677)\end{array}$ & $\begin{array}{l}5.131^{*} \\
(3.040)\end{array}$ \\
\hline Month 08 & $\begin{array}{c}9.099^{* * * *} \\
(3.209)\end{array}$ & $\begin{array}{c}3.699 \\
(2.337)\end{array}$ & $\begin{array}{c}13.668^{* * * *} \\
(3.755)\end{array}$ & $\begin{array}{l}8.569^{* *} \\
(3.622)\end{array}$ \\
\hline Month 09 & $\begin{array}{l}-0.349 \\
(2.516)\end{array}$ & $\begin{array}{l}2.412 \\
(2.192)\end{array}$ & $\begin{array}{l}6.564^{* *} \\
(2.966)\end{array}$ & $\begin{array}{l}2.997 \\
(2.727)\end{array}$ \\
\hline Month 10 & $\begin{array}{l}2.649 \\
(2.705)\end{array}$ & $\begin{array}{l}2.863 \\
(2.381)\end{array}$ & $\begin{array}{c}10.629^{* * *} \\
(3.126)\end{array}$ & $\begin{array}{c}8.742^{* * *} \\
(2.831)\end{array}$ \\
\hline Month 11 & $\begin{array}{c}0.632 \\
(2.667)\end{array}$ & $\begin{array}{c}0.267 \\
(1.977)\end{array}$ & $\begin{array}{l}8.141^{* *} \\
(3.339)\end{array}$ & $\begin{array}{l}6.163^{* *} \\
(3.066)\end{array}$ \\
\hline Month 12 & $\begin{array}{c}2.167 \\
(2.511)\end{array}$ & $\begin{array}{l}-2.326 \\
(1.835)\end{array}$ & $\begin{array}{l}5.441^{*} \\
(3.204)\end{array}$ & $\begin{array}{l}5.234^{*} \\
(2.789)\end{array}$ \\
\hline Constant & $\begin{array}{c}19.466 \\
(12.569)\end{array}$ & $\begin{array}{l}-2.077 \\
(10.967)\end{array}$ & $\begin{array}{l}-12.207 \\
(11.303)\end{array}$ & $\begin{array}{l}10.607 \\
(9.440)\end{array}$ \\
\hline Observations & 1,762 & 1,767 & 1,759 & 1,625 \\
\hline $\mathrm{R}^{2}$ & 0.396 & 0.398 & 0.457 & 0.389 \\
\hline Adjusted $\mathrm{R}^{2}$ & 0.386 & 0.388 & 0.448 & 0.378 \\
\hline Res. Std. Error & $16.6(\mathrm{df}=1733)$ & $12.1(\mathrm{df}=1738)$ & $16.7(\mathrm{df}=1730)$ & $13.3(\mathrm{df}=1596)$ \\
\hline F Statistic & $40.542^{* * *}$ & $41.039^{* * *}$ & $52.056^{* * *}$ & $36.290^{* * *}$ \\
\hline Note: & & & ${ }^{*} \mathrm{p}<0.1$ & $\mathrm{p}<0.05 ;{ }^{* * *} \mathrm{p}<0.01$ \\
\hline
\end{tabular}

Table 5 shows the results of this additional analysis. These results suggest that positive wind energy updates generally affect intraday prices more substantially than negative updates, hinting 
at asymmetric price effects and therefore confirming H4. For situations of low residual load, a large negative effect of positive updates (compared to the positive effect of negative updates) can be rooted in the occurrence of negative prices which is confirmed by the last two columns of Table 5. The effect of positive updates increases from a statistically insignificant $-0.65 \frac{\mathrm{EUR} / \mathrm{MWh}_{\mathrm{el}}}{\mathrm{GW}_{\text {Wind }}}$ to a significant $-1.12 \frac{\mathrm{EUR} / \mathrm{MWh}_{\mathrm{el}}}{\mathrm{GW}_{\text {Wind }}}$ when negative prices are considered, whereas the effect of negative updates stays rather constant. For high residual loads, the effects of positive and negative updates are similar (-1.69 vs. $\left.1.31 \frac{\mathrm{EUR} / \mathrm{MWh}_{\mathrm{el}}}{\mathrm{GW}_{\text {Wind }}}\right)$, although the effect of positive updates is larger and more highly significant. For medium residual loads, the interpretation is more challenging. Additional wind energy leads to clear price drops, an expected result. With negative updates, however, the positive price changes are insubstantial and insignificant. These situations may be characterized by many active base/mid-load unit that can easily increase their output when negative wind energy updates occur. This ability may stem from spinning-up reserves of these units. With positive updates, however, units appear to drop out of the market, resulting in units with lower marginal costs to set the price.

\subsection{Non-linear model for different situations of residual load}

The above-described conclusion initiates the challenge to measure the effect of wind energy updates on intraday prices dependent upon different load situations. The intuitive method for measuring this would be an interaction term between the wind update and the load variable. However, no clear sign could be attributed to the coefficient of such a variable since both increasing and decreasing amounts of load (deviating from the mean load) lead to an increased negative effect of wind updates on intraday prices. Thus, for the non-linear model, the interaction term of Wind $\mathrm{d}_{\mathrm{t}}^{\mathrm{update}}$ and DevLoad $d_{t}^{2}$ is added to Eq. 2, resulting in Eq. 3:

$$
\begin{aligned}
& \operatorname{Price}_{t}^{I D}=\beta_{0}+\beta_{1} W_{i n d}^{D A}+\beta_{2} W_{i n d}^{\text {Update }}+\beta_{3} W_{i n d}^{\text {Update }} \cdot \operatorname{DevLoad}_{t}^{2}+ \\
& \beta_{4} \operatorname{Load}_{t}^{\text {DA }}+\beta_{5} \text { Solar }_{t}^{\text {DA }}+\beta_{6} \text { Avail }_{t}^{\text {Lignite }}+\beta_{7} \text { Avail }_{t}^{\text {HardCoal }}+ \\
& \beta_{8} \text { Avail Nuclear }+\beta_{9} \text { Avail }{ }_{t}^{\text {Gas }}+\mathbf{H \eta}+\mathbf{M} \boldsymbol{\mu}+\epsilon_{\mathrm{t}}
\end{aligned}
$$

The term DevLoad $d_{t}^{2}$ expresses the squared term of the load deviation from the mean load. This way, any deviation from the mean can be assigned a positive or negative value. The underlying hypothesis is that the coefficient of this term will be assigned a negative values. How wind energy updates affect intraday price therefore depends on the level of load.

The goal is to measure these non-linear effects for different categories of residual loads, Table 6 summarizes the residual load for all available hours and forms the basis for defining the categories for different residual loads. Hour $0 \& 3$ are characterized by low average residual load and low variance in residual load. Hour $12 \& 15$ are characterized by a similar low average residual load but the variance is greater compared to the previous category, indicated by lower minimum and 1st quantile values and higher maximum and 3rd quantile values. Hour $6 \& 9$ show larger average residual loads and are characterized by a large variance in values. Hour $18 \& 21$ show the highest average values but have a low to medium magnitude of variance.

Table 7 displays the regression results for these entire dataset (all hours) as well as for four 
Table 6: Summary statistics of residual load by hour

\begin{tabular}{lrrrrrrrr}
\hline Hour & Min & 1st Qu. & Median & Mean & 3rd Qu. & Max & St. Dev. & Category \\
\hline 00 & 5.30 & 33.12 & 38.39 & 36.88 & 42.31 & 52.67 & 8.11 & Low average and low variance \\
03 & 4.04 & 29.77 & 35.88 & 34.32 & 39.69 & 50.73 & 8.16 & \\
06 & 2.63 & 34.45 & 42.83 & 41.35 & 49.94 & 61.23 & 10.96 & Medium average and high variance \\
09 & 1.86 & 31.98 & 40.77 & 40.09 & 48.09 & 66.31 & 12.21 & \\
12 & -4.15 & 26.14 & 34.52 & 34.35 & 42.24 & 64.96 & 12.51 & Low average and high variance \\
15 & -2.06 & 28.01 & 37.09 & 36.81 & 45.73 & 66.97 & 13.28 & \\
18 & 20.72 & 41.61 & 48.58 & 48.27 & 54.92 & 71.57 & 10.07 & High average and low/medium variance \\
21 & 11.51 & 41.35 & 47.31 & 45.93 & 51.95 & 62.92 & 8.37 & \\
\hline
\end{tabular}

subsets of the data, detailed in Table 6. The categorical effects are visualized in Figure 7. Furthermore, for each category, the ranges of the loads are indicated by dashed vertical lines (minimum and maximum per category) to show what part of the estimated curve is out of sample. The entire displayed range corresponds to the overall available range of loads.

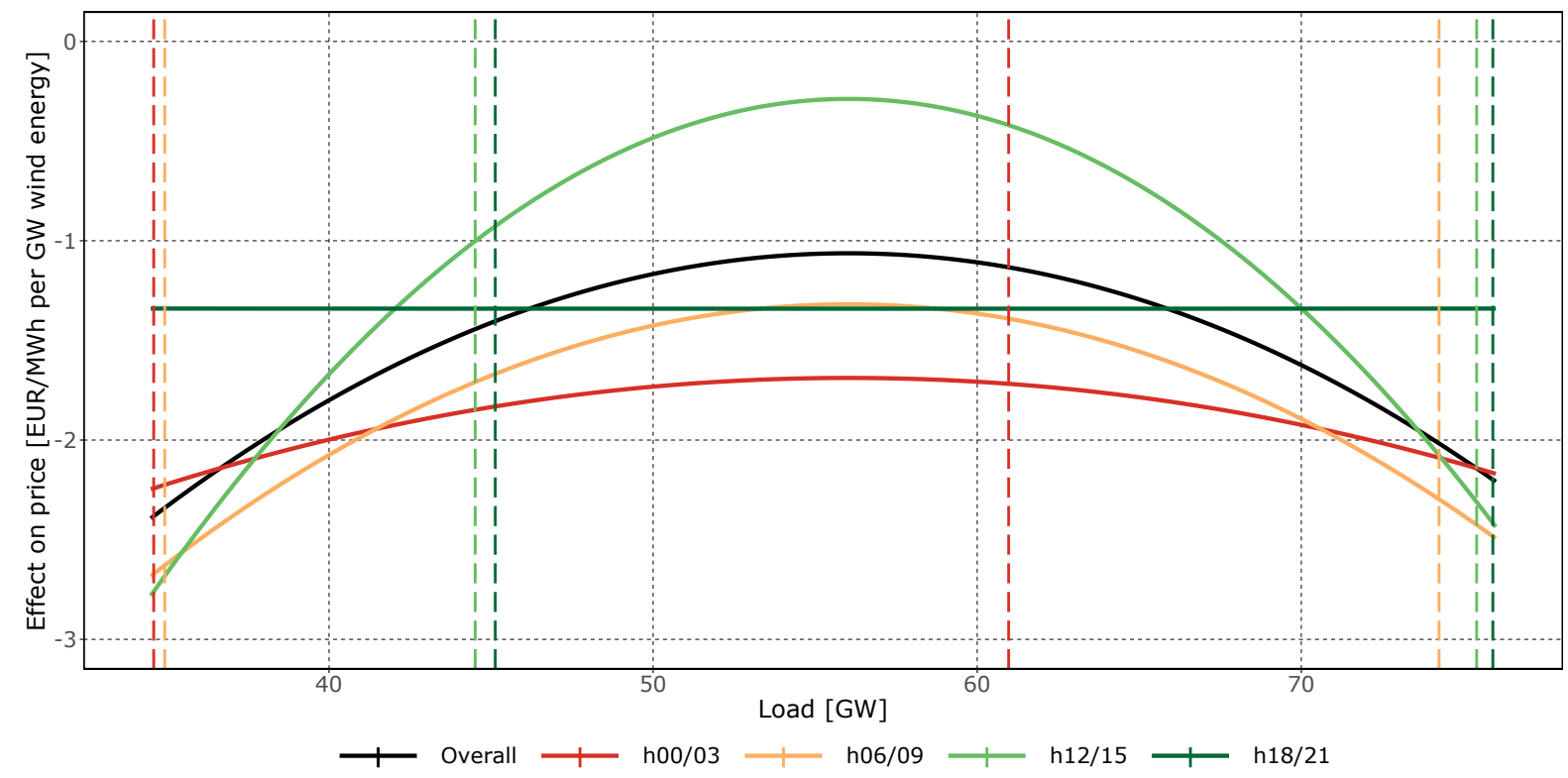

Figure 7: Effect of wind energy updates on intraday prices (price change in EUR/MWh per GW wind) for different levels of residual load, computed as an overall effect (entire data set), and separately for hour 0 \& 3 , hour $6 \& 9$, hour $12 \& 15$, and hour $18 \& 21$ (DevLoad computed with overall average of Load).

Noticeably, the $\mathrm{R}^{2}$-values in Table 7 are larger than in Table 4 . This signifies added explanatory power due to the inclusion of the quadratic term. The analysis suggest that different hours, i.e. different residual load situations, are affected by wind energy updates to varying degrees. For night hours $0 \& 3$, the effect of additional wind feed-in is always large and remains in a rather narrow bandwidth between around roughly $-2 \frac{\mathrm{EUR} / \mathrm{MWh}}{\mathrm{GW}_{\text {Wind }}}$. For morning hours $6 \& 9$, the effect is at least $-1.3 \frac{\mathrm{EUR} / \mathrm{MWh}_{\mathrm{el}}}{\mathrm{GW}_{\text {Wind }}}$ and larger at low and and high loads. Mid-day hours $12 \& 15$ are affected very differently, depending on the load, with the effect being at least $-0.28 \frac{\mathrm{EUR} / \mathrm{MWh}_{\mathrm{el}}}{\mathrm{GW}_{\text {Wind }}}$ and substantially larger at low and and high loads. Lastly, evening hours 18 \& 21 show a virtually constant effect at roughly $-1.34 \frac{\mathrm{EUR} / \mathrm{MWh}_{\mathrm{el}}}{\mathrm{GW}_{\mathrm{Wind}}}$. Generally, the magnitudes of these coefficients are smaller compared to the results of Ziel (2017) but the estimated results reconfirm that the price 
Table 7: Results for linear regressions for different hours, with a non-linear consideration of load

\begin{tabular}{|c|c|c|c|c|c|}
\hline \multirow[b]{2}{*}{ Subset of hours } & \multicolumn{5}{|c|}{ Dependent variable: Intraday price (PriceID) } \\
\hline & All & $00 / 03$ & $06 / 09$ & $12 / 15$ & $18 / 21$ \\
\hline WindDA & $\begin{array}{c}-0.133^{* *} \\
(0.062)\end{array}$ & $\begin{array}{c}-0.242^{* *} \\
(0.106)\end{array}$ & $\begin{array}{l}0.0005 \\
(0.096)\end{array}$ & $\begin{array}{c}-0.182^{* *} \\
(0.088)\end{array}$ & $\begin{array}{c}-0.151 \\
(0.099)\end{array}$ \\
\hline WindUpdate & $\begin{array}{c}-1.063^{* * *} \\
(0.282)\end{array}$ & $\begin{array}{c}-1.688^{* *} \\
(0.855)\end{array}$ & $\begin{array}{c}-1.319^{* * *} \\
(0.436)\end{array}$ & $\begin{array}{c}-0.288 \\
(0.534)\end{array}$ & $\begin{array}{c}-1.341^{* * *} \\
(0.408)\end{array}$ \\
\hline WindUp. DevLoad ${ }^{2}$ & $\begin{array}{l}-0.003 \\
(0.002)\end{array}$ & $\begin{array}{c}-0.001 \\
(0.006)\end{array}$ & $\begin{array}{l}-0.003 \\
(0.005)\end{array}$ & $\begin{array}{l}-0.005 \\
(0.005)\end{array}$ & $\begin{array}{c}0.00000 \\
(0.004)\end{array}$ \\
\hline LoadDA & $\begin{array}{c}0.276^{* * *} \\
(0.075)\end{array}$ & $\begin{array}{c}0.519^{* * * *} \\
(0.164)\end{array}$ & $\begin{array}{l}0.300^{* *} \\
(0.129)\end{array}$ & $\begin{array}{c}0.324^{* * *} \\
(0.119)\end{array}$ & $\begin{array}{c}0.170 \\
(0.123)\end{array}$ \\
\hline SolarDA & $\begin{array}{c}-0.499^{* * *} \\
(0.095)\end{array}$ & & $\begin{array}{l}-0.045 \\
(0.194)\end{array}$ & $\begin{array}{c}-0.544^{* * *} \\
(0.175)\end{array}$ & $\begin{array}{c}-0.844^{* *} \\
(0.363)\end{array}$ \\
\hline PriceDA & $\begin{array}{c}0.817^{* * * *} \\
(0.048)\end{array}$ & $\begin{array}{c}0.792^{* * *} \\
(0.074)\end{array}$ & $\begin{array}{c}0.743^{* * *} \\
(0.082)\end{array}$ & $\begin{array}{c}0.824^{* * * *} \\
(0.091)\end{array}$ & $\begin{array}{c}0.890^{* * * *} \\
(0.082)\end{array}$ \\
\hline AvailLignite & $\begin{array}{l}-0.237 \\
(0.337)\end{array}$ & $\begin{array}{c}-0.936^{* *} \\
(0.394)\end{array}$ & $\begin{array}{c}-0.233 \\
(0.568)\end{array}$ & $\begin{array}{c}-0.286 \\
(0.646)\end{array}$ & $\begin{array}{c}0.298 \\
(0.552)\end{array}$ \\
\hline AvailHardCoal & $\begin{array}{c}0.093 \\
(0.324)\end{array}$ & $\begin{array}{c}-0.079 \\
(0.458)\end{array}$ & $\begin{array}{c}-0.142 \\
(0.481)\end{array}$ & $\begin{array}{c}1.023 \\
(0.649)\end{array}$ & $\begin{array}{l}-0.399 \\
(0.581)\end{array}$ \\
\hline AvailNuclear & $\begin{array}{l}-0.568 \\
(0.375)\end{array}$ & $\begin{array}{c}0.254 \\
(0.478)\end{array}$ & $\begin{array}{c}-1.199^{* *} \\
(0.567)\end{array}$ & $\begin{array}{c}-0.195 \\
(0.701)\end{array}$ & $\begin{array}{l}-1.126^{*} \\
(0.622)\end{array}$ \\
\hline AvailGas & $\begin{array}{l}-0.251 \\
(0.385)\end{array}$ & $\begin{array}{c}0.470 \\
(0.447)\end{array}$ & $\begin{array}{c}0.607 \\
(0.595)\end{array}$ & $\begin{array}{l}-1.138^{*} \\
(0.646)\end{array}$ & $\begin{array}{l}-1.032^{*} \\
(0.563)\end{array}$ \\
\hline Hour 03 & $\begin{array}{c}0.323 \\
(0.601)\end{array}$ & $\begin{array}{c}0.783 \\
(0.714)\end{array}$ & & & \\
\hline Hour 06 & $\begin{array}{c}0.047 \\
(0.746)\end{array}$ & & & & \\
\hline Hour 09 & $\begin{array}{c}4.191^{* * *} \\
(1.243)\end{array}$ & & $\begin{array}{c}0.629 \\
(1.578)\end{array}$ & & \\
\hline Hour 12 & $\begin{array}{c}6.168^{* * *} \\
(1.640)\end{array}$ & & & & \\
\hline Hour 15 & $\begin{array}{c}4.674^{* * *} \\
(1.244)\end{array}$ & & & $\begin{array}{l}-1.661 \\
(1.068)\end{array}$ & \\
\hline Hour 18 & $\begin{array}{c}0.547 \\
(1.059)\end{array}$ & & & & \\
\hline Hour 21 & $\begin{array}{l}-0.086 \\
(0.814)\end{array}$ & & & & $\begin{array}{l}-1.605 \\
(1.559)\end{array}$ \\
\hline Month 02 & $\begin{array}{c}1.162 \\
(1710)\end{array}$ & $\begin{array}{l}4.327^{*} \\
(2.463)\end{array}$ & $\begin{array}{c}0.507 \\
(1.971)\end{array}$ & $\begin{array}{c}-2.532 \\
(2.950)\end{array}$ & $\begin{array}{l}1.594 \\
(2.682)\end{array}$ \\
\hline Month 03 & $\begin{array}{c}2.467 \\
(2.170)\end{array}$ & $\begin{array}{c}2.903 \\
(2.602)\end{array}$ & $\begin{array}{c}1.163 \\
(2.790)\end{array}$ & $\begin{array}{c}0.996 \\
(3.899)\end{array}$ & $\begin{array}{c}3.717 \\
(2.394)\end{array}$ \\
\hline Month 04 & $\begin{array}{c}1.795 \\
(1.956)\end{array}$ & $\begin{array}{l}4.234 \\
(2.814)\end{array}$ & $\begin{array}{l}-0.065 \\
(2.306)\end{array}$ & $\begin{array}{c}2.689 \\
(3.784)\end{array}$ & $\begin{array}{c}0.255 \\
(3.028)\end{array}$ \\
\hline Month 05 & $\begin{array}{l}4.992^{* *} \\
(2.065)\end{array}$ & $\begin{array}{l}6.504^{* *} \\
(3.048)\end{array}$ & $\begin{array}{l}1.414 \\
(2.544)\end{array}$ & $\begin{array}{c}6.144 \\
(4.530)\end{array}$ & $\begin{array}{l}5.182 \\
(3.158)\end{array}$ \\
\hline Month 06 & $\begin{array}{l}4.676^{* *} \\
(2.028)\end{array}$ & $\begin{array}{l}5.171^{*} \\
(2.981)\end{array}$ & $\begin{array}{c}3.390 \\
(2.495)\end{array}$ & $\begin{array}{c}3.460 \\
(4.084)\end{array}$ & $\begin{array}{l}5.970^{* *} \\
(3.022)\end{array}$ \\
\hline Month 07 & $\begin{array}{l}4.254^{* *} \\
(2.139)\end{array}$ & $\begin{array}{c}4.116 \\
(3.239)\end{array}$ & $\begin{array}{c}4.063 \\
(2.492)\end{array}$ & $\begin{array}{c}4.239 \\
(4.731)\end{array}$ & $\begin{array}{c}3.978 \\
(3.323)\end{array}$ \\
\hline Month 08 & $\begin{array}{c}9.063^{* * *} \\
(2.162)\end{array}$ & $\begin{array}{l}6.717^{* *} \\
(3.099)\end{array}$ & $\begin{array}{c}10.801^{* * *} \\
(2.461)\end{array}$ & $\begin{array}{l}8.252^{* *} \\
(4.108)\end{array}$ & $\begin{array}{c}10.084^{* * *} \\
(2.929)\end{array}$ \\
\hline Month 09 & $\begin{array}{c}3.057 \\
(1.864)\end{array}$ & $\begin{array}{l}4.901^{*} \\
(2.832)\end{array}$ & $\begin{array}{c}6.873^{* * *} \\
(2.012)\end{array}$ & $\begin{array}{c}-1.451 \\
(3.896)\end{array}$ & $\begin{array}{c}2.184 \\
(2.486)\end{array}$ \\
\hline Month 10 & $\begin{array}{c}6.083^{* * *} \\
(1.910)\end{array}$ & $\begin{array}{l}6.489^{* *} \\
(2.606)\end{array}$ & $\begin{array}{c}7.939^{* * *} \\
(2.250)\end{array}$ & $\begin{array}{c}5.352 \\
(3.356)\end{array}$ & $\begin{array}{c}4.143 \\
(2.630)\end{array}$ \\
\hline Month 11 & $\begin{array}{c}3.149 \\
(1.990)\end{array}$ & $\begin{array}{c}3.004 \\
(2.581)\end{array}$ & $\begin{array}{c}5.624^{* * *} \\
(2.156)\end{array}$ & $\begin{array}{c}4.312 \\
(3.265)\end{array}$ & $\begin{array}{l}-0.688 \\
(2.363)\end{array}$ \\
\hline Month 12 & $\begin{array}{l}1.994 \\
(2.052)\end{array}$ & $\begin{array}{l}1.763 \\
(2.803)\end{array}$ & $\begin{array}{c}2.114 \\
(2.027)\end{array}$ & $\begin{array}{c}2.075 \\
(3.251)\end{array}$ & $\begin{array}{c}1.914 \\
(2.402)\end{array}$ \\
\hline Constant & $\begin{array}{l}-0.526 \\
(6.617)\end{array}$ & $\begin{array}{l}-9.016 \\
(9.533)\end{array}$ & $\begin{array}{c}0.976 \\
(9.964)\end{array}$ & $\begin{array}{c}-2.252 \\
(13.934)\end{array}$ & $\begin{array}{c}11.678 \\
(11.906)\end{array}$ \\
\hline Observations & 5,288 & 1,332 & 1,322 & 1,322 & 1,322 \\
\hline $\mathrm{R}^{2}$ & 0.535 & 0.546 & 0.493 & 0.528 & 0.506 \\
\hline Adjusted $\mathrm{R}^{2}$ & 0.533 & 0.538 & 0.484 & 0.520 & 0.498 \\
\hline Res. Std. Error & $15.3(\mathrm{df}=5259)$ & $11.9(\mathrm{df}=1310)$ & $15.6(\mathrm{df}=1299)$ & $17.1(\mathrm{df}=1299)$ & $15.9(\mathrm{df}=1299)$ \\
\hline F Statistic & $216.514^{* * *}$ & $74.887^{* * *}$ & $57.402^{* * *}$ & $65.993^{* * *}$ & $60.480^{* * *}$ \\
\hline Note: & & & & ${ }^{*} \mathrm{p}<0.1 ;{ }^{* *}$ & $<0.05 ;{ }^{* * *} \mathrm{p}<0.01$ \\
\hline
\end{tabular}

effect depends on the hour of the day.

These results reconfirm $\mathbf{H} 1 \& \mathbf{2} / \mathbf{a} / \mathbf{b}$ as they show that the effect of wind updates on intraday 
prices has different magnitudes, depending on the residual load situation (contrary to Kiesel and Paraschiv, 2017). It also suggests that the variance of this effect for varying loads within the categories is vastly different across hours. For hours with low and medium average residual loads, the size of the effect strongly depends on the given load. In hours with high average residual loads, the effect is rather static. It is important to add, however, that that quadratic term's coefficients are statistically insignificant. Much explanatory power is absorbed by the variables Wind $\mathrm{d}_{\mathrm{t}}^{\text {update }}$ and $\operatorname{Load}_{\mathrm{t}}^{\mathrm{DA}}$ which can help explain the insignificance. The VIF of the interaction term lies between 1.6 and 2.8, depending on the subset. This indicates the presence of slight multicollinearity, further reducing the coefficients' significance.

\subsection{Implications of results}

The results imply that different risk assessments are needed dependent upon the predicted residual load as an approximation of the position within the merit order. While the price uncertainties are larger for high residual loads, low residual loads exhibit more frequent negative prices and larger average forecast errors. These situations can lead to strategic behavior of wind park operators on the day-ahead market, as there are different penalties for short and long positions. Concretely, marketers of wind energy may have an incentive to underestimate renewable feed-in on the day-ahead market due to larger additional costs in case of overestimations (cf. Section 3). This suspicion is confirmed by more frequent positive than negative wind energy updates, i.e. more frequent under- than overestimations.

The wind energy-related uncertainties may also have implication for balancing markets. Balancing strategies can gain in importance when the uncertainty of forecast errors increases. This can be situations-dependent, i.e. more pronounced in situations of low residual load, but also a long-term trend with greater levels of renewable feed-in. These strategies may emerge when the costs for intraday balancing substantially differ from balancing costs for control energy. The market design is decisive in avoiding asymmetries and discouraging from strategic behavior.

Also, the price uncertainties due to forecast errors will augment the role and importance of technologies that provide flexibility (cf. Zöphel et al., 2018) for situations which forecast errors are costly. With more frequent situations of low residual load flexibility providers would benefit and the flexibility of conventional power plants is needed to cover high residual loads. The challenge is not limited to managing renewable energy feed-in by counteracting it with flexibility. The significance of connected markets with sufficient transmission and cross-border capacities gains in importance to aid the integration of renewable energy within and between countries. With a rising interconnection of market, there is an increasing possibility to utilize possible balancing effects of forecast errors across wind parks. However, simultaneous over- or underestimations of many wind turbine locations (Schönheit and Möst, 2019) may still occur.

\section{Conclusion and implications}

This contribution analyzes and quantifies the effect of wind energy on intraday prices, particularly of corrective short-term updates in wind energy forecasts. The hypotheses are derived from the 
merit order theory. The exploratory and regression model-based analyses confirm most hypothesis fully $(\mathbf{H} 1 / 2 / 2 a / 3 / 4)$ and one partially $(\mathbf{H} 2 \mathbf{b})$. The results show that the effect of wind energy updates on prices is negative in all cases (H1). The effect's magnitude depends on the residual load as an approximation of the position within the merit order (H2). The effect for high residual loads is largest(H2a), rather static and only slightly asymmetrical (H4). The effect is of medium magnitude for medium residual loads and largely depends on the given load. The effects of positive and negative updates are very asymmetrical (H4). The negative effect during low residual loads appears to be caused by negative prices (confirming $\mathbf{H} \mathbf{2} \mathbf{b}$ ), as the results show that switches from positive day-ahead prices to negative intraday prices occur more often than the reversed case (H3). The effect is generally smaller than for medium residual loads (not confirming $\mathbf{H 2 b}$ ), the effect depends largely on the load and is slightly asymmetrical (H4). However, the price effect is likely augmented by more frequent large wind energy updates in situations of low residual load which would confirm both aspects of $\mathbf{H} \mathbf{2} \mathbf{b}$.

This analysis discusses implications of the results, such as different risk assessments, dependent on the predicted residual load, the possibility of strategic underestimations of wind energy and strategic behavior on balancing markets. Also, the increasing role of flexibilities within power sectors is highlighted due to larger shares of renewable energy. Further research is needed to investigate the possible strategic behavior due to wind energy-related forecasts errors. Additionally, this analysis should be re-conducted for other countries with large renewable generation capacities to check if the results can be generalized.

\section{References}

50Hertz, Amprion, TenneT, and TransnetBW (2019). EEG-Anlagenstammdaten zur Jahresabrechnung 2018. https: / / www . netztransparenz. de/EEG/Anlagenstammdaten, accessed on 13.01.2020.

Clò, S., Cataldi, A., and Zoppoli, P. (2015). The merit-order effect in the italian power market: The impact of solar and wind generation on national wholesale electricity prices. Energy Policy, 77:79-88.

Copernicus Atmosphere Monitoring Service (2020). CAMS Near-real-time. https : / / apps . ecmwf . int / datasets/data/cams-nrealtime/, accessed on 03.01.2020.

Copernicus Climate Change Service (C3S) (2018). ERA5: Fifth generation of ECMWF atmospheric reanalyses of the global climate. C3S Climate Data Store (CDS). https://apps.ecmwf.int/ data-catalogues/era 5/?class=ea, accessed on 05.12.2018.

Eising, M., Hobbie, H., and Möst, D. (2020). Future wind and solar power market values in germany evidence of spatial and technological dependencies? Energy Economics.

ENTSO-E (2020). ENTSO-E Transperency Platform. https://transparency.entsoe.eu/, accessed on 24.03.2020.

Gelabert, L., Labandeira, X., and Linares, P. (2011). An ex-post analysis of the effect of renewables and cogeneration on spanish electricity prices. Energy economics, 33:S59-S65.

González-Longatt, F., Wall, P., and Terzija, V. (2012). Wake effect in wind farm performance: Steady-state and dynamic behavior. Renewable Energy, 39(1):329-338.

Goodarzi, S., Perera, H. N., and Bunn, D. (2019). The impact of renewable energy forecast errors on imbalance volumes and electricity spot prices. Energy Policy, 134(October 2018):110827.

Gürtler, M. and Paulsen, T. (2018). The effect of wind and solar power forecasts on day-ahead and intraday electricity prices in Germany. Energy Economics, 75:150-162.

Hagemann, S. (2015). Price determinants in the german intraday market for electricity: an empirical analysis. Journal of Energy Markets. 
Jónsson, T., Pinson, P., and Madsen, H. (2010). On the market impact of wind energy forecasts. Energy Economics, 32(2):313-320.

Ketterer, J. C. (2014). The impact of wind power generation on the electricity price in Germany. Energy Economics, 44:270-280.

Kiesel, R. and Paraschiv, F. (2017). Econometric analysis of 15-minute intraday electricity prices. Energy Economics, 64:77-90.

Kremer, M., Kiesel, R., and Paraschiv, F. (2019). A Fundamental Model for Intraday Electricity Trading. SSRN Electronic Journal, pages 1-25.

Kulakov, S. (2020). X-Model: Further Development and Possible Modifications. Forecasting, 2(1):20-35.

Narajewski, M. and Ziel, F. (2020). Econometric modelling and forecasting of intraday electricity prices. Journal of Commodity Markets, 19:100107.

Schönheit, D. and Möst, D. (2019). The Effect of Offshore Wind Capacity Expansion on Uncertainties in Germany's Day-Ahead Wind Energy Forecasts. Energies, 12(13):2534.

Uniejewski, B., Marcjasz, G., and Weron, R. (2019). Understanding intraday electricity markets: Variable selection and very short-term price forecasting using lasso. International Journal of Forecasting, 35(4):15331547.

von Roon, S. and Wagner, U. (2009). The interaction of Conventional Power Production and Renewable Power under the aspect of balancing Forecast Errors. Proceedings 10th IAEE European Conference, (August 2007).

von Selasinsky, A. (2016). The integration of renewable energy sources in continuous intraday markets for electricity. Series of the chair of energy economics, TU Dresden, Volume 9.

Woo, C.-K., Horowitz, I., Moore, J., and Pacheco, A. (2011). The impact of wind generation on the electricity spot-market price level and variance: The texas experience. Energy Policy, 39(7):3939-3944.

Ziel, F. (2017). Modeling the impact of wind and solar power forecasting errors on intraday electricity prices. International Conference on the European Energy Market, EEM, pages 1-5.

Zöphel, C., Schreiber, S., Müller, T., and Möst, D. (2018). Which Flexibility Options Facilitate the Integration of Intermittent Renewable Energy Sources in Electricity Systems? Current Sustainable/Renewable Energy Reports, 5(1):37-44.

\section{A First Appendix}

The location of wind power turbines is retrieved from 50Hertz et al. (2019), creating two location datasets, separately for 2017 and 2018. The dataset for 2019 was not available at the time of download. Wind speeds are obtained from Copernicus Atmosphere Monitoring Service (2020), with a predefined grid of $0.125^{\circ}$-by- $0.125^{\circ}$ longitude by latitude. The dataset provides forecasts made 1 ) on the day ahead at 12:00 (D-1 12:00) and 2) on the day of delivery at 0:00 (D-0 0:00). Forecasts are available for points in time with three hour intervals, i.e. for hour $0,3,6$ and so forth. The wind energy capacities are aggregated by postal code and the postal codes are then assigned to the wind speed grid. If one or numerous grid points exist within the postal code polygon, the capacities are distributed equally across the grid points. If no grid point exists within the polygon, the nearest neighbor (grid point) is found. All forecast values are at a height of $10 \mathrm{~m}$. Roughness values are obtained from using wind speeds from Copernicus Climate Change Service (C3S) (2018). This dataset contains actual values at heights of $10 \mathrm{~m}$ and $100 \mathrm{~m}$ from which hourly roughness values can be calculated. The location specific median roughness values are used here; as a hub height 90m is assumed, the average hub height in 2018 (cf. method in Schönheit and Möst, 2019) 


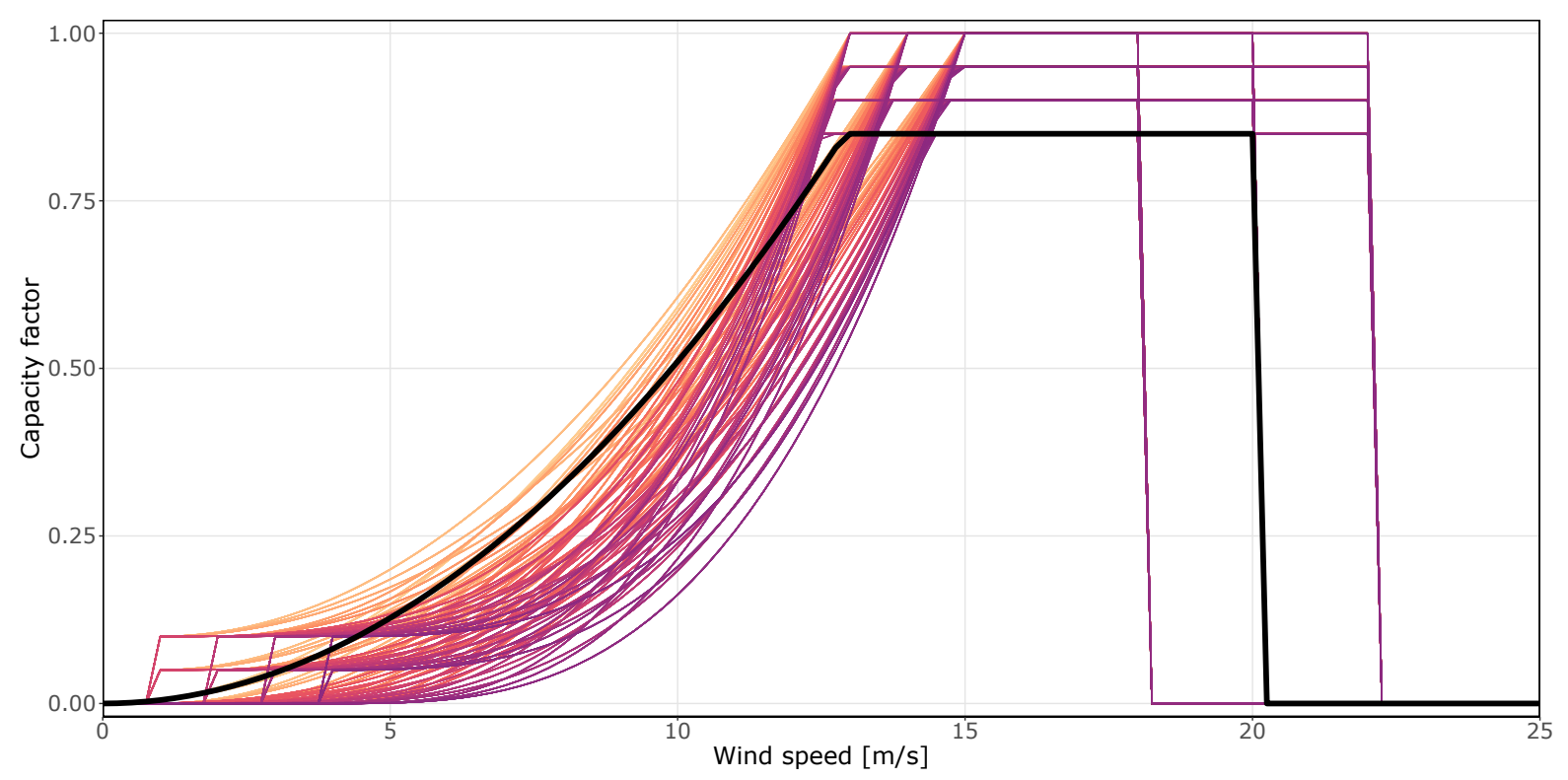

Figure 8: Different tested power curves with squared and cubic relation.

Different power curves are tested to transform the wind speeds into capacity factors (see Figure 8 ). The best power curve is found by transforming the day-ahead wind speeds and comparing the resulting energy amounts to the day-ahead wind energy forecast (the wind energy forecast used in Section 5, also see Table 1). Different levels are tested for cut-in speed (0, 1, 2, and 3), rated wind speed $(13,14$, and 15), shut-down speed (18, 20 and 22) and different levels of the starting capacity factor at the cut-in wind speed $(0,0.05$ and 0.1$)$. Furthermore, the systematic testing revealed that a transformation from wind speed to wind energy based on a common power curve can lead to an overestimation of wind energy at high wind speeds. ${ }^{6}$ Hence, different cut-off levels are tested which set a maximum for the power curve $(1,0.95,0.9$ and 0.85). All combinations are tested with a squared and cubic function between cut-in and rated wind speed, resulting in a total of 864 tested power curves. ${ }^{7}$ The best performing power curve assumes a squared function, with a cutin speed of $0 \mathrm{~m} / \mathrm{s}$, a rated wind-speed of $14 \mathrm{~m} / \mathrm{s}$, a shut-down wind speed of $20 \mathrm{~m} / \mathrm{s}$, a starting capacity factor of 0 and a maximum of 0.85 , resulting in a MAE of 2897.2 MW.

\section{B Second Appendix}

Table 8 displays the correlations of all involved continuous variables for regressions based on Eq. 2 , separately for four subsets of residual load.

\footnotetext{
${ }^{6}$ A possible explanation could be the yield reduction in wind parks due to losses and wake effects (cf. GonzálezLongatt et al., 2012).

${ }^{7}$ The number of combinations is 864 , but when the cut-in wind speed is set to 0 , the starting capacity factor is forced to be 0 , taking out 144 combinations, resulting in 720 tested ones.
} 


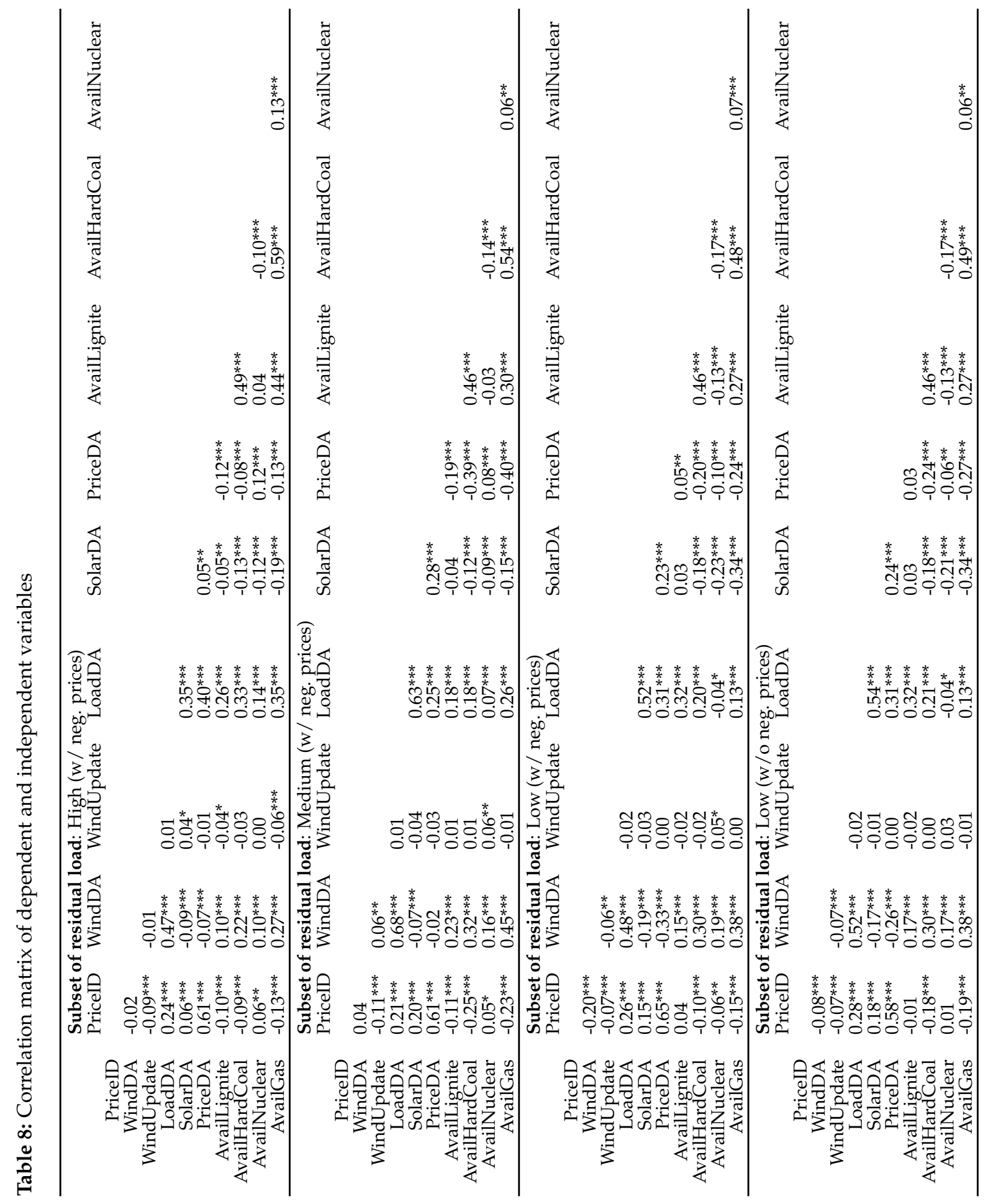




\section{B.4 The impact of different strategies for generation shift keys (GSKs) on the flow-based market coupling domain: A model-based analysis of Central Western Europe}

Authored by Schönheit, D., Weinhold, R. \& Dierstein, C.

Published on 09.11.2019 (online) in Applied Energy, 258, 114067

IF: 8.8, H: 189, SJR: 3.61 (Q1) ～DOI: https://doi.org/10.1016/j.apenergy.2019.114067

Declaration of authorship for Article 4

TECHNISCHE

UNIVERSITÄT

DRESDEN

Fakultät Wirtschaftswissenschaften, Lehrstuhl für Energiewirtschaft

Technische Universitat Dresden, 01062 Dresden

Lehrstuhl für Energiewirtschaft

Münchner Platz 3,

01069 Dresden
Prof. Dr. Dominik Möst

Lehrstuhlinhaber

Kontakt: Linda Schwabe

phone: $\quad+4935146333297$

fax: $\quad+\quad+4935146339763$

e-mail: $\quad$ ee2@mailbox.tu-dresden.de

ERKLÄRUNG AUTORENSCHAFT

Am folgenden Beitrag:

The impact of different strategies for generation shift keys (GSKS) on the flow-based market coupling domain: A model-based analysis of Central Western Europe

haben folgende Personen:

$$
\begin{array}{ll}
\text { Autor 1: } & \text { David Schönheit (DS) } \\
\text { Autor 2: } & \text { Richard Weinhold (RW) } \\
\text { Autor 3: } & \text { Constantin Dierstein (CD) }
\end{array}
$$

die Autorenschaft. Die Reihenfolge der Autoren richtet sich dabei nach den anteiligen Beiträgen. Die Beiträge der einzelnen Autoren, die die Veröffentlichung verantwortlich mittragen, gliedern sich nach den Kriterien der DFG (2013) zur guten wissenschaftlichen Praxis dabei wie folgt:

- Konzeption der Studie:

- Erarbeitung der Daten:

DS, RW, CD

- Modellierung und Analyse der Daten:

DS, RW

- Interpretation der Daten:

Interpretation der Rohdaten

Interpretation der Ergebnisse

- Formulierung des Manuskripts:

DS, RW, CD

$D S, R W, C D$

DS, RW, CD

Die Autoren stimmen mit Ihrer Unterschrift unter diesem Dokument einer Veröffentlichung des Beitrages sowie einer Nutzung des Beitrages zur wissenschaftlichen Qualifikation im Rahmen des Promotionsvorhabens durch andere Autoren zu.

Ort und Datum: Dresden, 17. Juli 2019
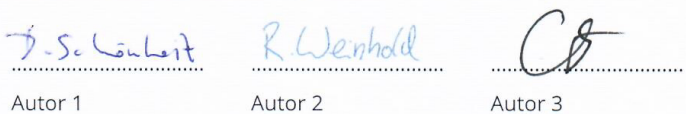

Autor 1

$$
\text { Autor } 2
$$

Autor 3
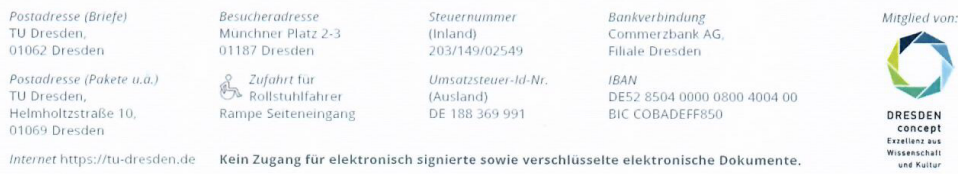



\section{B.5 Zone-wide prediction of generating unit-specific power outputs for electric grid congestion forecasts}

Authored by Schönheit, D., Dierstein, C., Lorenz, L. \& Möst, D.

Published on 01.06.2021 in Journal of Energy Markets, 14(2), 1-32

Handelsblatt-Gewicht VWL 2015: 0.05

DOI: https://doi.org/10.21314/JEM.2020.224

Declaration of authorship for Article 5

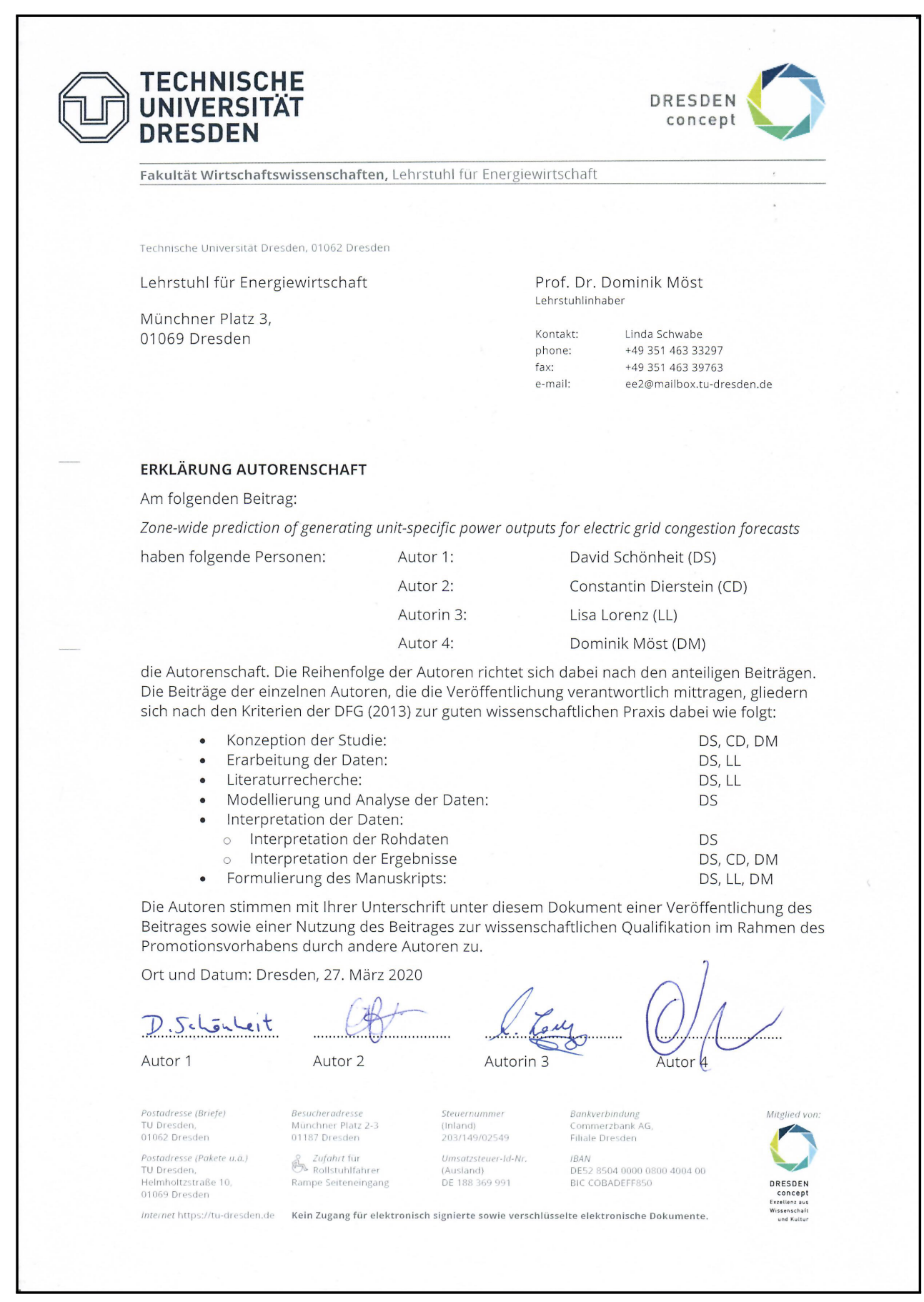



B.6 An Improved Statistical Approach to Generation Shift Keys: Lessons Learned from an Analysis of the Austrian Control Zone

Authored by Schönheit, D.

Published on 11.10.2019 in Zeitschrift für Energiewirtschaft, 43(3), 193-212

VHB: C

DOI: https://doi.org/10.1007/s12398-019-00261-w 



\section{B.7 Do minimum trading capacities for the cross-zonal exchange of electricity lead to welfare losses?}

Authored by Schönheit, D., Dierstein, C. \& Möst, D.

Published on 20.11.2020 (online) in Energy Policy, 149, 112030

VHB: B

DOI: https://doi.org/10.1016/j.enpol.2020.112030

Declaration of authorship for Article 7

\section{TECHNISCHE \\ UNIVERSITÄT \\ DRESDEN}

Fakultät Wirtschaftswissenschaften, Lehrstuhl für Energiewirtschaft

Technische Universität Dresden, 01062 Dresden

Lehrstuhl für Energiewirtschaft

Prof. Dr. Dominik Möst

Münchner Platz 3

01069 Dresden

Lehrstuhlinhaber

Kontakt: Linda Schwabe

phone: $\quad+4935146333297$

fax: $\quad+\quad+4935146339763$

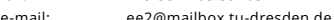

\section{ERKLÄRUNG AUTORENSCHAFT}

Am folgenden Beitrag:

Do minimum trading capacities for the cross-zonal exchange of electricity lead to welfare losses?

haben folgende Personen:

$$
\begin{array}{ll}
\text { Autor 1: } & \text { David Schönheit (DS) } \\
\text { Autor 2: } & \text { Constantin Dierstein (CD) } \\
\text { Autor 3: } & \text { Dominik Möst (DM) }
\end{array}
$$

die Autorenschaft. Die Reihenfolge der Autoren richtet sich dabei nach den anteiligen Beiträgen Die Beiträge der einzelnen Autoren, die die Veröffentlichung verantwortlich mittragen, gliedern sich nach den Kriterien der DFG (2013) zur guten wissenschaftlichen Praxis dabei wie folgt:

\begin{tabular}{|c|c|c|c|}
\hline 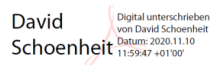 & 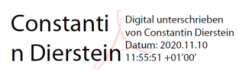 & $\begin{array}{l}\text { Dominik } \\
\text { Moest }\end{array}$ & 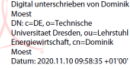 \\
\hline Autor 1 & Autor 2 & & \\
\hline
\end{tabular}

$$
\begin{array}{ll}
\text { - Konzeption der Studie: } & \mathrm{DS}, \mathrm{CD}, \mathrm{DM} \\
\text { - } & \mathrm{DS} \\
\text { - } & \text { Modellierung und Analyse der Daten: } \\
\text { - Interpretation der Daten: } & \mathrm{DS} \\
\hline \quad \text { Interpretation der Rohdaten } & \mathrm{DS}, \mathrm{CD} \\
\text { - Interpretation der Ergebnisse } & \mathrm{DS}, \mathrm{CD}, \mathrm{DM} \\
\text { - Formulierung des Manuskripts: } & \mathrm{DS}, \mathrm{CD}, \mathrm{DM}
\end{array}
$$

Die Autoren stimmen mit Ihrer Unterschrift unter diesem Dokument einer Veröffentlichung des Beitrages sowie einer Nutzung des Beitrages zur wissenschaftlichen Qualifikation im Rahmen des Promotionsvorhabens durch andere Autoren zu.

Ort und Datum: Dresden, 23. Juni 2020

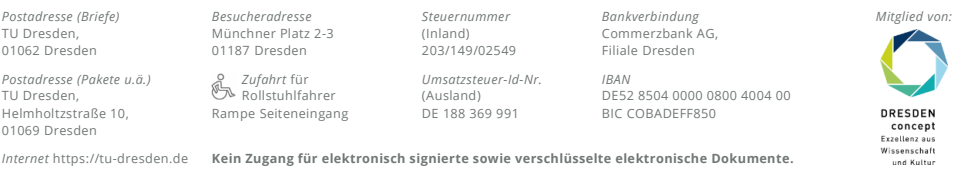





\section{B.8 Toward a fundamental understanding flow-based market coupling for cross-border electricity trading}

Authored by Schönheit, D., Kenis, M., Lorenz, L., Möst, D., Delarue, E. \& Bruninx, K. Published on 30.04.2021 to Advances in Applied Energy, 2, 100027

Top 1-2\% of accepted papers from Applied Energy

DOI: https://doi.org/10.1016/j.adapen.2021.100027

Declaration of authorship for Article 8

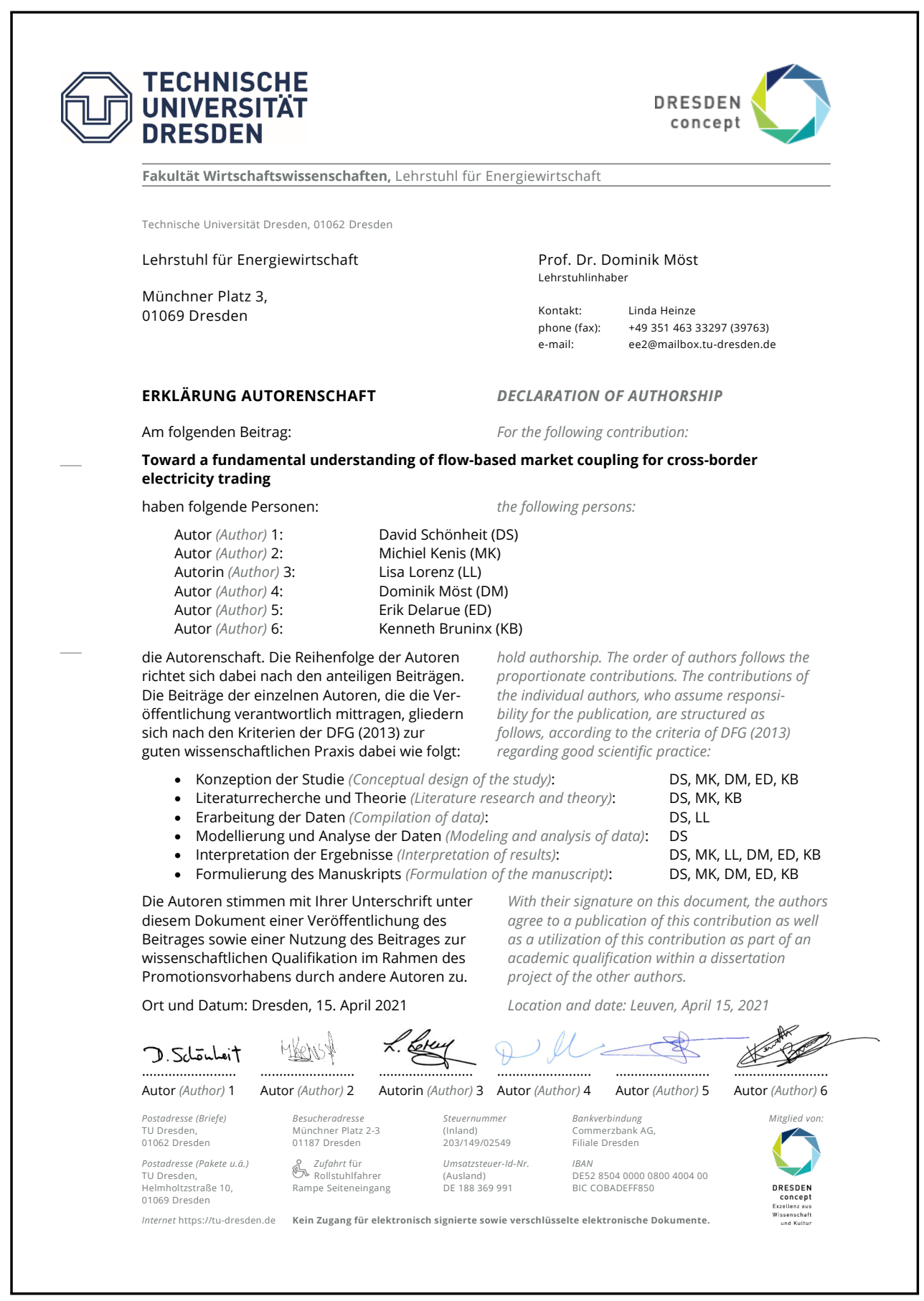






\section{Schriften des Lehrstuhls für Energiewirtschaft, TU Dresden}

Technische Universität Dresden

Fakultät Wirtschaftswissenschaften

Lehrstuhl für Energiewirtschaft

In der Schriftenreihe sind auf Qucosa ${ }^{\circledR}$, dem sächsischen Dokumenten- und Publikationsserver, bisher erschienen:

Band 1 Managing Congestion and Intermittent Renewable Generation in Liberalized Electricity Markets

(Friedrich Kunz)

http://nbn-resolving.de/urn:nbn:de:bsz:14-qucosa-108793

Band 2 Der Stromausfall in München - Einfluss auf Zahlungsbereitschaften für Versorgungssicherheit und auf die Akzeptanz Erneuerbarer Energien

(Daniel K. J. Schubert, Thomas Meyer, Alexander von Selasinsky, Adriane Schmidt, Sebastian Thuß, Niels Erdmann und Mark Erndt)

http://nbn-resolving.de/urn:nbn:de:bsz:14-qucosa-117777

Band 3 Abschätzung der Entwicklung der Netznutzungsentgelte in Deutschland (Fabian Hinz, Daniel Iglhaut, Tobias Frevel, Dominik Möst) http://nbn-resolving.de/urn:nbn:de:bsz:14-qucosa-141381

Band 4 Potenziale der Elektrizitätserzeugung aus erneuerbaren Ressourcen im Freistaat Sachsen

(Hannes Hobbie, Vera Schippers, Michael Zipf, Dominik Möst)

http://nbn-resolving.de/urn:nbn:de:bsz:14-qucosa-153350

Band 5 Energiewende Sachsen - Aktuelle Herausforderungen und Lösungsansätze Beiträge der Abschlusskonferenz des ENERSAX-Projektes

(Dominik Möst und Peter Schegner (Hrsg.)) http://nbn-resolving.de/urn:nbn:de:bsz:14-qucosa-156464

Band 6 Electricity transmission line planning: Success factors for transmission system operators to reduce public opposition

(Stefan Perras)

http://nbn-resolving.de/urn:nbn:de:bsz:14-qucosa-161770

Band 7 Renewable energy in North Africa: Modeling of future electricity scenarios and the impact on manufacturing and employment (Christoph Philipp Kost) http://nbn-resolving.de/urn:nbn:de:bsz:14-qucosa-176538

Band 8 Kurzgutachten zur regionalen Ungleichverteilung der Netznutzungsentgelte (Dominik Möst, Fabian Hinz, Matthew Schmidt, Christoph Zöphel)

http://nbn-resolving.de/urn:nbn:de:bsz:14-qucosa-184452

Band 9 The integration of renewable energy sources in continuous intraday markets for electricity

(Alexander von Selasinsky)

http://nbn-resolving.de/urn:nbn:de:bsz:14-qucosa-202130

Band 10 Bewertung von Szenarien für Energiesysteme

(Daniel K. J. Schubert)

http://nbn-resolving.de/urn:nbn:de:bsz:14-qucosa-202226

Band 11 Deutschland, ein Solarmärchen? Die Zweite Phase der Energiewende zwischen Richtungsstreit und Systemintegration

(Sebastian Thuß)

http://nbn-resolving.de/urn:nbn:de:bsz:14-qucosa-231486 
Band 12 Voltage Stability and Reactive Power Provision in a Decentralizing Energy System - A Techno-economic Analysis

(Fabian Hinz)

http://nbn-resolving.de/urn:nbn:de:bsz:14-qucosa-229585

Band 13 Electricity, Heat, and Gas Sector Data for Modeling the German System

(Friedrich Kunz, Mario Kendziorski, Wolf-Peter Schill, Jens Weibezahn, Jan Zepter, Christian von Hirschhausen, Philipp Hauser, Matthias Zech, Dominik Möst,

Sina Heidari, Björn Felten, Christoph Weber)

http://nbn-resolving.de/urn:nbn:de:bsz:14-qucosa-233511

Band 14 Demand Side Management in Deutschland zur Systemintegration erneuerbarer Energien

(Theresa Ladwig)

http://nbn-resolving.de/urn:nbn:de:bsz:14-qucosa-236074

Band 15 Modellgestützte Wirtschaftlichkeitsbewertung von Betriebskonzepten für Elektrolyseure in einem Energiesystem mit hohen Anteilen erneuerbarer Energien

(Julia Michaelis)

http://nbn-resolving.de/urn:nbn:de:bsz:14-qucosa-235773

Band 16 Begleitstudie WindNODE - Lastverschiebepotentiale in Dresden (Carl-Philipp Anke, Constantin Dierstein, Dirk Hladik, Dominik Möst) http://nbn-resolving.de/urn:nbn:de:bsz:14-qucosa2-312491

Band 17 Einflussfaktoren auf das Übertragungsnetz im Jahr 2030 für Deutschland Eine techno-ökonomische Analyse der Wechselwirkungen auf den Umfang des Netzausbaus, die Systemkosten und die Integration erneuerbarer Energien (David Gunkel) https://nbn-resolving.org/urn:nbn:de:bsz:14-qucosa2-716026

Band 18 Auswirkungen der Kopplung von Strom- und Wärmemarkt auf die künftige Integration der erneuerbaren Energien und die CO2-Emissionen in Deutschland (Gerda Deac) https://nbn-resolving.org/urn:nbn:de:bsz:14-qucosa2-725153

Band 19 Fristigkeit und Politik. Konzeptualisierung und Analyse von langfristigkeitsfördernden Institutionen im Kontext energiepolitischer Steuerung (Nick Pruditsch) https://nbn-resolving.org/urn:nbn:de:bsz:14-qucosa2-748650

Band 20 Economics of Ancillary Services for Electricity - Managing Uncertain Power Generation and Grid Operation in the Distribution Network (Michael Zipf) https://nbn-resolving.org/urn:nbn:de:bsz:14-qucosa2-751856

Band 21 Short- and mid-term uncertainties affecting the trade and transmission of electricity with a focus on flow-based market coupling (David Josua Schönheit) https://nbn-resolving.org/urn:nbn:de:bsz:14-qucosa2-751888 


\section{Kurzzusammenfassung}

Die kumulative Dissertationsschrift besteht aus zwei Teilen. Der erste Teil beleuchtet die Auswirkungen von erhöhten Mengen stromerzeugender erneuerbarer Energien auf den deutschen Strommarkt. In drei Papieren werden die Effekte von erneuerbaren Energien auf die Handelsbilanz, die Emissionsreduktionen und die Preisunsicherheit im Intraday-Markt in Deutschland mit Hilfe von Regressionsanalysen quantifiziert. Der zweite Teil adressiert die Kapazitätsberechnungen für internationalen Stromhandel im Rahmen von Flow-based Market Coupling. Diese Methodik löst sukzessive die bilateralen Handelskapazitäten ab und basiert ihre Kapazitätsbestimmung auf Netzberechnungen und einer Quantifizierung, wie sich Handel auf einzelne kritische Netzwerkelemente auswirkt. Dies ermöglicht im Durchschnitt höhere Handelskapazitäten, was zur Erreichung der deutschen und europäischen Ziele - hohe Versorgungssicherheit, bezahlbare Strompreise, bessere Integration von erneuerbaren Energien und schließlich die Dekarbonisierung der Stromsysteme - einen sehr wichtigen Beitrag leistet. In fünf Papieren werden einerseits statistische Ansätze für wichtige Prognoseparameter im Flow-based Market Coupling entwickelt, insbesondere Generation Shift Keys und die Prognose von konventionellem Kraftwerkseinsatz. Andererseits werden Optimierungsmodelle entwickelt, die den Prozess von Flow-based Market Coupling Engpassprognose und Marktkopplung - komplett abbilden. Diese Schritte werden durch Engpassmanagement-Berechnungen ergänzt, um aktuelle Fragestellungen zu beantworten, wie z.B. die Wohlfahrtseffekte von Mindesthandelskapazitäten.

\section{Autor}

David Josua Schönheit schloss 2017 sein Masterstudium des Wirtschaftsingenieurwesens mit dem Schwerpunkt Energie- und Ressourcenmanagement an der TU Berlin ab. Während seines Studiums studierte er ein Jahr lang am Davidson College in North Carolina, USA im Rahmen eines Vollstipendiums. Als Werkstudent war er bei der Deutschen Energie-Agentur, Naturstrom und 50Hertz Transmission tätig. Von 2018 bis 2021 war er wissenschaftlicher Mitarbeiter am Lehrstuhl für Energiewirtschaft der TU Dresden und in diversen nationalen und internationalen Forschungsprojekten involviert. 